\title{
WestVirginiaUniversity
}

THE RESEARCH REPOSITORY @ WVU

Graduate Theses, Dissertations, and Problem Reports

2004

\section{Teachers' beliefs in relation to their instructional technology practices}

Deniz Palak

West Virginia University

Follow this and additional works at: https://researchrepository.wvu.edu/etd

\section{Recommended Citation}

Palak, Deniz, "Teachers' beliefs in relation to their instructional technology practices" (2004). Graduate Theses, Dissertations, and Problem Reports. 2608.

https://researchrepository.wvu.edu/etd/2608

This Dissertation is protected by copyright and/or related rights. It has been brought to you by the The Research Repository @ WVU with permission from the rights-holder(s). You are free to use this Dissertation in any way that is permitted by the copyright and related rights legislation that applies to your use. For other uses you must obtain permission from the rights-holder(s) directly, unless additional rights are indicated by a Creative Commons license in the record and/ or on the work itself. This Dissertation has been accepted for inclusion in WVU Graduate Theses, Dissertations, and Problem Reports collection by an authorized administrator of The Research Repository @ WVU.

For more information, please contact researchrepository@mail.wvu.edu. 
Teachers' Beliefs in Relation to Their Instructional Technology Practices

Deniz Palak

Dissertation submitted to the College of Human Resources and Education at

West Virginia University in partial fulfillment of the requirements

for the degree of

\section{Doctor of Education}

in

Technology Education

John G. Wells, Ph.D., Chair

David L. McCrory, Ph.D.

Cheryl Prichard, Ed.D

Neal Shambaugh, Ph.D

Richard T. Walls, Ph.D

Department of Advanced Educational Studies

Morgantown, West Virginia

2004

Keywords: teachers' beliefs, teachers' attitudes,

technology integration, professional development, instructional technology, student-centered beliefs, teacher-centered beliefs

Copyright () 2004 Deniz Palak 


\begin{abstract}
Teachers’ Beliefs in Relation to Their Instructional Technology Practices
\end{abstract}

Deniz Palak

This study investigated how teachers' beliefs and factors other than teachers' beliefs relate to teachers' instructional technology practices. Teachers' beliefs were identified as teacher-centered beliefs, student-centered beliefs, and attitudes toward technology integration. Teacher confidence and comfort, technical support, general school support, and ratio of computers-to-students in the classroom were identified as factors other than teachers' beliefs.

The study employed both quantitative and qualitative research methodologies. The research population of this study involved 113 technology-using P-12 teachers who worked in technology-rich schools in West Virginia. The quantitative research methods employed two surveys and computed a series of correlational and multiple regression analyses in answering the specific technologies and instructional strategies teachers used when integrating technology. The qualitative case study research followed the qualitative design. Using the maximum variation sampling strategy, four teachers were sampled: two with student-centered beliefs and two with teacher-centered beliefs. Upon individual case study descriptions, within-case and cross-case analyses were conducted to answer how teachers' beliefs and factors other than teachers' beliefs related to the types of technologies and instructional strategies teachers used when integrating technology.

The results obtained from this research point to the following: instructional technology practices of teachers in substantial ways relate to (1) their beliefs about teaching and technology and (2) the contextual conditions in their teaching environments. Teachers' beliefs are the primary agents for their instructional technology decisions specifically for their selections of technologies for student use. The types of technologies teachers have their students use are directly related to the ways teachers approach teaching and technology. Teachers use a variety of instructional strategies regardless of their studentcentered and teacher-centered beliefs. 


\section{DEDICATION}

To my mother, Havva Palak, who instilled the value of education and perseverance in me. Rest in Peace, mother. 


\section{ACKNOWLEDGEMENTS}

I wish to acknowledge the following people who assisted me during the journey of my doctoral studies and in the process of writing this dissertation. I treasure the contributions that each of you made and take this opportunity to sincerely thank you all.

Specifically, I wish to thank Dr. John G. Wells, my chair, for his advice and leadership. I will always cherish the experiences you provided me to grow, learn, and do better. Dr. Richard T. Walls, my mentor, I wish to thank you for devoting numerous hours for mentoring and inspiring me. I am grateful to Dr. Cheryl L. Prichard for her guidance, thoughtfulness, and kindness. Many thanks to Dr. David L. McCrory for his feedback, and Dr. Paul Chapman for inspiring my soul and fueling my enthusiasm. Equally, I am thankful to my friend, Dr. Senel Poyrazli, for her treasures wisdom and assistance.

I could not have accomplished this work without the unconditional love of my family. My dear sisters, Nese Gokce, Hulya Uygun, and Aysegul Ayhan, and my father, Halis Palak, I am grateful to you all. Your affection and encouragement transcended the borders of Turkey and embraced me here to do the best I can. I honor you all.

I sincerely thank to the participants of this study and those school administrators who assisted me during my data collection with special thanks to the four case study participants. Without any hesitation, all of you gave me the privilege to accomplish this work and made my data collection process most pleasurable. 


\section{List of Tables}

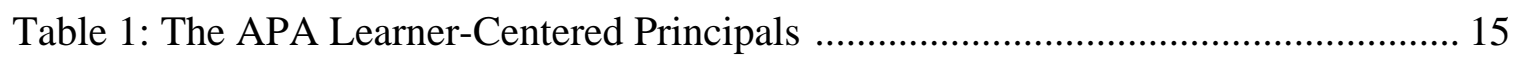

Table 2: Cronbach Alpha scores in Perceptions of Computers and Technology............. 55

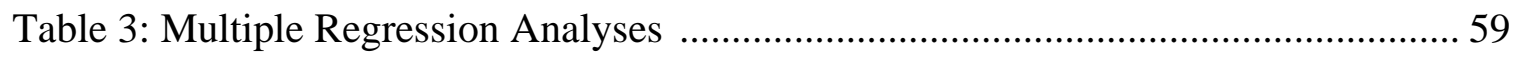

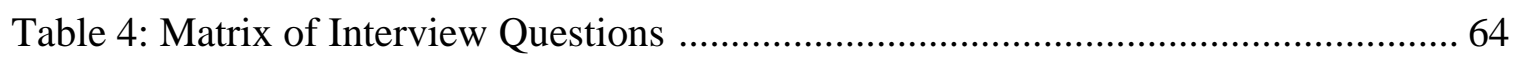

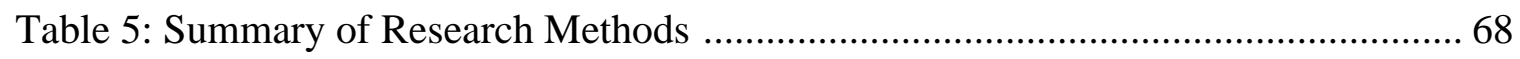

Table 6: Descriptive Statistics of the Inverval Variables .......................................... 74

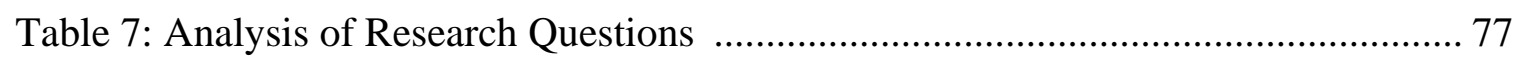

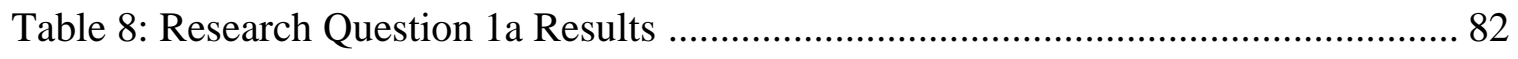

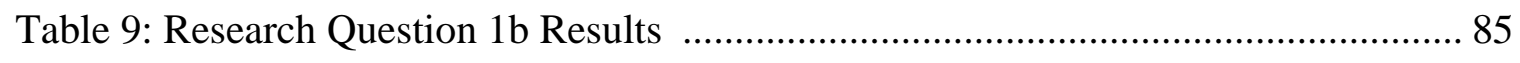

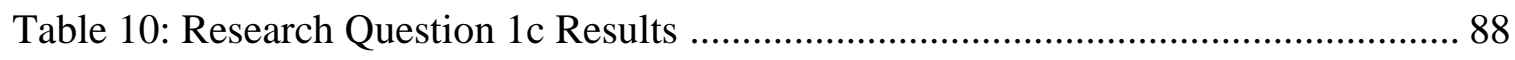

Table 11: Research Question 2a Results .............................................................. 92

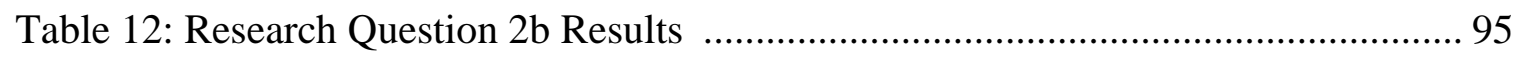

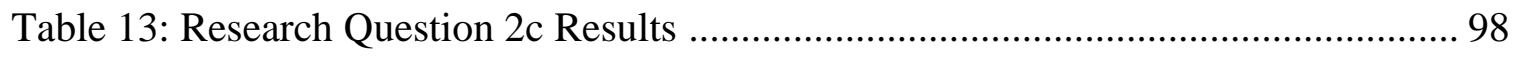

Table 14: Intercorrelations of the Ten Variables Used in the Study............................. 101

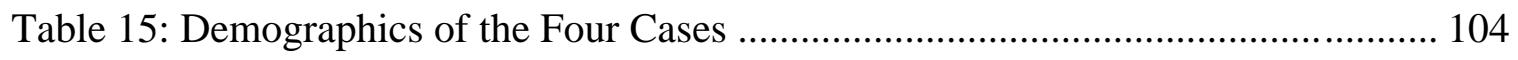

Table 16: Summary of Case Study Design and Analysis ........................................ 110

Table 17: Summary of Case Study Analysis ...................................................... 141 


\section{List of Figures}

Figure 1: Distribution of Teacher-Centered Scores of the Participants ........................ 103

Figure 2: Distribution of Student-Centered Scores of the Participants ......................... 103 


\section{Table of Contents}

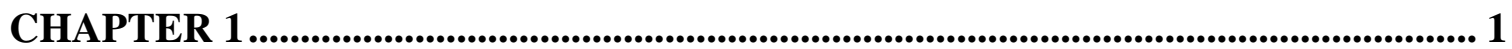

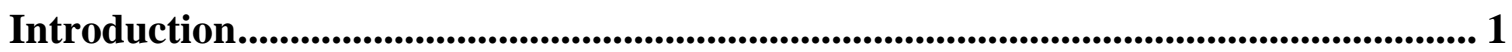

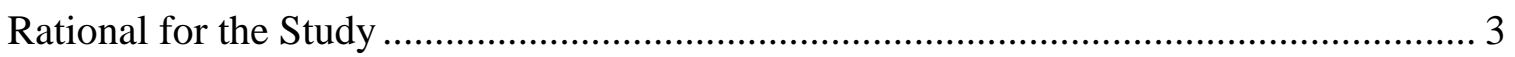

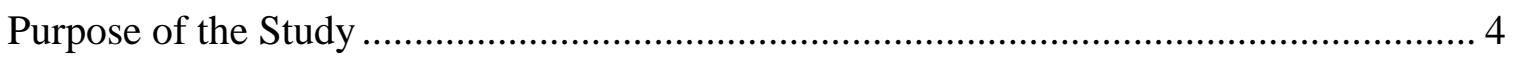

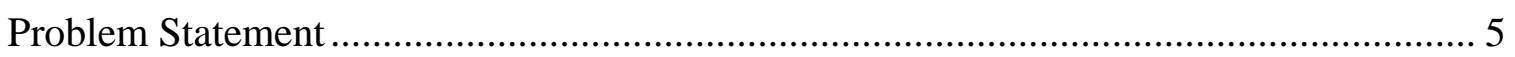

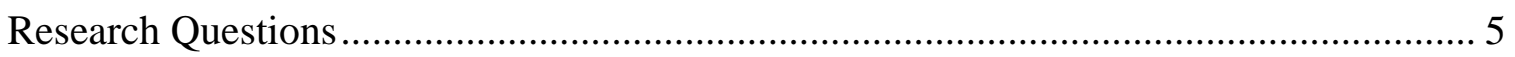

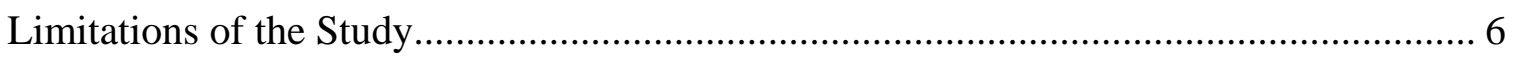

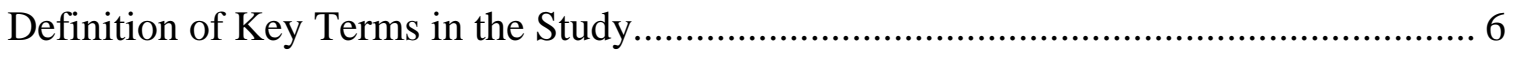

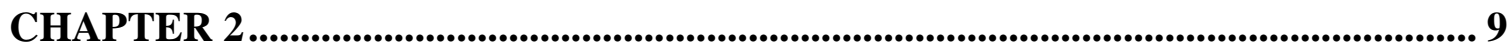

Literature Review ....................................................................................................................... 9

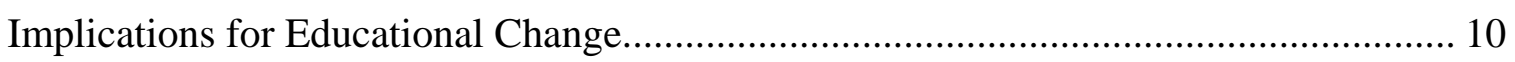

Student and Teacher-Centered Approaches .............................................................. 12

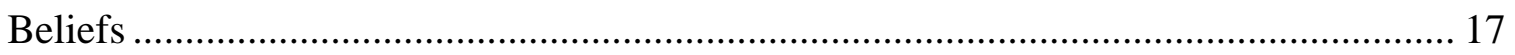

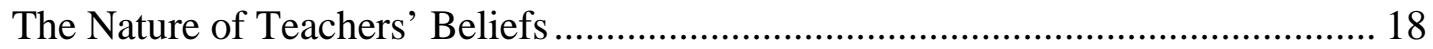

Theories behind Change in Teachers' Beliefs ....................................................... 22

Teachers’ Beliefs and Approaches to Technology Integration....................................... 26

Technology Integration: Overall Teacher Population............................................ 27

Technology Integration: Technology-Using Teachers .......................................... 36

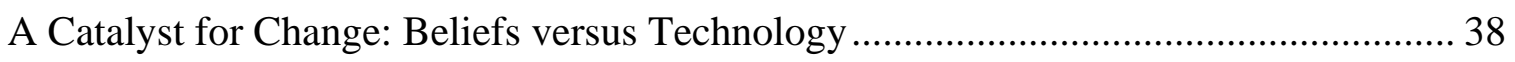

Factors Affecting Teachers’ Technology Integration ................................................ 44

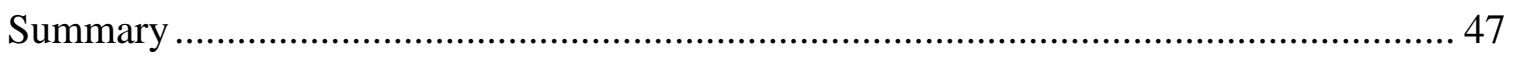

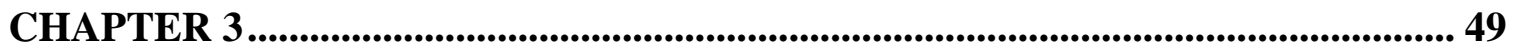

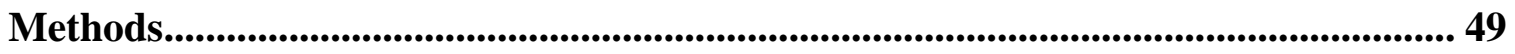

Rationale for Mixed Methods .................................................................................. 51

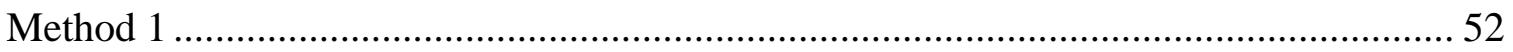

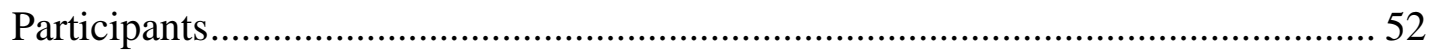

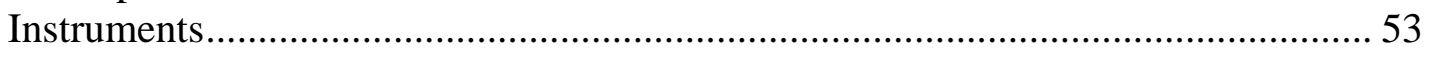

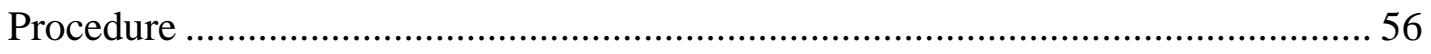

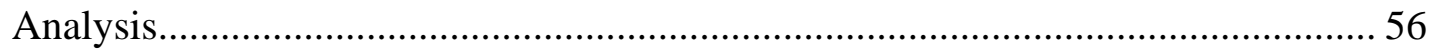

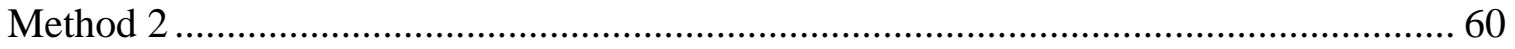

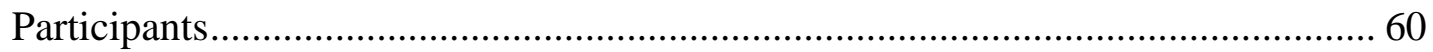

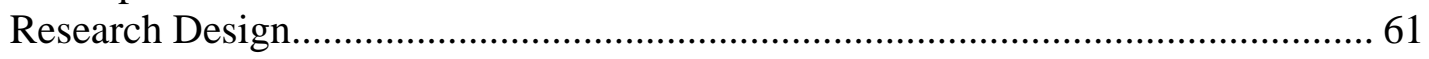

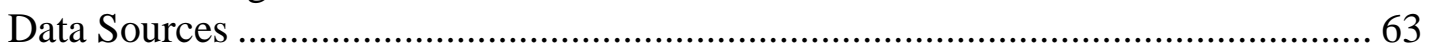




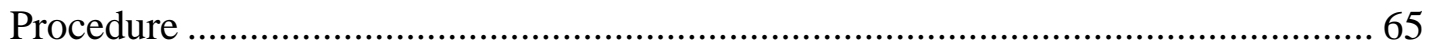

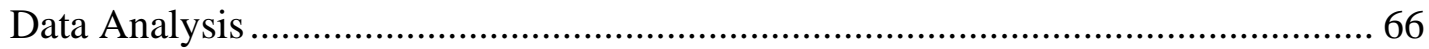

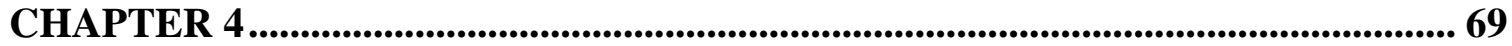

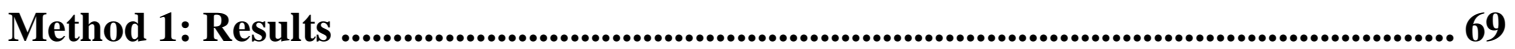

Overview of Research Design ................................................................................ 70

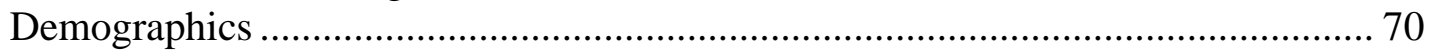

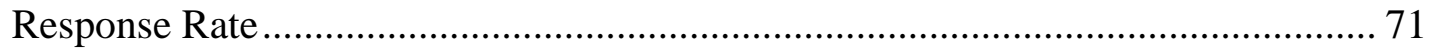

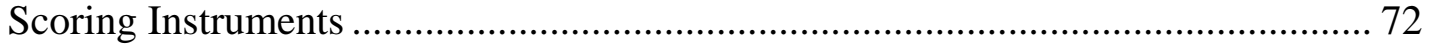

Analyses of Research Questions ............................................................................. 75

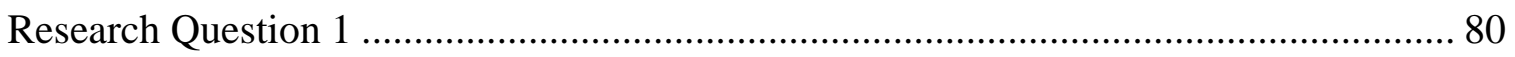

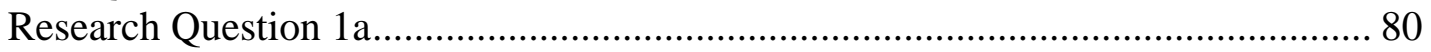

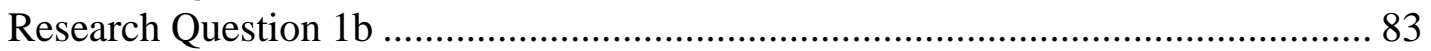

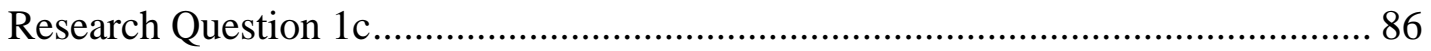

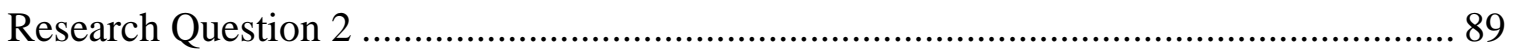

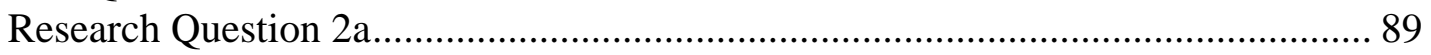

Research Question 2b .................................................................................... 93

Research Question 2c............................................................................................. 96

Intercorrelations of the Ten Variables in the Study ........................................................... 99

Method 2: Case Study Results ............................................................................................ 102

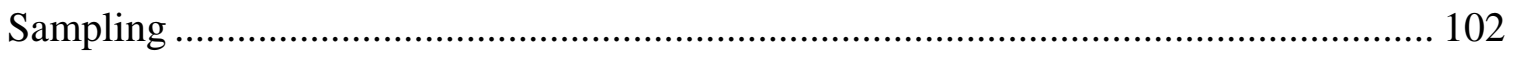

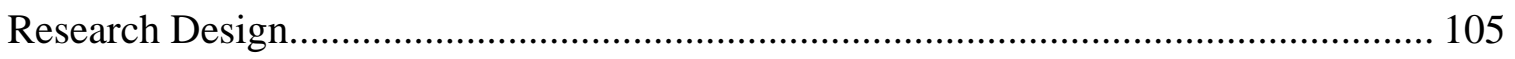

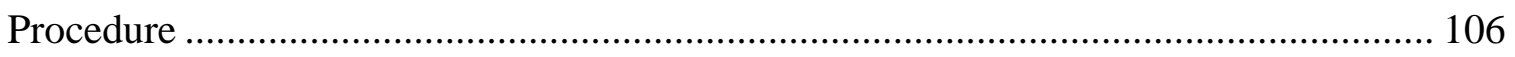

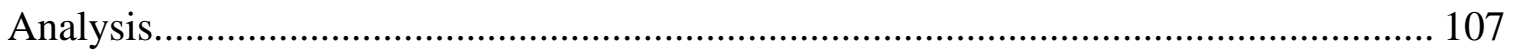

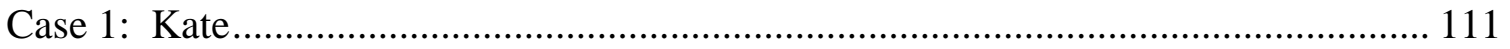

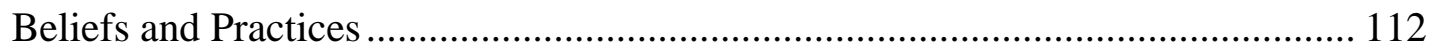

Incentives and Barriers ................................................................................... 115

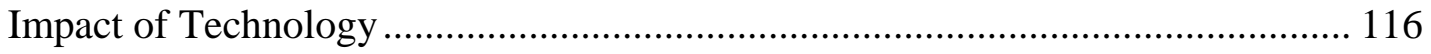

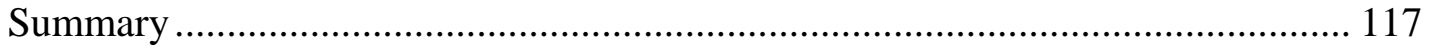

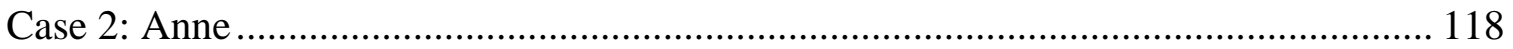

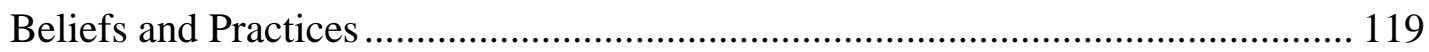

Incentives and Barriers ..................................................................................... 123

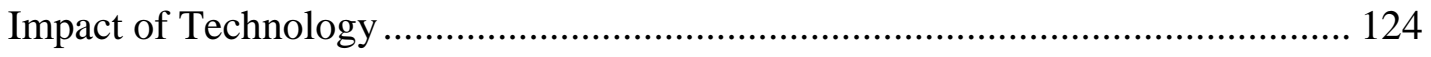

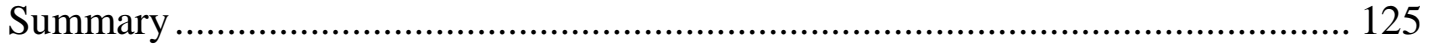

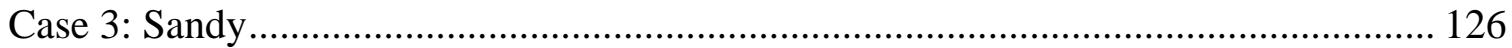

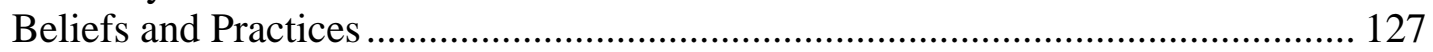

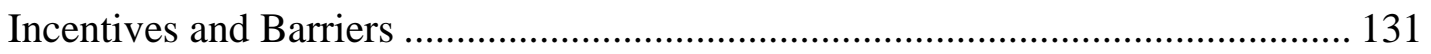

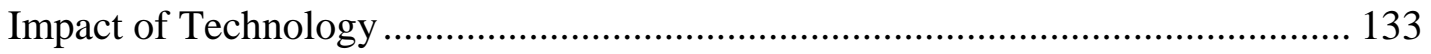

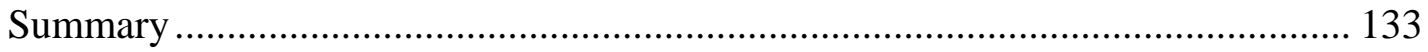




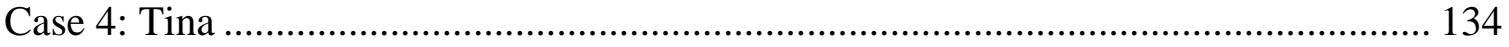

Beliefs and Practices ......................................................................................... 135

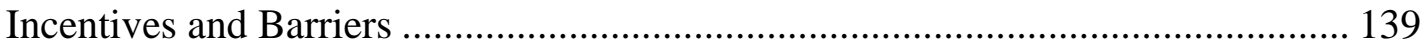

Impact of Technology .................................................................................... 140

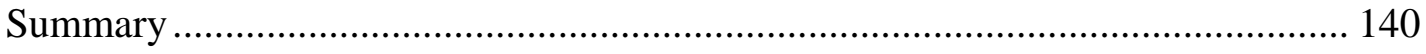

Within-Case Analysis ............................................................................................... 142

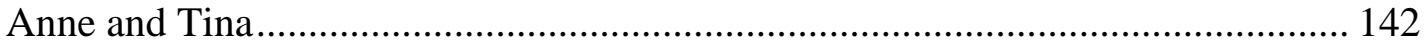

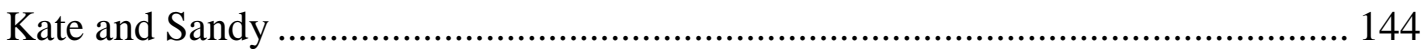

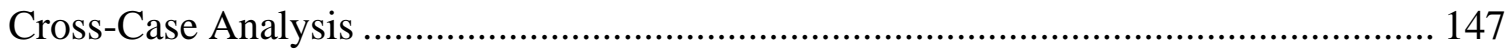

Cases of Kate, Anne, Sandy, and Tina............................................................... 147

Conclusion of Case Study Analysis ............................................................................... 150

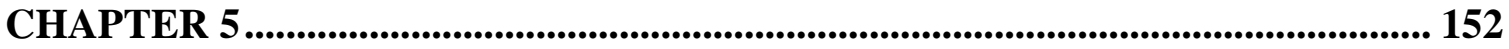

Summary, Discussion, and Implications........................................................................... 152

Summary of Research Design.......................................................................... 152

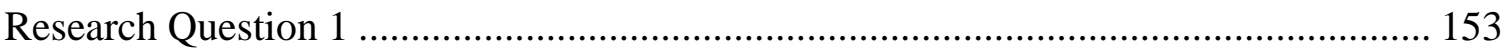

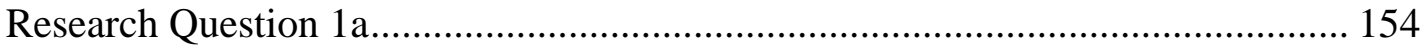

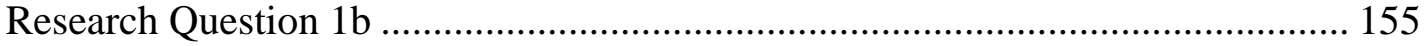

Research Question 1c.......................................................................................... 155

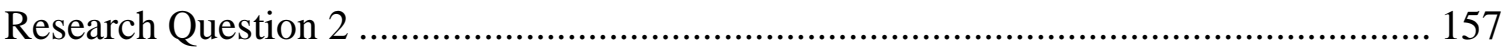

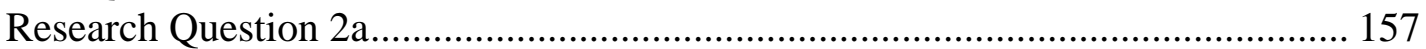

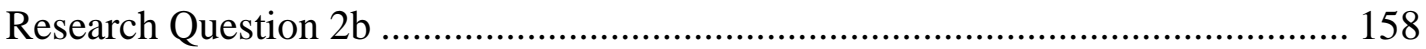

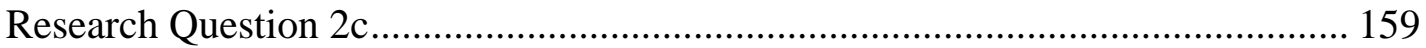

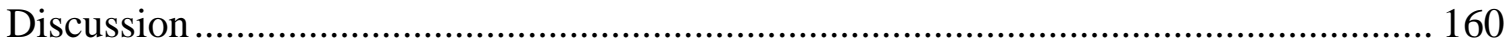

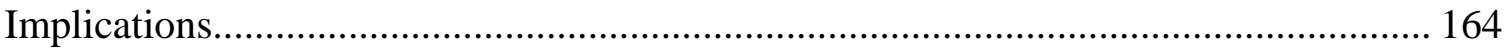

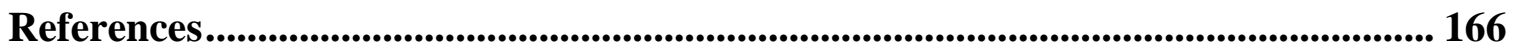

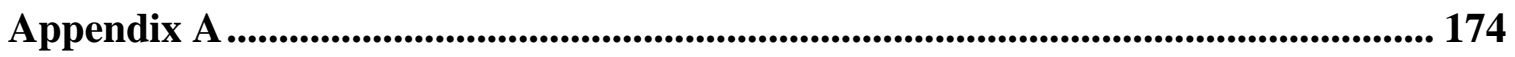

Inventory Philosophies of Education ......................................................................... 174

Appendix B .............................................................................................................................. 178

Perceptions of Computers and Technology ............................................................. 178

Appendix C ............................................................................................................. 183

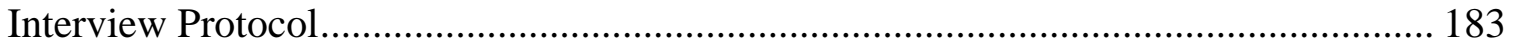

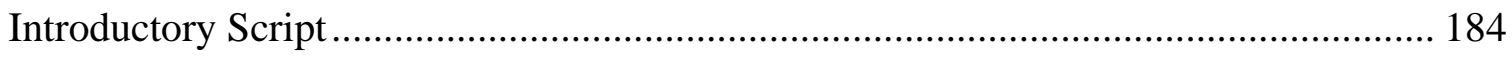

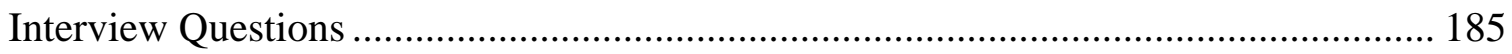


Appendix D ....................................................................................................................................... 186

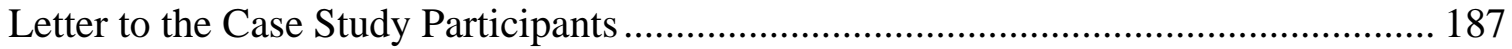

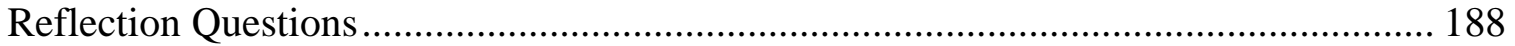

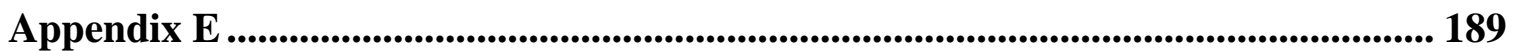

Letter to All Participant Teachers .............................................................................. 189 


\section{CHAPTER 1}

Introduction

In response to the changing face of education reform since the early 1990s, U.S. teachers have been increasingly responsive to the integration of technologies into their day-to-day teaching. As technology is seen supporting school reform, significant amounts of resources have been expanded to equip schools with computer hardware and software over the last two decades (Christensen, 2002). One estimate suggested that 3.2 billion dollars were spent in U.S. schools as of late 1990s (Coley, Cradler, \& Engel, 1997). Another study estimated that over $\$ 6.2$ billion was spent in 1999 and 2000 (SivinKachala \& Bialo, 2000) to help P-12 schools prepare the students of the $21^{\text {st }}$ century. In the meantime, technology integration has been reinforced through the National Educational Standards (NETS), making teachers more accountable to use technology in their day-to-day classroom practices.

As technology availability improved at schools due to funding within the years of 1998 and 1999, several federal initiatives, such as E-Rate, Community Technology Centers, Learning Anytime Anywhere Partnership, and Preparing Tomorrow’s Teachers to Use Technology became available to help teachers integrate technology. In contrast to earlier federal initiatives, whereby the majority of funding was spent to equip schools both with hardware and software (OTA, 1995), teachers themselves have become the major recipients of funding in recent federal initiatives as they are the ultimate implementers of curriculum.

Behind all the funding for hardware, software, and professional development initiatives, teachers are being encouraged to change in practice toward a student-centered 
paradigm, where instructional technologies are integrated to support active student learning. The current educational reform supports student-centered practices (Fullan, 2001; Cuban, 2002; McCombs, 2001; Morrison \& Lowther, 2002; Riel \& Becker, 2000). Since little progress was observed in teachers’ use of technology for instruction that focused on funding schools with hardware and software (OTA, 1995; Sandholtz, Ringstaff, \& Dwyer, 1997), it became apparent that placing the equipment at schools neither changes teachers' classroom practices nor teachers' use of technology (Norton, McRobbie, \& Cooper, 2000; Windschitl \& Sahl, 2002). Increased availability of computer technologies in the classroom does not necessarily translate into increased teacher use with reform-oriented student-centered practices (Cuban, 2002).

Despite the availability of the hardware, software, and several federal initiatives for teacher professional development, to this date, teachers use technology infrequently with mainly teacher-centered approaches (Cuban, 2002). Since teachers are the ultimate implementers of curriculum, they play a significant role in selecting what technologies are used and how these technologies are used to support active student learning in the classroom (Cuban, 2002; Fullan, 2001; Niederhauser, Salem, \& Fields, 1999). Teachers’ lack of technical skills and technology integration models as well as contextual constraints such as, time, equipment, and support, have been identified contributing to teachers' limited and infrequent use of technology. However, a growing body of research is suggesting that teachers' limited and infrequent use of technology and sustaining teacher-centered practices are related to their beliefs (ACOT 1996; Cuban, 2002; Hannafin \& Freeman, 1995; Niederhauser, 1994; Norum, Grabinger, \& Duffield, 1999; 
Wang, 2002; Saye, 1988; Windschitl \& Sahl, 2002). This current study is an attempt to investigate how teachers' beliefs are related to their technology integration practices.

\section{Rational for the Study}

Representation of knowledge has undergone a paradigm shift in recent years around student-centered beliefs (Fullan, 2001; Tobin, Tippins, \& Gallard, 1994). Change in practice is evident when teachers effectively integrate technology to accomplish curriculum-specific goals. Fullan (2001) argued that change efforts will fail unless teachers accommodate their beliefs to support reform-oriented student-centered practices. Technology can be used to support student-centered teaching practices since it facilitates shifting the source of knowledge away from the teacher and text-books (traditional classroom) to online (open-ended) learning environments (McCombs, 2001). Effective instructional technology integration takes place beyond the "use” of technology toward “application” in which teachers integrate technology as a tool to accomplish their curriculum-specific goals to improve teaching and learning (Harris, 1998). Thus, change in practice occurs when teachers use technology as a tool to support student learning to accomplish their curriculum-specific goals.

Some argue that such change in practice must occur at the deeper level of the teachers’ knowledge base, which represents teachers’ beliefs about education (Cuban, 2002; Fullan, 2001; Niederhauser, Salem, \& Fields, 1999; Ringstaff \& Kelley, 2002; Sandholtz, Ringstaff, \& Dwyer, 1997). Teachers’ beliefs influence their perceptions and judgments whose effects can be observed in their classroom behavior (Pajares, 1992). Recent studies suggest that teachers who effectively integrate instructional technology move toward a student-centered instructional practices and this in turn suggests a shift in 
teachers' beliefs as teachers experience new patterns of teaching and learning (Sandholtz, Ringstaff, \& Dwyer, 1997; Becker, 2000; Becker, 2001; Becker \& Ravitz 1999; Ravitz, Becker, \& Wong, 2000). Although some argue that this is a technology-induced change in that change in beliefs follows adoption of student-centered "constructivist practices" (Becker, 2000; Becker, 2001; Becker \& Ravitz 1999; Ravitz, Becker, \& Wong, 2000), research has yet to confirm this assumption. More research is necessary if technologyusing teachers change their practices toward student-centered paradigm.

\section{Purpose of the Study}

The study will investigate only technology-using teachers' beliefs in relation to their instructional technology practices. Teachers' beliefs in this study include their beliefs about teaching and learning and their beliefs toward technology. Investigating teachers' beliefs in relation to their instructional technology practices will shed light on our understanding of how teachers with student-centered and teacher-centered beliefs are likely to integrate technologies. In addition to teachers' beliefs, this study will consider factors other than beliefs such as, comfort and confidence, ratio of computers-to-students, general and technical support available within the context of teachers' practices to determine how beliefs and factors other than teachers' beliefs can be related to their instructional technology practices. Teachers' instructional technology practices will be examined in terms of (1) the technologies teachers use, (2) the technologies teachers have their students use, and (3) the instructional strategies teachers use when integrating technologies. Findings of this study may have important implications for instructional designers, school administrators, and curriculum reformers who are interested in transforming teaching through effective instructional technology integration. 


\section{Problem Statement}

Examining teachers' beliefs in relation to their instructional technology practices is the focus of this study. The problem of this study is to determine how teachers make their instructional technology decisions to use technologies with their students for teaching and learning. This study will seek to answer how teachers' beliefs and factor other than beliefs relate to their instructional technology integration practices. Beliefs in this study include teachers' educational beliefs about teaching and learning in addition to their beliefs (attitudes) toward instructional technology integration. Teachers’ instructional practices include the types of technologies teacher use, types of technologies teachers have their students use, and instructional strategies that teachers use when integrating technology for teaching and learning with their students.

\section{Research Questions}

1. How do teachers' beliefs relate to the types technologies and instructional strategies teachers use with their students for instruction?

a. How do teachers' beliefs relate to the types of technologies teachers use for instruction?

b. How do teachers' beliefs relate to the types of technologies teachers have their students use for instruction?

c. How do teachers' beliefs relate to the types of instructional strategies teachers use for instruction when integrating technology?

2. How do factors other than teachers' beliefs relate to the types technologies and instructional strategies teachers use with their students for instruction? 
a. How do factors other than beliefs relate to the types of technologies teachers use for instruction?

b. How do factors other than beliefs relate to the types of technologies teachers have their students use for instruction?

c. How do factors other than teachers' beliefs relate to the types of instructional strategies teachers use for instruction when integrating technology?

\section{Limitations of the Study}

The participants selected for this study will include only technology-using P-12 teachers who worked at the 28 Benedum Collaborative Professional Development Schools in the five counties in the state of West Virginia. Therefore, the study results can be generalized to the technology-using P-12 teacher population in the Benedum Collaborative Professional Development Schools. Additionally, it is reasonable to propose that results can be at least partially generalizable to technology-using teachers nationwide who work at P-12 schools with adequate technology and infrastructure.

\section{Definition of Key Terms in the Study}

Below are the key terms that are used throughout this study. Definition of key terms appears in such an order that the former definition complements the latter.

Instructional Technology: For the purposes of this study, instructional technology (sometimes also referred as technology) includes "computer related technologies" that are used in the classroom for teaching and learning. Computer related technologies consist of hardware, software, and networked tools as well as resources that are accessed via the World Wide Web. 
Instructional Technology Integration: This includes various types and levels of technologies used for teaching and learning that are accomplished by both teachers and learners to attain curriculum-specific goals.

Teachers' Beliefs: Teachers' beliefs in this study refer to (1) teachers' educational beliefs and (2) teachers' beliefs about technology integration. Teachers' educational beliefs are manifested in their personal philosophies of education and include their knowledge of various strategies for creating learning environments and conducting lessons, and more fundamentally knowledge and beliefs about learners, how they learn, and how that learning can be fostered by teaching (Borko \& Putnam, 1995). Teachers' beliefs about technology integration are manifested in the attitudes they hold toward the value of using technology for instruction in the classroom.

Philosophies of Education: Philosophies of education are reflected in teachers' educational beliefs. Valesey (2002) defined philosophy as a screen through which curriculum, instructional strategies, and assessment are sifted.

Approaches: Broad styles of teaching that relate directly to teachers' educational beliefs in terms what content should be taught, how the content must be taught, and how students must learn (Conti, 1989).

Instructional Approaches: Teachers' beliefs are translated into pervasive action in the classroom through two broad teaching styles that are classified as leaner-centered and teacher-centered approaches (Conti, 1989).

Instructional Strategies: Instructional strategies are teachers' actions in the classroom directly related to their knowledge about how to teach a subject (Borko \& Putman, 1995). 
Teacher-Centered Approaches: Classic and formal learning usually emphasizing the acquisition of knowledge through transmitting knowledge from the teacher to the student (Chall, 2000).

Student-Centered Approaches: Focuses less on facts and rote skills and more on individual learner and on their thinking, problem solving, understanding, and creating (Chall, 2000). 


\section{CHAPTER 2}

Literature Review

The field of education is under a new educational change, the new school reform. One aspect of this reform is unfolding new practices of teaching to suit social and global challenges with the needs of the next generation of citizens of the world. Teachers are in the frontiers of this change wave as the success of the new educational reform depends on what teachers think and do (Fullan, 2001). Teachers now must adopt new practices, adapt to new teaching environments, and all in all change the methods with which they learned from their teachers at the time of their schooling.

Murphy (2000) best describes this current of educational change using the story of Robinson Crusoe as a metaphor. Robinson Crusoe reached a sense of calmness and inner peace only when he adapted himself to his new environment instead of changing his environment to suit him. Peace and harmony settled in Crusoe when he detached himself from old habits by changing his outdated beliefs and habits. Murphy made the analogy here to point to the existing change in learning environments for teaching to which teachers need to adapt in order to realize their greater potentials. Murphy suggested that teachers can realize their greatest potential only if "they can accommodate their personal theories, beliefs and practices to suit the characteristics of the new environment” (p.3).

Examining teachers' beliefs in relation to their instructional technology practices is the focus of this study. Significant recent research suggests a shift in teachers' beliefs that integrate technology effectively. Technology by no means, however, is an end by itself or a remedy for educational problems. Technology is a combination of tools or artifacts teachers use for instruction to realize their greatest potential teaching practices 
and greatest learning outcomes for their students. In brief "technology in and of itself will not change education; what matters is how it is used” (Sandholtz, Ringstaff, \& Dwyer, 1997, p.10). This is the starting point of the literature review presented below.

This chapter will document the selected findings in literature under the following six sections. The first section of the review will briefly discuss (1) the implications for educational change to provide a framework of reference for technology integration. The second section will represent (2) the theoretical background for the two possible instructional technology integration practices: teacher-centered and student-centered. The third section will review the literature on (3) teachers' beliefs separated in two subheadings as (a) the nature of beliefs and (b) theories behind change in beliefs. The forth section will document the selected findings in literature on (4) teachers' beliefs and approaches to technology integration. This section will be organized in two subheadings: (a) beliefs and approaches to technology integration among the general overall teacher population and (b) beliefs and approaches to technology among frequent technology-using teachers. The fifth section will discuss different views on research for (5) a catalyst of change: teachers' beliefs versus technology. Finally, (6) other factors relating to teachers' instructional technology practices will be discussed in the sixth section.

\section{Implications for Educational Change}

Based on the convergence of evidence from a number of scientific research findings, researchers have recently documented a positive relationship between the amount of experience in a complex environment and the amount of structural change in the human brain (Bransford, Brown, \& Cocking, 1999). These findings suggest that 
human intelligence is not to be a fixed entity, but a spiraling and ever-evolving human capacity. Human learning is non-linear, recursive, continuous, complex, relational, natural, and highly contextualized (McCombs, 2001). As the recent findings from neuroscience and cognitive science research reveal new capacities of human intelligence, learning theories have begun to be revised from a cognitive psychological perspective. This perspective shifted the focus on human learning from drill-and-practice to knowledge building and application as to create new learning environments to optimize human capacity for knowledge construction.

Thus the paradigm shift is in place from objectivist perspective to constructivist perspective. This has created uncertainty in the education community as educators began "learning to learn” about how to optimize teaching. As Fullan (2001) suggested "teachers are uncertain about how to influence students, and even about whether they are having an influence” (p.32). Fullan argued that change efforts would fail unless teachers are assisted in developing infrastructures for a better understanding of educational change. Fullan claimed that teachers' implementation of educational change is multidimensional. Successful technology implementation for the classroom has the following three dimensions: (1) possible use of instructional technology, (2) possible use of new teaching approaches, and (3) possible alteration of beliefs, pedagogical assumptions.

Teachers are the ultimate implementers of educational change (Cuban, 1993; Cuban, 2002; Eisenhart, Cuthbert, Shrum, \& Harding, 1988). Teacher beliefs are an important factor in how curriculum is implemented and how technology is used (Cuban, 2002; Niederhauser, Salem, \& Fields, 1999). Having computers and resources available 
to schools does not directly translate into change in practice (Brown, 1999; Cuban, 2002;

Norton, McRobbbie, \& Cooper, 2000). In order for the change toward a student-centered paradigm to fully take place, teachers must understand the implications for change in practice. Otherwise, old habits linger and change occurs only on the surface (Fullan, 2001). When teachers implement change without specifically understanding the principles or rationale for change, they imitate the behavior. In this case, teachers "add a repertoire of strategies, rather than replace the old ones” (Brown, 1999, p. 371). Change is three dimensional; all three dimensions are interrelated, and cannot be achieved in the absence of one or the other. Teachers need to be convinced why they are doing what they are doing (Fullan, 2001) and encouraged that the effective use of technology can support learning (Norton, McRobbie, \& Cooper, 2000).

Student-Centered and Teacher-Centered Approaches

Representation of knowledge has had a paradigm shift in the recent years. This paradigm shift centers on a set of beliefs about knowledge-construction (Tobin, Tippins, \& Gallard, 1994). Current reform efforts are supporting a change in teachers’ pedagogies toward a student-centered approach to help students develop critical thinking skills and solve complex problems through inquiry and collaboration (Riel \& Becker, 2000; Morrison \& Lowther, 2002). As the reform movement is supporting the student-centered pedagogy that is manifested in teachers’ instructional approaches, many teachers who have been educated in the traditional objectivist paradigm are asked to make substantial changes in their approaches to teaching. Such changes are challenging teachers to acquire a new knowledge or belief system about their pedagogy, their teaching, and student learning (Borko \& Putnam, 1995). 
According to Driscoll (2000) student-centered approaches to learning can be associated with the combination of pragmatism and interpretivism orientations to teachers' epistemological beliefs. These epistemological orientations to teaching are evident in the following learning theories: cognitive psychology, situated cognition, and constructivism. Teacher-centered approaches to learning, on the other hand, are associated with objectivism that is evident in behaviorism, cognitive information processing, and Gagne’s instructional theory.

Objectivism is the epistemological orientation to teacher-centered approaches. The objectivist paradigm views reality as objective, singular, and fragmentable. Because reality exists independently from and outside of the knower, learning becomes a matter of transferring reality from the knower to learner (Driscoll, 2000). Driscoll argued that objectivism is the dominant epistemology in the psychology of learning. Objectivism is the paradigm with which most learners and teachers associate classic formal learning (Chall, 2000; Driscoll, 2000). Both behavioral and cognitive information-processing theories emerged from the objectivist tradition. The teacher-centered curriculum is formally divided by grade levels and different subject. This traditional approach to teaching can be briefly summarized as whole-class instruction with heavy reliance on textbooks and high-stakes testing for measuring the outcomes of student learning. Pragmatism and Interpretism reflect the epistemological orientations to studentcentered approaches to teaching and learning. The new reform movement calls for student-centered (also called learner-centered) approaches to teaching. The studentcentered approaches to teaching focus less on facts and rote skills and more on thinking, problem solving, understanding, and creating (Chall, 2000). The student-centered 
curriculum is more integrated, basing learning on student interests; learning environments are designed to have students inquire and solve problems in groups of students through cooperation and collaboration. The sources of information move beyond the teacher and textbook to online sources and other communities of learners, experts, and others. Evaluation is non-traditional and usually project-based.

The American Psychological Association (APA, 1995) described the learnercentered construct in 14 principles that were drawn from a large body of research to aid the current educational reform and school redesign efforts. These 14 principles reflect a combination as well as current revision of learning theories. The APA learner-centered principles described learner characteristics, teacher beliefs, instructional practices, and social relationships that are linked to enhanced learning outcomes for all students. The APA research provides a framework to support designing knowledge-based learning. The 14 APA principles, organized into four factors, are presented in Table 1. 
Table 1

The APA Learner-Centered Principals

\section{COGNITIVE AND METACOGNITIVE}

1. Nature of learning process: Learning of complex subject matter is most affective when it is an intentional process of constructing meaning from information and experience.

2.Goals of the learning process: The successful learner, over time and with support and instructional guidance, can create meaningful, coherent representations of knowledge.

3. Construction of knowledge: The successful learner can link new information with existing knowledge in meaningful ways.

4. Strategic Thinking: The successful learner can create and use a repertoire of thinking and reasoning strategies to achieve complex learning goals.

5. Thinking about thinking: Higher order strategies for selecting and monitoring mental operations facilitate creative and critical thinking.

6.Context of learning: Learning is influenced by environmental factors, including culture, technology, and instructional practices.

\section{MOTIAVATIONAL \& AFFECTIVE}

7.Motivational and emotional influences on learning: What and how much is learned influenced by the learner's motivation. Motivation to learn, in turn, is influenced by individual's emotional states, beliefs, interests and goals, and habits of thinking.

8. Intrinsic motivation: The learners' creativity, higher order thinking, and natural curiosity, all contribute to motivation to learn. Intrinsic motivation is stimulated by tasks optimal novelty and difficulty, relevant to personal interests, and providing for personal choice and control.

\section{DEVELOPMENTAL \& SOCIAL}

9. Effects of motivation on effort: Acquisition of complex knowledge and skills requires extended learner effort and guided practice. Without learners' motivation to learn, the willingness to exert this effort is unlikely without coercion.

10.Developmental influence on learning: As individuals develop, they encounter different opportunities and experience different constraints for learning. Learning is most effective when differential development within and across physical, intellectual, emotional, and social domains is taken into account.

11.Social influences on learning: Learning is influenced by social interactions, interpersonal relations, and communication with others.

\section{INDIVIDUAL DIFFERENCES}

12.Individual differences in learning: Learning is most effective when differences in learners' linguistic, cultural, and social backgrounds are taken into account.

13.Learning and diversity: Learning is most effective when differences in learners' linguistic, cultural, and social backgrounds are taken into account.

14.Standards and assessment: Setting appropriately high and challenging standards and assessing the learner and learning process - including diagnostic, process, and outcome assessment - are integral parts of leaning process. 
McCombs (2000) argued that the principals for the learner-centered curriculum design reflect teaching practices for this millennium as opposed to the past century. These learner-centered principals look at learning from more integrative and holistic perspective other than focusing only behavioral, emotional, or cognitive aspects of learning. The principals include the knowledge base for both learners and learning, and clarify what is needed to design learning environments to support context and communities of learning.

Technologies may transform traditional teacher-centered individual classrooms beyond physical boundaries when students and learners of other communities aspire to build knowledge toward their common goals (McCombs, 2000). They enhance learning contexts and help developing learning communities. In technology supported studentcentered learning environments teachers play a considerably different role, giving students more control over their learning as in the case of collaboration and project-based learning (Cuban, 2002). The Internet tools facilitate complex non-linear thinking and learning. Technology may transform traditional environments because it facilitates transcending physical boundaries and developing communities of learners who work toward a common goal where knowledge is shared and built with collective experience. Riel (2000) explained this transformation with the following quote: "fundamental change in the next decades will result from participation in education by a larger community of people who the Internet brings together, rather then from access to technology.” Curriculum-based use of technology is a means to support this transformation for building communities of learners who bring their collected knowledge and people together for active and authentic learning toward building new knowledge. 
Niederhauser, Salem, and Fields (1999) argued that reform-oriented instruction is not based on technology use for instruction; rather, reform efforts suggest "a fundamental shift in teachers’ epistemological and pedagogical orientations” (p. 154) toward a student-centered paradigm. Teachers will determine how they implement technology, and the way they implement seems to be consistent with what their epistemological and pedagogical orientations to teaching. In another study, Niederhauser and Stoddart (2000) stated that it is in fact not surprising that computer use has been incorporated into traditional approaches because teachers are likely to select and use instructional technology consistent with their instructional philosophies.

In summary, we may conclude that today's educational reform efforts are based on a student-centered approach in an open-ended environment, and is not usually supported by traditional teacher-centered approach where instruction is delivered or transferred to the students (Morrison \& Lowther, 2002). Technology’s role in these open-ended learning environments is to foster (as opposed to deliver instruction) learning that is participated by a community of learners toward solving common problems through inquiry, problem-based learning, and active engagement.

\section{Beliefs}

Much research suggests teachers’ knowledge and beliefs about teaching and learning is inextricably associated with how teachers make curricular and instructional decisions (Brown, 1999; Borko \& Putnam, 1995; Pajares, 1992; Sadker \& Sadker, 2002; Valesey, 2000). Teachers' beliefs have a potent implication influence on the way in which curriculum is implemented (Tobin, Tippins, \& Gallard 1994) and instructional strategies selected (Driscoll, 2000). Teachers’ knowledge and beliefs have a great impact 
not only on the depth and breath of their teaching craft, but also on what students learn, how they learn, how teachers approach to teaching and learning, and what roles they assign to learners.

There is debate about the difference between teachers’ knowledge and beliefs. However, this study will hold the assumption that teachers' beliefs are related to their pedagogical knowledge as “what teachers know and believe is complexly intertwined, both among domains and with actions and context” (Borko \& Putnam, 1996). Teachers’ beliefs in this study include teachers' knowledge of various strategies for creating learning environments, their knowledge and beliefs about learners on how they learn, their views of learning as well as learners (Borko \& Putnam, 1995), and finally their beliefs (values and attitudes) about technology’s potential for instruction. The Nature of Teachers' Beliefs

Beliefs are often described as both valuable and difficult construct to define since belief “does not lend itself to empirical investigations” (Pajares, 1992, p. 308). Pajares argued that beliefs “travel in disguise and often under alias - attitudes, values, judgments, axioms, opinions, ideology, perceptions, conceptions, conceptual theories, internal mental processes, action strategies, rules of practice, practical principles, perspectives, repertoires of understanding, and social strategy” (p. 309).

Connelly and Clandinin (1988) proposed that teachers’ personal philosophies contain beliefs, values, and action preferences that are grounded and contextualized in the classroom events. They argued that teachers' beliefs about instruction indeed reflect their views of curriculum implementation including the roles they assume, the roles they 
assign to their students, and their approaches to how they teach the content in the pertaining learning environments that teachers create for teaching and learning.

Nespor (1987) argued that belief is a very important determinant about how teachers organize their knowledge to arrange the classroom activities or tasks. However, Nespor claimed that the relationship between beliefs and tasks are highly complex, since belief systems are "loosely-bound with highly variable and uncertain linkages to events, situations, and teachers’ knowledge system” (p. 321).

Borko and Putnam (1995) argued that teachers' thinking, knowledge, experience, and beliefs and actions are interrelated, and they play a center role in their perceptions of implementing instructional strategies. Teachers’ general pedagogical knowledge “includes knowledge of various strategies and arrangements for effective classroom managements; and more fundamental knowledge and beliefs about learners, how they learn, and how that learning can be fostered by teaching” (p. 39). Putnam and Borko (2000) argued teacher learning from the perspective of situated cognition is that teacher learning is situated and is intertwined with their ongoing practice.

Clark (1988) referred to teachers' beliefs as teachers’ implicit theories in his research on teacher thinking, and argued that teachers develop and hold implicit theories about their students, the subject-matter, and their roles in the classroom. Clark defined teachers' implicit theories as being “generalizations drawn from personal experience, beliefs, values, biases, and prejudices” (p.6). Teachers’ implicit theories are not as neatly nor clearly defined in practice as they are in the textbooks, and tend to be eclectic and cause-effect related. Clark affirmed that these theories are thought to play an important role in the judgments and decisions teachers make in their teaching. 
Orton (1996) considered teacher beliefs from the situated cognition point of view and argued that teacher beliefs are context bound (situational). "Teacher beliefs are not rooted in general theories of learning, cognition, or instruction, but in what had evolved in the past situations, particular instances, trial and error, and muddling through” (p.140). Teacher beliefs are knowledge, experience, and environment-based (Chiou, 1995). Teachers are pragmatic, and may establish or validate their beliefs in context specific environments where their instructional experience is successful. Orton argued that teachers justify their beliefs or may attain new sets of beliefs when they successfully experiment with new instructional approaches that work in a given context.

The situational aspect of teachers' socially constructed beliefs has been identified in other research. Calderhead (1996) pointed to the evidence for the need to take teachers' beliefs and knowledge into account in the context in which they have been learned and used. Other researchers (Tobin, Tippins, \& Gallard , 1994; Tobin \& LaMaster, 1995) defined beliefs as socially viable learned knowledge that can be observed in the classroom practices of teachers. Their examination of teachers' beliefs reflected the social nature of thinking and knowing, and they argued that teacher learning cannot be isolated from the social situations in which the curriculum is implemented. Teachers’ classroom practices are led by their beliefs; however, teachers’ beliefs and knowledge is always situationally determined. Thus, teachers' classroom decisions are not only related to what they know, but also how their knowledge is represented in their social setting, where teaching and learning occur.

The above reviewed research indicates that beliefs are context-bound (Tobin \& LaMaster, 1995; Orton, 1996; Putnam \& Borko, 2000), implicitly defined (Clark, 1988), 
and ill-structured (Nespor, 1987). Beliefs can neither be clearly defined, nor do they have a single correct clarification. Beliefs involve attending to multiple and sometimes conflicting perspectives. Teachers' beliefs tend to be more experience-based than theorybased (Orton, 1996). Teachers’ classroom approaches to teaching are important referents in our understanding of their beliefs and knowledge base.

To summarize, we may need to come back to Pajares’ (1992) synthesis, which provides the most robust and through synthesis of teachers' beliefs in literature. Pajares’ synthesis of teachers' beliefs cover the major assumptions relevant to this study on teachers' beliefs. Below, a few of these assumptions are listed.

- Knowledge and beliefs are inextricably intertwined, but the potent affective, evaluative, and episodic nature of beliefs makes them a filter through which new phenomena are interpreted.

- Thought process may well be precursors to and creators of belief, but the filtering effect of belief structures ultimately screens, redefines, distorts, or reshapes subsequent thinking and information processing.

- Beliefs are prioritized according to their connections or relationship to other beliefs or other cognitive and affective structures.

- Belief substructures, such as educational beliefs, must be understood in terms of their connections not only to each other but also to other, perhaps more central, beliefs in the system.

- Beliefs strongly influence perception, but they can be an unreliable guide to the nature of reality.

- Individuals’ beliefs strongly affect their behavior. 


\section{Theories behind Change in Teachers' Beliefs}

In literature, studies that explored teachers' beliefs for modeling change in teachers' practices make similar suggestions despite the differences in the theoretical framework they use. Most of these studies associate teachers' epistemological beliefs with their beliefs about teaching, learning, and learners and argue that teachers' epistemological beliefs filter teachers' knowledge and beliefs. Either for pre-service or in-service teachers examining and understanding the teachers’ own epistemological beliefs is recommended to become aware of one's own beliefs, and monitor one's own learning process. From the professional development point of view Borko and Putnam (1995) argued that teachers must need to expand and elaborate on their knowledge systems to help them change in practice. For many teachers the current education reform recommends a shift toward a student-centered paradigm. This entails a substantial departure of teachers' approaches from traditional transmission of knowledge to cognitive and social construction of knowledge (Borko \& Putnam, 1995; Niederhauser \& Stoddart, 1994).

When we accept the view that teachers tend to teach the way they were taught, we suggest that a majority of teachers substantively change their transmission-oriented approaches with which they completed their schooling. To change teachers’ practice toward a student-centered paradigm, teachers will need to think in different ways about teaching, learning, and learners. "Such changes in thinking will require new kinds of knowledge and beliefs as well as willingness” (Borko \& Putnam, 1995) (p. 38). Reflection and critical thinking come into play when teachers encounter a new set of beliefs that constitute a conflict with their existing thinking, knowledge, and beliefs. 
The relationship between teachers’ knowledge system (their beliefs) and actions must be studied to initiate teacher change, as teachers' knowledge and beliefs affect how they perceive and approach teaching. In one study, Tobin and LaMaster (1995) observed changes in one teacher's beliefs through metaphors, beliefs, and actions. They argued that teacher's change in beliefs involves more than teacher learning and classroom practices. Teachers need to experience the learned knowledge in a social context to test if this new concept meets their curricular goals. Change in curriculum is change in teachers' beliefs that can be observed in teachers' classroom practices. To change the practices of educators, teachers need to become aware of their philosophy of education and their actions in the classroom. They need to reflect why events occur as they do in their classroom to be able to conceptualize alternatives to their practices in their teaching context that is adaptive to the efforts of change. Overall, teachers need to be learners and experience their viable knowledge for change in beliefs.

In another study, Windschitl and Sahl (2002) observed a change in one teacher's practice over a two-year ethnographic study. The researchers argued that it was not the condition of ubiquitous laptop technology that was available both to this teacher and all of his students compelled this teacher to change in practice. Rather, this teacher's professional participation in a university course that focused on constructivist principles and student motivation shifted his image of teaching from being exclusively contentoriented to process-oriented. This teacher's former knowledge base was challenged with experiencing new knowledge in a learning environment in which he participated as a learner. The teacher's belief eventually shifted toward a more student-centered approach as he tested the viability of this new knowledge in his teaching context. 
From the cognitive science research perspective, Niederhauser, Salem, and Fields (1999) argued that the individual's coherence to beliefs is a predictor if the individual involved with a conceptual change will adopt a new set of beliefs. When teachers' existing beliefs are disturbed (as a result of experiencing new practices and models to teaching), they begin to restructure their beliefs to regain coherence. This may create disequilibrium or a cognitive conflict (Piaget, 1971 as cited in Niederhauser, Salem, \& Fields, 1999) because individuals try to make sense of the new structure in response to their existing knowledge structure. Restructuring one’s beliefs is often difficult and creates uncertainty in the learner. Gaining back coherence in teachers’ new adapted beliefs can be facilitated through active engagement, reflection, and critical thinking of what is being learned compared to what was known. Although this process appears to be more intrinsic than extrinsic, the research emphasizes the importance of cooperation and collaboration during the adoption of new knowledge because learning cannot be achieved in isolation.

If change in curriculum is in fact change in teachers' beliefs as teachers are the ultimate implementers of the curriculum, the purpose of examining teachers' beliefs is twofold: (1) to help teachers understand their underlying beliefs and (2) to have teachers experience new knowledge-base toward change in practice. To change teacher thinking, both the researchers and teachers need to understand teachers' already existing beliefs toward instruction. Clark (1988) argued that this can be understood by having teachers to “think aloud” (p. 8). The way the instructor plans and delivers instruction is a way of understanding teachers' beliefs. Other methods of thinking aloud include reflection and analysis by teachers of their own thinking and behavior. 
Enabling teachers to become reflexive or self-conscious of their own beliefs has been reflected in much research (Brownlee, Purdie, \& Boulton-Lewis, 2001; Brown, 1999; Clark, 1988; Connelly \& Clandinin, 1988; Dexter, Anderson, \& Becker, 1999; Nespor, 1987; Putnam \& Borko). Reflection requires metacognition (Brown, 1999; Brownlee, Purdie, \& Boulton-Lewis, 2001). Journals, metaphors, images, interviews, and classroom observations are given as methods to facilitate this reflection process.

Much research offers insights about reflection by tapping into teachers' knowledge base through professional development for in-service teachers and through modeling new practices for pre-service teachers. Teachers need to be learners in the learning environment that models this change (Brown, 1999). They need to experience the new knowledge. Teachers need to understand what the innovation is, and what their purposes are for using the innovation. In summary, toward a successful adoption of new practices, teachers need to be learners, experience the new model, have successes with their implementation, and reflect on their practices. Darling-Hammond, Bullmaster, and Cobb (1995) called this process a "liberating process" that occurs when teachers experience being learners in the learning environments in which new practices are modeled. Upon building a new knowledge base, teachers transform their existing knowledge, reflect on new practice, and thus generate new knowledge.

The Apple Computers of Tomorrow (ACOT) project research is an earlier example of how teacher reflection contributed to change in teachers' beliefs and practices (Sandholtz, Ringstaff, \& Dwyer, 1997). The ACOT researchers affirmed that "the process of reflection helped teachers to see for themselves the benefits and drawbacks of different instructional approaches” (p.49). In fact, their data collection strategy cultivated 
the very same phenomenon: teacher reflection. Teacher journals and audiotaped reflections provoked teachers to make their own analysis of their teaching in the classroom as well as their own potentials of learning through the ACOT project. Teachers' experiences as learners in combination with their reflections led them to reconsider their new roles and philosophies of teaching.

\section{Teachers’ Beliefs and Approaches to Technology Integration}

Teachers hold a set of beliefs about the value of instructional technology use for teaching and learning. The following quote best describes the influence of teachers' values toward technology use (Ertmer, Addison, Lane, \& Woods, 1999).

"If the computer does not teach what teacher stresses, teaches different things the teacher does not, or requires types of intelligent activity the teacher does not emphasize, it is unlikely the teacher will assign high value to its use. On the other hand, if the teacher perceives that the computer addresses important instructional and learning needs, the perceived value will be higher” (p. 55).

Studies reviewed below suggest how influential teachers' beliefs can be in teachers' frequency, type, and effective use of technology. While considering the following, it is important, however, to pay close attention to the lens through which the researchers examined teachers' instructional technology practices.

Two research lenses have been reported here documenting the differences in a continuum of teachers' instructional technology use. The first type of studies investigated teachers' approaches to technology among the selected research population of teachers. Because these first types of studies reflect the likelihood or tendency of technology use among the general teacher population, they are classified as approaches to 
technology among the overall teacher population. The second type of research lens examined only those technology-using teachers who represent teachers with more frequent, effective, and appropriate technology integration. This second type of research studies is classified as approaches to technology among technology-using teachers because these teachers represent the teacher population who more frequently and effectively use technology compared to the general population.

\section{Technology Integration: Overall Teacher Population}

In the study of teachers' beliefs in relation to their technology integration, Honey and Moeller (1990) investigated if teachers' discernable patterns of pedagogical beliefs facilitated or detracted them from integration of technology in the classroom. They interviewed twenty teachers who used and did not use computer technologies. The researchers found four groups of teachers emerging from their interviews. The first three groups of teachers had student-centered progressive beliefs but differed in their technology integration practices. The last group of teachers had teacher-centered beliefs.

The teachers with progressive student-centered practices fell into three categories: (1) those who integrated technology successfully, (2) those who were ambivalent about technology, and (3) those who had had lacked the opportunity. The first group of teachers who successfully integrated technology viewed the relationship between technology and education valuable, viable, and productive. These teachers claimed that technology had enabled them to make some desired changes in their teaching and thus technology and curriculum mutually influenced each other. They stated that their teaching practice took a new quality toward a process-oriented teaching approach as 
opposed to content-oriented teaching. These teachers employed student-collaboration and project-work.

The second group of teachers had student-centered practices but were ambivalent toward technology integration. Although they had identical pedagogical beliefs with the first group of teachers, the second group of teachers was reluctant to integrate computers because of their deeply rooted personal fear about technology. The third group of teachers with student-centered beliefs also viewed computers as a viable tool to enhance learning and teaching; however, these teachers were not technology users because of limited access to technology. They lacked understanding and modeling of how technologies could be incorporated into their classroom.

The forth group of teachers with traditional practices had conventional pedagogical beliefs toward teaching. These teachers stated that there had been no significant change in their teaching practices. Similarly, when they spoke of change, they spoke of what they were required to teach or the students that they were teaching. The teachers with traditional practices also differed in their view of technology integration and did not share "a vision of technology as deeply integrated into curriculum” (p.12). Their view of technology was a "special treat” or an “add-on”.

Honey and Moeller’s study (1990) is perhaps one of the earliest descriptive studies to point to the evidence of the relationship between teachers' beliefs and their practices of technology integration. They concluded that "unless teachers are personally ambivalent about computers or have lacked the opportunity to get involved with computer technologies, their educational beliefs play an important role in how they choose to appropriate and make use of technologies in their classroom” (p. 14). 
In a more recent study Norton, McRobbie, and Cooper (2000) examined secondary math teachers' reasons for not using computers in their teaching in a technology-rich school in Australia. The researchers conducted five case studies and restricted their conclusions to (1) a domain specific subject matter teachers (in this case mathematics teachers) and (2) a school where difficulties were associated with hardware, software, computer access, and ratio of students-to-computers were not in question. Within the above framework of reference, Norton et al. explored five teachers' beliefs and their practices toward the use of computers. Their study concluded a none-to-rare use of computers among all five of the teachers despite the availability and access to computers at this school.

From the interviews, the researchers discovered that four of the five teachers had a transmission image of mathematics teaching, and a single teacher had a learnercentered approach. Although all five teachers were none-to-rare users of computer technologies for instruction, they differed in their reasons for not using computers. Two of the four teachers with transmission image of mathematics teaching stated their lack of expertise with technology for rare use, while the other two stated their belief that technology could hinder learning or had no use at all. One of the teachers who refused to use computers in fact had a high level of computer expertise with software and data base programs. The teacher with high level computer expertise refused to use computers because he believed that computers could hinder learning and do not prepare students for assessment.

In summary, four of the five non-to-rare computer using teachers had traditional pedagogical approach to mathematics teaching although they varied in their expertise to 
use technology. These teachers stated that "they would use the computers to support their transmission of mathematical knowledge” (p.104). They believed "student use of computers could have negative effects as computers could deprive students of the opportunity to practice basic skills and procedures that they believed were the essence of mathematics learning” (p.104).

The fifth teacher with social constructivist image of mathematics teaching also rarely used computers. Although this teacher viewed technology as a viable tool and believed technology can support student learning, she stated that her lack of expertise and lack of modeles showing how to integrate technology into mathematics teaching were her reasons for rare use. This teacher with a learner-centered teaching pedagogy was ideologically isolated among the other staff at this school.

Ertmer, Addison, Lane, Ross, and Woods (1999) examined teachers’ beliefs about the role of technology in the framework of two factors affecting teachers' uses of technology: first-order (external) and second-order (internal) beliefs. The first-order factors included lack of access to computers and software, insufficient time to plan instruction, and inadequate technical and administrative support. The second-order barriers were intrinsic to teachers including beliefs about teaching, computer use, classroom practices, and unwillingness to change.

Out of seven, three teachers used computers frequently in the classroom with more learner-centered instruction focus. Sometimes, these three teachers used the computer to "help student master skills, but focused more on the excitement that computer brought to their theme-based lessons” (p.63). The remaining four teachers used computers less frequently as an "add-on" or as a reward. These four teachers did not see 
any value integrating computer technology to curriculum. They believed computer use was secondary compared to the content that they need to cover.

Ertmer et al. concluded that “teachers’ beliefs about classroom practice appeared to shape their goals for technology use as well as the weight they assigned to different barriers” (p. 66). Although every teacher stated that lack of equipment was a barrier, they had different reasons for wanting more equipment. The lack of equipment held different meaning for these teachers as each had varying beliefs as to what can be accomplished given the current technology availability at their school. The four teachers who used technology as a supplement to curriculum experienced the second-order (external) barriers more than the other three teachers and believed technology can be used neither to support nor enrich the curriculum.

Saye (1998) examined the relationship between teachers' educational practices and their perceptions of technology integration. His study findings reported no radical shift toward student-centered approaches to technology integration among the 10 teachers involved in the study. Although "some teachers appeared to have embraced its potential for alternative approaches to schooling, others adapted technology to bolster traditional teacher-centered instruction” (p. 223). However, when Saye described the study results in terms of teachers' thinking about technology and teaching in relation to technology integration, the researcher reached different conclusions. The differences in teachers’ thinking about technology and teaching were explained with two metaphors: Accidental Tourists and Voyageurs. The Accidental Tourists were the structural, content-focused teachers with teacher-centered approaches to teaching. The Voyageurs, on the other hand, were open, flexible, experimental, and process-oriented with student-centered 
Saye reported that only one teacher was committed to Voyageur perspective and two others exhibited some Voyageur characteristics without a strong commitment. All other remaining teachers were clustered toward the middle of the continuum with substantial ambivalence to Voyageurs perspective. Teachers with Accidental Tourists perspective viewed technology not supporting “serious learning” as it took time away from the content that they needed to focus. Their technology use was essentially drilland-practice and word processing. On the other hand, the Voyageurs recognized technology's potential and used technology as a tool for thinking and adventure. In brief, Saye concluded teachers' adoption decisions are more likely to be related to their educational beliefs.

Similar to Saye's study, Wang (2002) found no significant shift among the 78 preservice teachers computer use toward student-centered practices. The pre-service teachers involved in this study stated that classroom computer employment can be both student-centered and teacher-centered; however, they were more likely to use computer technologies as a teacher-centered tool than a student-centered tool.

Any review of literature on teachers' computer use and approaches would be incomplete without Cuban's input on the investigation of this phenomenon among the U.S. schools through history. In a recent study Cuban (2002) examined technology rich schools in Silicon Valley to find out (1) how teachers and students use the machines for instruction and (2) if teaching and learning changed as a consequence of heavy technology investments. Cuban selected Silicon Valley schools as they made great investment and encouragement to make new technologies available to teachers and 
students assuming that increasing availability in the classroom would lead to increasing use among teachers and students.

Cuban noted that there had been a modest shift among the U.S. teachers from non users to occasional users and from occasional users to serious users; yet over half of elementary and middle school teachers continue to be nonusers of computers. Particularly, Cuban examined two Silicon Valley high schools for teachers' frequency, types, and approaches to using computers in the classroom. Cuban found computer use was achieved among a minority of teachers (between 25 to 32 percent), and was mainly conducted for teaching students how to use computers. Cuban found that integration of computers into curriculum was minimal (less than 5\%) ranging from entry to adoption. Despite abundant access to technology, and contrary to expectations, the overwhelming majority of teachers made infrequent and limited use of technology, and adapted the use of technology to maintain their routine teacher-centered practices even in the technologyrich schools.

Secondly, Cuban investigated if teaching practices were altered as a result of heavy investment on technology. Out of 21, 13 teachers who were interviewed said "their teaching had indeed changed because of their use of information technologies" (p. 94). However, the changes these teachers mentioned were related to technology's role in their planning, preparation, communication, and using computer as another tool to teach. Only four of the 21 teachers said they became more student-centered in their teaching as they now act like a coach than a performer on stage. Cuban noted that "teacher-centered instruction was the norm, even in computer-based classroom” (p.95). Except for the four teachers, Cuban noted little evidence of student-centered instruction among technology- 
rich Silicon Valley high school teachers. He concluded that teachers at technology-rich Silicon Valley, similar to teachers nationwide, had adapted computers to fit their customary practices and had not revolutionized their practice. They continued using machines to fit the familiar practices of teacher-centered instruction.

In the conclusion of his study, Cuban argued that teachers' beliefs shaped in the organizational school environment are the most important factors for the type and frequency of computer use. More specifically, teachers' beliefs filter their decisions in answering the following questions when it comes to selecting to use technology. The questions that Cuban enlisted are as follow (p. 168):

1. Is the machine or software program simple enough for me to learn quickly?

2. Is it versatile, that is, can it be used in more than one situation?

3. Will the program motivate my students?

4. Does the program contain skills that are connected to what I am expected to teach?

5. Are the machine and software reliable?

6. If the system breaks down, is there someone else who fix it?

7. Will the amount of time I have invest in learning to use the system yield a comparable return in students learning?

8. Will student use of computers weaken my classroom authority?

Similar to Cuban's study of computer use in a technology-rich school, Windschitl and Sahl (2002) investigated teachers' use of technology at a single school site where barriers to accessing technology were removed as each teacher and student had a laptop computer in the classroom. Windschitl and Sahl study pointed teachers' beliefs as being 
the most important determinants as to what technologies teachers use and how they use them. The single teacher who transformed her teaching practice made the connection between technology's potential and a student-centered classroom. This teacher acknowledged her students' privileged backgrounds and their maturing attitudes toward exploring adult identities. She, therefore, conceptualized the laptop "as a gateway for them to a world of information shared by adults and as a set of tools enabling her students to create professional-looking products” (p. 196). This teacher was willing to empower her students' independence and thinking with the laptop computer.

Windschitl and Sahl's study similar to Cuban's and Norton et al study concluded that the differences in teachers' approaches and frequency of computer use were mediated through teachers' interrelated belief systems. Windschitl and Sahl presented these interrelated beliefs as (1) teachers' beliefs about what constituted "good teaching” shaped by a particular institutional culture of their teaching context, (2) their beliefs about technologies role for instruction, and (3) their views of learners potentials and their willingness to hand over control to students depending on their philosophy of teaching.

Briefly, the studies reviewed above point to consistent findings despite the range of years in which they were conducted between the years of 1990 and 2002. Among them Cuban, Norton and his colleagues as well as Windschitl and Sahl studies selected technology rich schools where barriers and access to technology were not in question. Their findings in the 2000s echo Honey and Moeller study in the year 1990. Despite increasing access, training, ease of use, and advances in technology, teachers' perception of technology use appears to be mostly related to their instructional beliefs and their beliefs about technology use in the classroom for instruction. 


\section{Technology Integration: Technology-Using Teachers}

Several studies were conducted based on the findings of a national survey on teachers' computer use. Generally speaking, the findings suggested that frequent computer-using teachers are distinctly constructivists compared to rare or infrequent computer-using teachers. Below, three of these reviewed research studies document this relationship among the technology-using teachers. The findings of these studies come from the national “Teaching, Learning, and Computing” survey (1988) that included over 4000 teachers and 1100 schools.

Riel and Becker (2000) stated that groups of teachers (teacher leaders, teacher professionals, interactive teachers, and private teachers) differ from one another in terms of their philosophy, practice, and using computer technologies for teaching and learning. The researchers measured teachers' instructional practices by examining how frequently these groups of teachers employed specific instructional strategies and, categorized these strategies as "knowledge construction" (compatible with constructivism) approaches versus “direct instruction” (compatible with knowledge transmission). Similarly, teachers' beliefs or philosophies of education were organized as teachers with traditional beliefs and constructivist beliefs. Riel and Becker concluded that teacher leaders (highly professionally engaged as leaders) and teacher professionals (those who are professionally oriented) were far more constructivist and more likely to have their students use computers on a regular basis for constructivist compatible approaches during class time than the other groups of teachers.

In the second study using the same data, Becker (2000) explored how teachers’ were using computers. Becker stated the way teachers use computers gives an indication 
of his/her underlying pedagogical philosophy, transmission-oriented versus

constructivist. Becker argued that teachers who use computers most productively are not very comfortable with a teacher-centered (transmission-oriented) pedagogy. Instead, the computer-using teachers are more distinctly constructivists. Reporting from the same data, Ravitz, Becker, and Wong (2000) argued again that this pattern - high computer using constructivist teachers - was very consistent among teachers in every academic subject-matter. They concluded that teachers who increasingly used computers became more constructivists over time at those schools which had abundant technology.

In brief, when we come back to the two research lenses through which the above studies are reported, specifically the following conclusions can be specifically drawn. When research studies examine the relationship between teachers' instructional approaches to technology and their educational beliefs among the entire research population selected for the study, the research findings state two general tendencies: (1) technology use among teachers is very limited if not rare and (2) teachers' use of technology is consistent with their educational beliefs, that is, a majority of them continue to use technology to support their teacher-centered approaches. However, when the research lens examines only those teachers who effectively and appropriately integrate technology, the following general tendencies are reported among this teacher population: one, teachers who effectively and appropriately integrate technology use technology with more student-centered approaches; two, the technology-using teachers are distinctively more constructivists in their educational philosophy. 


\section{A Catalyst for Change: Beliefs versus Technology}

The Apple Computers of Tomorrow (ACOT) project is the earliest longitudinal project that reported changes in teachers' practice due to change in their beliefs (Sandholtz, Ringstaff, \& Dwyer, 1997). The ACOT researchers focused on changes in teacher practice as well as student learning when teachers and students had constant access to technology in technology-rich learning environments. The project modeled effective instructional technology integration through their developmental professional development project. The researchers collected longitudinal data over ten years to draw their conclusions, and their data relied on teachers' reflections, weekly reports, teacher journals, and on-site observations.

The researchers did not observe any changes in teacher practice other than transformation in the physical classroom set-up in the early stages of the project. As the project progressed, researchers identified changes in teachers' long-held instructional beliefs and approaches, their collegial relations among themselves, and their mastery of technology. However, the most significant findings of the ACOT research points to the evidence in teachers' beliefs as teachers progressed through the five stages of instructional evolution: entry, adoption, adaptation, appropriation, and invention.

The ACOT research related teachers' change in practice to teachers' building knowledge gradually through the stages of the evolution. This research suggested that effective instructional technology integration resulting in a change of practice toward a student-centered paradigm occurs "only if there is a concomitant change in teachers' beliefs about their practice” (p. 48). This change, however, is not about abandoning beliefs but "one gradually replacing them with more relevant ones shaped by experiences 
in an altered context” (p. 48). Shift in beliefs occurred as teachers began to see the benefits for both themselves and their students. Eventually, teachers appropriated technology in their instruction, resulting in more engagement, interactivity, and collaboration. In summary, the ACOT research concluded that teachers' beliefs about learning had the most influence on how technology would be used.

The findings from the national survey stated the shift among technology-using teachers toward a student-centered constructivist paradigm (Riel \& Becker, 2000; Becker, 2001; Becker, 2000; Becker \& Ravitz, 2001; Ravitz, Becker, \& Wong, 2000; Becker \& Ravitz, 1999). These studies implied that the paradigm shift among constructivist teachers is likely to be technology-induced as their results indicate a clear relationship between teachers' constructivist compatible philosophies and their extent of technology integration. Becker and Ravitz’s (1999) affirmed that “computers and the Internet is more consistently related to certain types of changes in practice and teacher perception than others... it seems that the relationship between technology use and pedagogical change is truly casual and not the mere conjunction of innovative teachers who happened to both use technology and develop a more constructivist pedagogy” (p. 381). However, the researchers link this casual relationship to only those school environments, where an information and social support is available and where a sufficient technological infrastructure is in place.

In another study (Dexter, Anderson, \& Becker, 1999) researchers found somewhat conflicting results for reasons of change in practice among technology-using teachers. The focus of this study was to understand teachers' views of computers as catalysts for changes in teaching practice. Researchers collected qualitative data along 
side the questionnaire from 47 teachers as part of their preliminary study for a national survey. This study also categorized technology-using teachers as constructivist versus non-constructivist and reported teachers’ views of technology accordingly.

In the interviews teachers were asked to describe recent changes in their instructional practices and the roles of the computers in making those changes. All the 32 constructivist compatible teachers said they had made changes in their practice over the years in the classroom. Of the 32 interviewed, 22 teachers said technology did not change how they taught; technology allowed them to make the changes that they already wanted to make. Only two of the 32 teachers said that computers changed the way they taught. This meant nearly all teachers "did not feel that computers were catalysts for change” (p. 226).

The researchers offered three reasons for this type of change. The primary reason was internal: "Change was the consequence of reflecting on teaching practice, its goals, and its efficacy” (p. 226). The second reason had a combination of both internal agency and external origin; teachers' learning in formal classroom settings in conjunction with experience and reflection. The third reason stood out among the teachers who had the strongest constructivist learning. These teachers mentioned external sources, schoolwide expectations on new approaches and assessment methods, as being a catalyst for change.

Dexter, Anderson, and Becker (1999) concluded that computers were not a catalyst for change since "across the board, teachers made it clear that the computer did not automatically cause more constructivist practices. Instead, they offered a variety of reasons for changing practice” (p. 236). Teacher reflections upon experience, their 
educational beliefs, and their professional knowledge, and schoolwide initiatives were given as catalysts for change.

Cuban (2002) drew upon other literature findings to point to the puzzling evidence that Silicon Valley teacher computer use was consistent with the overall nationwide teacher population. Despite the technology supportive culture, reward, training, and access to computer technologies, Silicon Valley teachers’ integration of technology was minimal, similar to national findings. Teachers mainly adopted computer technologies to fit their customary teacher-centered practices.

Cuban offered three explanations for collective teacher behaviors in using or not using computers with mainly teacher-centered approaches: (1) slow-revolution, (2) history-and-context, and (3) contextually constrained choices teachers make based on their beliefs and values. Cuban also gave the same explanations for a catalyst of change (technology or beliefs) in his examination of change in practice among a minority of teachers who adapted technology with student-centered practices. Cuban argued that these explanations differ considerably; however, they are not mutually exclusive. The third explanation represents Cuban's perspective as he argued that this explanation gives a better understanding for (a) consistent teaching behaviors for rarely using computers among the general teacher population with teacher-centered approaches and (b) innovative teaching behavior of computer use among the early adopters who represent a minority of teacher population.

The point of view of the "slow-revolution" refers to the fact that change is achieved over time. “Technological change takes far longer to implement in formal education than in businesses because they are citizen-controlled and nonprofit” (p. 153). 
Schools’ primary mission is to prepare next generation of a literate work force.

Teachers' adoption of computers for classroom is mainly to do with the evolution of hard and soft infrastructure. Referring to the argument made by Ravitz, Becker, and Wong (2000) and Becker and Ravitz, (1999) whose study findings were based on a national survey, Cuban argued that these researches' view is a representative of the slowrevolution that is compatible with technological determinism. The proponents of the slow-revolution claimed that a 4 to 6 student-to-computer ratio, a large array of software for classroom use, and information and technological infrastructure will eventually result in a spread to most teachers. Changes will accumulate over the years, and by then teachers who have had these conditions available over the years will have transformed teaching practices from prevailing teacher-centered daily classroom routine to “constructivist” teaching practices.

The second explanation, the history-and-contexts perspective, emphasizes the societal role that schools perform in a democracy. In Cuban's words “this explanation locates the gap between home and school uses of technology in the social and political organization of schooling, societal expectations for schools, and historical legacies, all of which influence what occurs in classroom. Furthermore, this explanation tells us why teacher users of information technologies have continued rather than changed routine instructional practices” (p. 156). Cuban argued that the past and contemporary context of schooling, shaped by both external and internal forces, determine what kind of computer using patterns would occur at schools ranging from kindergarten to universities. Flaws, unreliability and complexity of computer technologies that are beyond the needs of the teachers for instruction are the explanations for the history-and-context perspective. 
Cuban argued that neither perspective provides explanations for (a) consistent teaching behaviors for rarely using computers among the general teacher population, and (b) innovative teaching behaviors of computer use among the early adopters. Cuban argued that teachers' beliefs and values drive many of the decisions they make in terms of what instructional tools (technology or books) they would use to best meet their goals for learning, and what content will be taught in which order. Cuban, therefore, holds the position of “contextually constrained choices” in that teachers make their instructional technology decisions depending on their beliefs and values they hold about teaching and learning. Although teachers' mindset cannot be the only accountable factor for all their classroom actions, because of organizational and contextual factors, they clearly influence how teachers organize the classroom activities and what approaches they will be used for instruction.

Windschitl and Sahl (2002) agreed with Cuban in that the slow-revolution cannot be an explanation for teachers change in practice. They conducted a two-year ethnographic study at a single technology-rich school. Contrary to the slow-revolution proponents argument (that is teachers' frequent use of technology play an important role and teachers change their instruction toward constructivist pedagogy over time when using technology with students), Windschitl and Sahl observed instructional change in practice only in one teacher who already had a pre-existing dissatisfaction with her traditional teacher-centered instruction. Despite the ubiquitous presence of laptop computers, technology was not a catalyst for change for both students and teachers. In conclusion, there is evidence in research that some teachers' beliefs and practices change over time when integrating technology. Most agree that this change in 
practice is developmental, occurs over a period of time, and is contingent upon teachers' beliefs and depend on many environmental factors. Although different researchers bring their perspectives to point a catalyst for change, most research consensus centers around teachers' beliefs that are shaped in the context of their organizational and school culture.

\section{Factors Affecting Teachers’ Technology Integration}

The ACOT research held teachers’ deeply rooted instructional beliefs as being the single most important barrier or factor influencing their level of instructional technology use. However, the same research also pointed to the evidence that change in beliefs and practices are multidimensional. Support and school culture for change are essential (Sandholtz, Ringstaff, \& Dwyer, 1997). The two case studies conducted by the ACOT researchers clearly demonstrated that the two teachers who both endeavored to change their practices in technology-supported learning environments differed in their endeavors, because of the context. Sandholtz, Ringstaff, and Dwyer argued that “instructional innovation involves not just change in people but also changes in organizational culture” (p. 31). Teachers who are bold enough to make changes in their beliefs toward instruction require modifications in their organizational culture. This cultural modification can be cherished in schools not only with collegial and administrative support but also technical and general support.

Ertmer, Addison, Lane, Ross, and Woods (1999) examined the relationship between the external and internal factors in relation to teachers' perceptions of instructional technology use and concluded that teachers' beliefs about classroom practice appeared to shape their goals for technology use as well as the weight they assigned to different barriers. They argued that the first-order external factors 
(equipment, time, and support) are easier to observe than the second-order internal factors (teachers' beliefs about teaching, computer use for instruction, and their willingness for change). Although the researchers do not make an explicit conclusion about the relationship between the internal and external factors to determine their weight of effect on teachers' perceptions of technology use, the researchers stated that “second-order (internal) barriers may persist even when first-order (external) barriers are removed” (p. 70).

Some other research rates teachers' beliefs secondary to the technical expertise and computer availability that teachers have at their schools. Teachers' beliefs are strongly tied to teachers' technical and professional expertise, computer availability and ratio, and their professional involvement (Becker, 1999; Becker, 2000; Becker 2001; Becker \& Ravitz, 2001). These studies indicated that the constructivist-compatible teachers who used computers most frequently and appropriately had at least 5 computers in their own classroom and teachers themselves had at least moderate computer expertise. Becker (2001) argued that there are even stronger factors than teachers' philosophies of education in determining if teachers will use computers and how they will use them. These factors are (1) teachers’ own technical expertise, (2) professional experience in using computer applications, (3) the number of computers in their own classroom, and (4) teachers’ professional involvement in their profession.

Becker and Ravitz study (1999) argued that “teachers’ pedagogical philosophies and practices are not static” and beliefs standing alone cannot be accountable for educational change. Becker and Ravitz restricted their conclusions on the relationship between computer use and pedagogical change to the schools with the following 
conditions: They argued that change in practice toward a student-centered technology use is possible at schools "where informational and social support network is available and where there is a sufficient technological structure is in place” (p. 356).

Dexter, Anderson, and Becker’s (1999) study emphasized more of the school's culture and teaching context for affecting teachers' computer use, because teachers socially construct their knowledge for their practices at their schools. They suggested that "experience in the classroom, reflection on those experiences, and professional school culture of a school are factors for influencing teachers' knowledge-construction process” (p. 237) for changes in teaching practice.

Saye (1998) argued that four prerequisite factors should be in place before teachers use technology. These factors are enlisted as (1) knowledge, (2) availability, (3) preparation for future, and (4) time. Saye, in agreement with Cuban, confirmed that these factors are largely controlled by decision-makers in the school structure, not by teachers, but "operating within the same environment, individuals respond to technological innovation in quite different ways. Teachers differ in when - or if - they perceive prerequisite factors to have been met. More importantly, individuals may differ greatly in the goals they pursue with technology once they have decided to use it” (p. 222).

Cuban (2002) argued that unreliability and complexity of technologies mainly undermined teacher confidence and technology use as an integral to the lesson rather than as an add-on. Cuban stated that a minority of serious users, who use computers at least once a week in the classroom, have continued being committed to using computers despite the glitches that might occur when using technology. Cuban suggested that the serious computer-using teachers are ardent computer users, and have a back-up lesson 
plan in case of technical difficulties or failures. Cuban stated that factors related to unreliability and complexity of technology are perceived differently by individual teachers, and therefore dealt with accordingly among teachers depending on their commitment to using computers. Cuban concluded that teachers who are committed to using computers for instruction act on their beliefs to seek substantial change in their instructional practices toward a student-centered paradigm.

In summary, the studies reviewed above suggest that integration of technology into curriculum is an important means to meet the needs of the changing face of education. Attainment of this goal is procedural, longitudinal, and influenced by many internal and external factors that affect the frequency and level of instructional technology use. Educational change is teacher change. Teachers' beliefs play a crucial role in their implementation of curriculum, therefore, integration of technology within curriculum.

\section{Summary}

Overall, the literature review pointed to evidence that (1) there is no significant shift toward student-centered practices among the overall teacher population, (2) the shift that occurred among a minority of teachers did so because they already had studentcentered beliefs, or they either changed or adapted a new set of beliefs compatible with student-centered approaches, and (3) teachers' beliefs are the most important explanation for their infrequent computer use with traditional approaches. Teachers’ beliefs become viable in the school context where teachers' actions take place. In addition to beliefs and school context, equipment, time, technical, and general support are highlighted as attributing factors relating to teachers' instructional technology practices. However, 
given the same variables in the teaching environment in terms time, equipment, support, and school culture, individual teachers may respond to the technological innovation differently due to their underlying beliefs what technology means and how it is used to support teaching.

The literature review revealed three important reasons for exploring teachers’ beliefs in relation to their instructional technology practices. First, teachers are likely to select and use instructional technology consistent with their beliefs. Second, several studies linked non-to-rare computer use for instruction and consistency of teachers’ computer use with teacher-centered practices to teachers' belief systems that filter teachers' actions in the classroom. Third, even in the technology-rich schools where barriers to access and availability to computer technologies were removed, the same consistency of teachers' computer use was observed. In short, the general teacher population continues to use technology infrequently with teacher-centered approaches. 


\section{CHAPTER 3}

Methods

This chapter will describe the methods used to conduct this study. Both quantitative and qualitative methods were employed to determine how teachers' beliefs and factors other than beliefs relate to teachers' instructional technology integration practices. The research questions that this study sought to answer are:

1. How do teachers' beliefs relate to the types of technologies and instructional strategies teachers use with their students for instruction?

a. How do teachers' beliefs relate to the types of technologies teachers use for instruction?

b. How do teachers' beliefs relate to the types of technologies teachers have their students use for instruction?

c. How do teachers' beliefs relate to the types of instructional strategies teachers use for instruction when integrating technology?

2. How do factors other than teachers' beliefs relate to the types technologies and instructional strategies teachers use with their students for instruction?

a. How do factors other than teachers' beliefs relate to the types of technologies teachers use for instruction?

b. How do factors other than teachers' beliefs relate to the types of technologies teachers have their students use for instruction?

c. How do factors other than teachers' beliefs relate to the types of instructional strategies teachers use for instruction when integrating technology? 
The independent variables (predictors) in this study are the following: (1) studentcentered educational beliefs, (2) teacher-centered educational beliefs, (3) teachers’ beliefs (attitudes) about technology use, (4) teacher confidence and comfort, (5) technical support, (6) general school support, and (7) ratio of computers-to-students.

The three dependent variables (criteria) of the study are the following: (1) instructional strategies teachers employ, (2) software teachers use for instruction, and (3) software that teachers have students use for learning. To determine how teachers' beliefs relate to their instructional practices, each dependent variable was tested against the independent variables (within-subjects) using quantitative data analysis methods. In addition to quantitative analyses, four qualitative case studies were conducted to describe how teachers' beliefs and factors other than beliefs relate to teachers' instructional technology decisions or instructional technology practices.

Below, the rationale for using mixed methods (qualitative and quantitative) will be described first. The remainder of this chapter will describe the research design and procedures used in examining the research questions with two methods. Two methods that are used in answering the research questions will be described in different headings as Method 1 and Method 2. The quantitative section (Method 1) will be framed according to the following: (a) participants, (b) instruments, (c) procedure, and (d) data analysis. The qualitative section of this study (Method 2) will be framed correspondingly: (a) participants, (b) research design (c) data sources, (d) procedure, and (e) data analysis. 


\section{Rationale for Mixed Methods}

The research approach for the study is qualitative primary, quantitative first (Morgan, 1997 as cited in Glatthorn, 2001); that is, "the researcher begins by collecting quantitative data as a basis for collecting and interpreting qualitative data” (p. 34). The quantitative approach to the study followed a corelational research type for conducting multiple regressions and correlations while the qualitative approach to the study was based on a multiple case study research type. The research methods included surveys and interviews (Glatthorn, 2001). Multiple regression and correlations were used to analyze the survey data. Multiple case study methods were employed to conduct, analyze, and describe the qualitative data.

The combination of mixed methods and research techniques was employed to strengthen the research design and add depth-and-breath to research findings. Using mixed methods research design is expected to minimize errors that may arise from a single technique and maximize the meaning of data interpretation (Patton, 2002). Additionally, the research topic of this study, teachers' beliefs, has been referred as being a messy construct in literature with added complications on the difficulties associated with its empirical investigations (Pajares, 1992). Therefore, the researcher became convinced that the mixed methods approach to this research design would add depth-andbreath to the surveys. All together the mixed methods approach to this study was employed to yield more robust interpretation of results based on multiples sources of qualitative and quantitative data in investigating this "messy construct.” 


\section{Participants}

\section{Method 1}

Participants of this study were selected from P-12 public schools among potential technology-using teachers. To determine the potential technology-using teachers, the following initial criteria were defined. Teachers would be selected among those (1) who have completed one of the longitudinal instructional technology professional development initiatives such as Trek 21, Phase 9, or Reinvent and (2) who worked at schools with adequate infrastructure and access to hardware and software to be able integrate technology.

Based on these initial criteria stated above, the Benedum Collaborative Professional Development Schools in the state of West Virginia were determined to be the schools to sample the teacher population for this study. Teachers were sampled only from the Benedum Collaborative Professional Development Schools (PDS) as the Benedum schools have committed to school reform, professional development, integrating instructional technologies, and have adequate technical infrastructure and equipment.

Once the Benedum Professional Development Schools were chosen to sample potential technology-using teachers, the researcher proceeded with investigating the names of teachers who (1) work at one of these schools and (2) have participated in either the Phase 9, Trek 21, or Reinvent project. Each project director or sometimes coordinator was contacted to help identify the names of teachers to include in the sample for this study. When some project directors/coordinators expressed their concerns in regards to privacy, the researcher pointed to the research agreement between West Virginia University and Professional Development Schools assuring that teacher names 
would only be used to sample teachers toward the completion of a dissertation research. As soon as the names of teachers were received, 162 teachers were randomly sampled in the 28 PDS schools. Participants were selected with varying years of teaching experience and subject-matter expertise regardless of the differences in gender, age, and ethnic background.

Instruments

Two instruments were employed to explore how teachers' beliefs relate to their instructional technology practices. The first survey, Inventory of Philosophies of Education, (Sadker \& Sadker, 2003) was used to measure teachers' educational beliefs: student-centered versus teacher-centered. The second survey, Perceptions of Computers and Technology (Hogarty, Lang, \& Kromrey, 2003) was used to measure teachers’ selfreported use of technology in the classroom.

Inventory of Philosophies of Education (Appendix A) is a 28-item self-reporting survey that measures a continuum of five educational philosophies: essentialism, perennialism, progressivism, social reconstructionism, and existentialism. Although this survey was intended for pre-service teachers to reflect their own beliefs on teaching and learning, this study extended the use of this survey to practicing teachers, as the statements in the survey were found to be the best fit for identifying teachers' tenets of their own educational philosophies. One of the authors of the survey reported that the survey had content validity for pre-service teachers.

Inventory of Philosophies of Education groups the first two philosophies (essentialism and perennialsim) as teacher-centered and the other three - progressivism, social reconstructionism, and existentialism - as student-centered tenets. Sadker and 
Sadker (2003) argued that teacher-centered philosophies “emphasize the importance of transferring knowledge, information, and skills from the older generation to the younger one” (p. 354). The survey statements measuring the teacher-centered beliefs cluster around themes such as teacher control, selected list of works for every student to master, competition and rewards for motivating students to learn. The survey statements that measure teachers' student-centered beliefs are concerned more with students' individual needs, contemporary relevance, preparing students for a changing future, and authentic learning as opposed to competition and reward.

The second survey, Perceptions of Computers and Technology (Appendix B), measures teachers' technology use in four broad domains. The four domains of the instrument fall into the categories of (1) integration, (2) teacher preparation, confidence, and comfort for computer use, (3) technical and general school support, and (4) attitudes toward computer use.

The Perceptions of Computers and Technology survey measures the first domain, integration, in three sections: (a) instructional strategies employed by the teacher when integrating technology, (b) software used by both teachers and students to school related learning activities, and (c) teachers' personal use of computers for various purposes. The second domain is designed to measure teacher (a) confidence and comfort using computers and (b) teacher preparation for computer use. The third domain measures support in the sections of (a) general school support and (b) technical support that is available to teachers at schools. The forth domain in the survey is concerned with teachers' general attitudes toward computer use for instructional purposes. The statements in the survey pertaining to teachers' attitudes are aimed at understanding 
teachers' views of technology and its impact on student learning as well as on teachers' instructional practices in the classroom.

The developers of the Perceptions of Computers and Technology survey (Hogarty, Lang, \& Kromrey, 2003) stated that they investigated the psychometric characteristics of the survey through the use of correlational and common factor analyses. They extracted factors based on the proportion of variance explained by each factor. The developers of the survey stated that Cronbach's alpha was then calculated for each of the score estimates to investigate the reliability of the scores. The Cronbach alphas for each section in the Perceptions of Computers and Technology survey are presented in Table 2.

Table 2

Calculated Cronbach Alpha Scores in Perceptions of Computers and Technology

\begin{tabular}{lc}
\hline Sections in the Survey & Cronbach Alpha \\
\hline Teacher Software Use & .79 \\
Factor 1 & .76 \\
Factor 2 & .55 \\
Interfactor correlation & \\
Student Software Use & .75 \\
Factor 1 & .76 \\
Factor 2 & .36 \\
Interfactor correlation & .89 \\
Integration of Computers in the Classroom & .82 \\
General School Support & .86 \\
Technical Support & .91 \\
Confidence and Comfort & .79 \\
Attitudes toward Computer Use & \\
\hline
\end{tabular}




\section{Procedure}

Upon receiving exemption from West Virginia University’s Board of Human Subjects to conduct this study, the researcher prepared a total of 162 envelops based on the sampling strategy described in Participants. Enclosed in the envelope was (1) a cover letter addressed to the teachers requesting their participation (Appendix E), (2) the Inventory of Philosophies of Education survey, and (3) the Perceptions of Computers and Technology survey. The researcher chose to hand deliver and collect the data in person to assure maximum number of returns in minimum amount of time necessary for data collection.

The researcher visited the 28 schools spread across 5 counties of West Virginia. When at a school, depending on the administrators' choice, the researcher either (1) met each teacher and handed in the surveys or (2) left the surveys with the administrator to be distributed to the selected teachers at a particular school. The survey collection date was negotiated with teachers giving them between five to seven days to fill out the survey items. The researcher then returned to the schools on the days that were negotiated between the researcher and teachers to complete the data collection process. In cases in which the teachers had been unable to complete the surveys due to lack of time by the time the researcher returned to the school to collect data, the researcher left a stamped self-addressed envelope with the teacher be sent to the researcher. Analysis

The Inventory of Philosophies of Education survey (Appendix A) is composed of 28 statements in a 5-point-Likert scale, with response options ranging from "Disagree Strongly” to “Agree Strongly.” Each view of philosophy (essentialism, perennialism, 
progressivism, social reconstructionism, and existentialism) is represented by five statements within items 1 through 25. The following statements represent how much teachers agree or disagree with one of the five philosophies: $1,6,11,16$, and 21 (essentialism), 2, 7, 12, 17, and 22 (perennialism), 3, 13, 18, and 23 (progressivism), 4, 9, 14, 19, and 24 (social constructivism), and the statements 5, 10, 15, 20, and 25 represent existentialism.

Possible scores range from 5 to 25 for each philosophy. Scores above 20 indicate a strong agreement, and scores below 10 indicate disagreement with the tenets of each philosophy. Although the three statements, 26 through 28, do not affect scoring, each statement represents by a psychological influence on education. These influences in the order they appear are: Behaviorism (Item 26), Constructivism (Item 27), and Informal Education (Item 28). For the purposes of this study only the responses to items 1 through 25 were taken into consideration for computational analysis, and the responses 26 through 28 were used when describing philosophical orientations.

Of the four domains measured in the eight sections of the Perceptions of Computers and Technology survey, two sections were left out in the computational statistical analysis. These sections were (1) teacher preparation and (2) teacher personal computer use from the integration domain. These sections were left out because they were determined neither as one of the predictors nor as one of the criteria in this study.

Specifically, to answer each of the research questions, multiple regression statistical analyses were conducted to assess the relationship between one dependent variable (DV) and several independent variables (IVs) (Tabachnick \& Fidel, 2001). Multiple regression analyses of this study included seven predictors (IVs) and three 
criteria (DVs). All three dependent variables (criteria) came from the integration domain of the Perceptions of Computers and Technology survey and were determined as (a) Teacher Software Use, (b) Student Software Use, and (c) Instructional Strategies teachers use when integrating technology. The independent variables (predictors) were determined as (a) Student-centered beliefs, (b) Teacher-centered beliefs, (c) Attitudes, (d) Confidence and Comfort, (e) Technical Support, (f) General School Support, and (g) Ratio of Computers-to-Students in the classroom.

The first two predictors (student-centered and teacher-centered beliefs) came from the Inventory of Philosophies of Education survey while the remaining five predictors were from the Perceptions of Computers and Technology survey. The ratio of computers-to-students was calculated dividing the average number of students per class by the number of computers available to that class. This information was taken from the first page of the Perceptions of Computers and Technology survey intended to elicit demographics information from teachers. Based on these three criteria and seven predictors, a total of six multiple regression analyses were computed. Table 3 represents the criteria, predictors, and the number of items used for computational analyses to answer each research question with multiple regression statistical analysis. 
Table 3

Predictors, Criteria, and Number of Items Used for Multiple Regression Analyses

Research Question 1: How do teachers' beliefs relate to the types technologies and instructional strategies they use with their students for instruction?

Regression 1

Predictors (IVs) Criterion 1 (DV)

(P1): Student-centered beliefs (15 items)

(P2): Teacher-centered beliefs (10 items)

Teacher software use (14 items)

(P3): Attitudes (20 items)

Regression 2

Predictors (IVs)

(P1): Student-centered beliefs (15 items)

(P2): Teacher-centered beliefs (10 items)

(P3): Attitudes (20 items)

Regression 3

Predictors (IVs)

(P1): Student-centered beliefs (15 items)

(P2): Teacher-centered beliefs (10 items)

(P3): Attitudes (20 items)

Research Question 2: How do factors other than teachers' beliefs relate to the types of technologies and instructional strategies teachers use with their students for instruction?

Regression 4

Predictors (IVs)

(P4): Confidence and comfort (9 items)

(P5): Technical support (5 items)

(P6): General school support (7 items)

(P7): Ratio of computers-to-students (1 item)

Regression 5

Predictors (IVs)

(P4): Confidence and comfort (9 items)

(P5): Technical support (5 items)

(P6): General school support (7 items)

(P7): Ratio of computers-to-students (1 item)

Regression 6

Predictors (IVs)

(P4): Confidence and comfort (9 items)

(P5): Technical support (5 items)

(P6): General school support (7 items)

(P7): Ratio of computers-to-students (1 item)
Criterion 2 (DV)

Student software use (14 items)

Criterion 3 (DV)

Instructional strategies (12 items)
Criterion 2 (DV)

Student software use (14 items)

\section{Criterion 1 (DV)
Teacher software use (14 items)}


The next section describes the qualitative method used for this study. The Inventory of Philosophies of Education survey was employed to determine the four participants selected for the case studies while the Perceptions of Computers and Technology survey results were used to describe the characteristics of the cases. The qualitative method described in the next section was employed to bring insight into teachers' self-reported responses to the surveys. In summary, the mixed methods were used to add depth-and-breath in describing the phenomenon of teachers' beliefs in relation to their instructional technology practices more holistically within the context of their teaching.

\section{Method 2}

\section{Participants}

In qualitative research, participants are carefully selected to represent the likelihood of the social phenomenon (Maykut \& Morehouse, 1994). Patton (2002) argued that the logic and power of sampling in a qualitative study lie in selecting information-rich cases for a study in-depth. The information-rich cases are purposefully selected as they have central importance to the purpose of the inquiry. Patton suggested the maximum variation strategy when the researcher wishes to seek out persons who represent the greatest differences in the phenomenon.

The maximum variation strategy was used to sample four teachers with diverse beliefs. Based on the beliefs survey, the researcher identified two teachers with studentcentered beliefs and two teachers with teacher-centered beliefs. The selection of extreme cases for the study was intended to yield a detailed description of the teachers' diverse 
beliefs, pointing out the similarities and differences in their instructional technology practices in relation to their beliefs.

\section{Research Design}

This study consisted of conducting multiple case studies involving hermeneutic qualitative inquiry. Patton (2002) argued that hermeneutic inquiry focuses on the following foundational question: What are the conditions under which a human act took place or a product was produced that make it possible to interpret its meaning? The literature review findings in Chapter 2 pointed to the importance of examining teachers' beliefs within their school context because teachers’ beliefs tend to be more experiencebased than theory-based (Orton, 1996); teachers’ beliefs are ill-structured (Nespor, 1987), they are context-bound (Tobin \& LaMaster, 1995), and beliefs are implicitly defined (Clark, 1988). Hermeneutic qualitative inquiry is a research perspective in that what something means depends on the cultural context in which it was created as well as the cultural context within which it is subsequently interpreted (Patton, 2002). Therefore, the researcher examined and interpreted teachers' beliefs in relation to their instructional technology practices in the context where teachers shape and reshape their beliefs and practices.

To determine how teachers' beliefs relate to their instructional technology practices, this study followed Yin’s (2003) multiple case study approach. Yin argued that multiple case study design should follow either direct replication or theoretical replication. Cases are carefully selected either for theoretical replication or literal replication. The cases carefully selected for theoretical replication produce contrasting results while cases selected for literal replication produce similar results for a predictable 
reason (theory). Yin stated that the investigator must choose cases carefully to serve a specific purpose within the overall scope of the inquiry.

Yin suggested developing a theoretical framework as a first step for designing multiple case studies. The theoretical framework of this study followed the assumption that Cuban (2002) made regarding teachers’ instructional technology integration practices. Cuban argued that teachers make contextually constrained choices in regards to their instructional technology practices. Teachers' beliefs and values drive many of their decisions they make in terms of what instructional tools they would use to best meet their goals for learning, and what content will be taught in which order.

Several studies reported in the literature review presented in Chapter 2 pointed to evidence of studying teachers' beliefs in the context where their actions take place (Borko \& Putnam, 1996; Calderhead, 1996; Putnam \& Borko, 2000; Tobin \& LaMaster, 1995; Tobin, Tippins, \& Gallard, 1995). Consequently, teachers’ beliefs in relation to their instructional technology practices were interpreted in the context of their school culture by taking organizational factors into account. The organizational and contextual factors were included both the tools as well the infrastructure at teachers' schools in addition to human support teachers may receive from colleagues and administration at their school site. Four cases (two with student-centered beliefs and two with teachercentered beliefs) were selected with maximum variation sampling technique to describe how teachers' beliefs and factor other than beliefs relate to their instructional technology practices taking the context of their practices into account. 


\section{Data Sources}

Open-ended interviews, reflections, a lesson plan, and school site-visit observations were employed as data sources to conduct the multiple case studies. Maykut and Morehouse (1994) characterized interviews as in-depth conversations, which move beyond surface talk to rich discussions of thoughts and feelings. This research study followed a semi-structured interview protocol. Careful attention, however, was given to pose open-ended questions that were supported with prompts during the conversations with teachers to invite them to reveal their beliefs in relation to their instructional technology practices. The same interview protocol (Appendix C) was used with all four interviewees with slight variations in the order of questioning and prompting.

The interview questions of this study centered on the following three types: (1) experience and behavior, (2) opinion and values (Patton, 2002). Further, the interview questions were based on three themes: (1) beliefs, (2) attitudes, and (3) barriers to technology integration in the context of their school culture. Table 4 displays the interview questions separated as question type (vertical) and question theme (horizontal). 
Table 4

Matrix of Interview Questions based on Themes and Types

\begin{tabular}{|c|c|c|c|}
\hline & Beliefs & Attitudes & Barriers \\
\hline 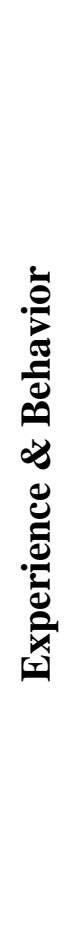 & $\begin{array}{l}\text { - Would you walk me } \\
\text { through this lesson plan } \\
\text { and describe to me how } \\
\text { you integrated } \\
\text { technology? } \\
\text { - Can you describe to me } \\
\text { the impact of } \\
\text { instructional technology } \\
\text { integration on your } \\
\text { teaching? } \\
\text { - Have you thought of } \\
\text { your philosophy } \\
\text { statement? How does } \\
\text { your philosophy } \\
\text { statement reflect your } \\
\text { instructional technology } \\
\text { use? }\end{array}$ & $\begin{array}{l}\text { How do you make } \\
\text { your decisions on } \\
\text { using or not using } \\
\text { technology for } \\
\text { instruction? What } \\
\text { factors influence } \\
\text { you most when } \\
\text { making those } \\
\text { decisions? }\end{array}$ & $\begin{array}{l}\text { - Can you give me an } \\
\text { example of what has } \\
\text { helped you and } \\
\text { hindered you from } \\
\text { integrating } \\
\text { instructional } \\
\text { technologies? }\end{array}$ \\
\hline 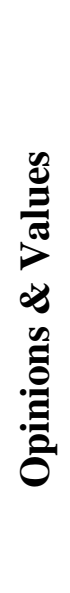 & $\begin{array}{l}\text { - Can you describe to me } \\
\text { the context in this } \\
\text { school for integrating } \\
\text { technology in terms of } \\
\text { human and technical } \\
\text { support? Any barriers or } \\
\text { incentives for } \\
\text { integrating technology? }\end{array}$ & $\begin{array}{l}\text { - Can you describe } \\
\text { to me your own } \\
\text { reasons why } \\
\text { technology needs } \\
\text { to be integrated } \\
\text { into curriculum? } \\
\text { - What is the role of } \\
\text { the teacher and } \\
\text { technology in the } \\
\text { integration } \\
\text { process? }\end{array}$ & $\begin{array}{l}\text { What factors } \\
\text { influence you most } \\
\text { when making } \\
\text { instructional } \\
\text { technology decisions? }\end{array}$ \\
\hline
\end{tabular}


In addition to the interviews, teacher reflections (Appendix D) were requested before the meeting teachers for the interview. The purpose of the reflection questions was twofold: (1) to prepare the participants for the interviews whose purpose was to query teachers' experiences focusing on their inner beliefs and attitudes about teaching and technology and (2) to receive mindful (reflective) feedback on teachers' beliefs and practices.

Site-visit and classroom observations were conducted at the schools to record the extent to which technical and human support was available at schools to the teachers. Classroom observations were requested to observe teachers' practices in their natural context. Notes from school site-visit and classroom observations were taken to describe the context of teachers’ instructional technology practices.

Finally, teachers who were selected for the case studies were asked to bring a lesson plan to the interview. In the letter to the case study participants (see Appendix D) teachers were requested to bring a lesson plan that demonstrated their typical instructional technology integration practices. The researcher used this document during the interview to prompt teachers and better place teachers thinking and actions in the context of their teaching.

\section{Procedure}

Following the IRB approval by the Associate Dean of the College of Human Resources and Education, four participants who were carefully selected based on the maximum variation sampling strategy. Case study participants were contacted to request their participation. Upon their agreement, the researcher informed the four participants about the nature of the study and requested the data sources as explained in Appendix D. 
Case study participants received a letter explaining the purpose of the study (see Appendix D) and the reflection questions requested from them before the interview (also Appendix D). The letter informed the participants about (1) the nature of the study and (2) the data sources (an interview, a lesson plan, and reflections) that were requested from teachers upon their consent to participate in the study. The letter stated that the interview would last approximately an hour. Also the letter pointed to the enclosed reflection questions and a lesson plan that would be used as prompts during the interview. Finally, the letter stated that interview would take place at the convenience of participant's time and place, and results would be shared with the participant upon her request.

All the interviews were tape recorded provided that the participants agreed with the researcher's request for audiotaping the conversations. The same interview protocol was used with each participant with some variations. The order of questions and prompts varied depending on the flow of the conversation. Site-visit and classroom observations were conducted on the same day of the interview meeting. Field notes were taken during and after the observations.

\section{Data Analysis}

Upon the completion of the interviews, all sources of case study data were brought together to analyze simultaneously for case descriptions. The initial analysis was done to reflect on data and try to discover the emerging themes coming from the data (Glesne \& Peshkin, 1992). During this phase, the researcher took notes, investigated the emerging themes, organized and coded the units of analysis. The initial data analysis helped the researcher to make sense of the emerging themes and prepare for the final analysis of triangulation, which involved all the data sources. 
All sources of qualitative data - interview transcript, classroom observations, lesson plan, and teacher reflections were - triangulated to compare the data both within subjects and between subjects. Within-subject comparison was conducted to compare the two teachers with identical beliefs (either student-centered or teacher-centered) and described in within-case analysis. Between-subject comparisons were conducted to find out similarities and differences among teachers with diverse beliefs and described in cross-case analysis.

Table 5 presents the summary of two methods employed for this study. 
Table 5

Summary of Research Methods

\begin{tabular}{|c|c|c|c|}
\hline \multicolumn{4}{|c|}{ Method 1} \\
\hline Research Questions & Participants & Instruments & Analyses \\
\hline $\begin{array}{l}\text { 1.How do teachers' } \\
\text { beliefs relate to the } \\
\text { types of technologies } \\
\text { and instructional } \\
\text { strategies teachers } \\
\text { use with their } \\
\text { students for } \\
\text { instruction? }\end{array}$ & \multirow[t]{2}{*}{$\begin{array}{l}162 \text { P-12 } \\
\text { technology- } \\
\text { using teachers } \\
\text { were sampled } \\
\text { from the } \\
\text { Benedum } \\
\text { Collaborative } \\
\text { PDS schools. }\end{array}$} & \multirow[t]{2}{*}{$\begin{array}{l}\text { 1. Inventory of } \\
\text { Philosophies } \\
\text { of Education } \\
\text { 2. Perceptions } \\
\text { of } \\
\text { Computers } \\
\text { and } \\
\text { Technology }\end{array}$} & $\begin{array}{l}\text { Three multiple } \\
\text { regression analyses: } \\
\text { three belief predictors } \\
\text { regressed on (a) } \\
\text { teacher software use, } \\
\text { (b) student software } \\
\text { use, and (c) } \\
\text { instructional strategies }\end{array}$ \\
\hline $\begin{array}{l}\text { 2. How do factors } \\
\text { other than beliefs } \\
\text { relate to the types of } \\
\text { technologies and } \\
\text { instructional } \\
\text { strategies teachers } \\
\text { use with their } \\
\text { students for } \\
\text { instruction? }\end{array}$ & & & $\begin{array}{l}\text { Three multiple } \\
\text { regression analyses: } \\
\text { the other four } \\
\text { predictors regressed } \\
\text { on (a) teacher software } \\
\text { use, (b) student } \\
\text { software use, and (c) } \\
\text { instructional } \\
\text { strategies. }\end{array}$ \\
\hline \multicolumn{4}{|c|}{ Method 2} \\
\hline $\begin{array}{l}\text { 1. How do teachers' } \\
\text { beliefs relate to the } \\
\text { types of technologies } \\
\text { and instructional } \\
\text { strategies teachers } \\
\text { use with their } \\
\text { students for } \\
\text { instruction? }\end{array}$ & \multirow{2}{*}{$\begin{array}{l}\text { - A total of } 4 \text { P-12 } \\
\text { technology-using } \\
\text { teachers were } \\
\text { sampled from the } \\
\text { Benedum } \\
\text { Collaborative } \\
\text { PDS schools } \\
\text { - Teachers were } \\
\text { sampled with } \\
\text { maximum } \\
\text { variation: } 2 \text { with } \\
\text { student-centered } \\
\text { beliefs and } 2 \\
\text { with teacher- } \\
\text { centered beliefs }\end{array}$} & \multirow{2}{*}{$\begin{array}{l}\text { - An interview } \\
\text { with each } \\
\text { participant } \\
\text { - A lesson plan } \\
\text { - Teacher } \\
\text { reflections } \\
\text { - School and } \\
\text { classroom } \\
\text { observations } \\
\text { - Survey } \\
\text { results }\end{array}$} & \multirow{2}{*}{$\begin{array}{l}\text { - Multiple case study } \\
\text { analyses were } \\
\text { conducted to } \\
\text { compare the beliefs } \\
\text { and practices of four } \\
\text { teachers (two with } \\
\text { student-centered } \\
\text { and two with } \\
\text { teacher-centered } \\
\text { beliefs). } \\
\text { - Data were analyzed } \\
\text { with constant } \\
\text { comparative method } \\
\text { - Within-case and } \\
\text { cross-case were } \\
\text { conducted }\end{array}$} \\
\hline $\begin{array}{l}\text { 2. How do factors } \\
\text { other than beliefs } \\
\text { relate to the types of } \\
\text { technologies and } \\
\text { instructional } \\
\text { strategies teachers } \\
\text { use with their } \\
\text { students for } \\
\text { instruction? }\end{array}$ & & & \\
\hline
\end{tabular}




\section{CHAPTER 4}

Results

This chapter will report the findings of the two main research questions. The first research question sought to answer how teachers' beliefs relate to their instructional technology practices, and the second research question sought to answer how factors other than teachers' beliefs relate to their instructional technology practices. Each research questions is further divided into three sections based on the three dependent variables: technologies teachers use for instruction, technologies teachers have students use for instruction, and instructional strategies teachers use when integrating technology. The research questions that this study sought to answer are:

1. How do teachers' beliefs relate to the types of technologies and instructional strategies teachers use for instruction?

a. How do teachers' beliefs relate to the types of technologies teachers use for instruction?

b. How do teachers' beliefs relate to the types of technologies teachers have their students use for instruction?

c. How do teachers' beliefs relate to the types of instructional strategies teachers use for instruction when integrating technology?

2. How do factors other than teachers' beliefs relate to the types of technologies teachers use for instruction?

a. How do factors other than teachers' beliefs relate to the types of technologies teachers use for instruction? 
b. How do factors other than teachers' beliefs relate to the types of technologies teachers have their students use for instruction?

c. How do factors other than teachers' beliefs relate to the types of instructional strategies teachers use for instruction when integrating technology?

Both quantitative and qualitative research methods were employed to answer how teachers' beliefs and how factors other than teachers beliefs relate to teachers' instructional technology practices. The quantitative statistical research findings will be reported first followed by the findings of the case study research.

\section{Method 1: Results}

This section will begin with an overview of the research design in terms of the demographics of the participants, response rate, scoring instruments, and analysis of research questions. Following this overview, findings of each research question will be discussed. Finally, method 1 results will be concluded with reporting the intercorrelations of the 10 continuous variables used in this research.

\section{Overview of Research Design}

\section{Demographics}

Of the 113 teachers who responded to both of the surveys, nine of them were male and 94 were female. The range for number of years of teaching experience was between two and 39 with a 22.13 mean. Of the 113 participant teachers, 16 (14\%) had two to 10 years of teaching experience, 25 (22\%) had 11 to 20 years, 52 (46\%) had 21 to 30 years, and 20 (18\%) of them had 31 to 39 years of teaching experience. Of these 113 participants, 60\% were teaching grades P-6, and 40\% were teaching grades 7-12. 
The number of years that participant teachers were experienced using computers in the classroom for instruction ranged from 2 to 20 years, with a mean of 9.48 years. Of the 113, two teachers did not report their years of computer experience. A total of 23 (21\%) participants had been using computers for instruction for two to five years, 52 (47\%) for six to ten years, 28 (25\%) for 11 to 15 years, and eight (7\%) of them for 17 to 20 years. Response Rate

A total of 162 teachers were randomly sampled from the 28 Benedum Professional Development Schools among the technology-using teachers, based on the criteria described in Method 1, Sampling. Six teachers were sampled from each of the 28 Professional Development Schools. All six (1) attended one of the three professional development projects: Phase 9, Trek 21, and Reinvent and (2) worked at one of the 28 Professional Development Schools. Although the research design called for sampling an equal number of teachers (6 from each school) with an equal number of participants from each project (two from each project), in reality these pre-determined numbers were skewed. Some teachers at certain schools had only attended two of the three projects, others had left the school, and a few schools did not have a total of six teachers who attended one of these instructional technology projects.

Of the162, targeted for participation, 27 teachers could not be located at the schools. Thus, a total of 135 teachers received the survey. Of the 135 , a total of 116 teachers responded to the study. Three surveys were not included in the study as several sections and occasionally whole pages were left blank. With these surveys removed, the total number included 113 usable returns. 
The return rate of the surveys was approximately 85\%. This surprisingly large response rate could be explained with the following assumptions. All teachers who were sampled worked at the 28 Professional Development Schools. They were familiar with conducting research and thus they were helpful. In addition, most surveys were delivered to individual teachers in person and picked up from the same teachers at schools by the researcher. In a few cases, when an administrator at a school wished to distribute the surveys to the teachers, the surveys were left with the administrator and were collected by the researcher in person from this contact person. Thus, it may be assumed that delivering the surveys in person and picking them up in person by the researcher may have enhanced the number of returned surveys.

\section{Scoring Instruments}

The Inventory of Philosophies of Education survey was scored as explained in Method 1, Analysis section. Briefly, total scores for teacher-centered and studentcentered beliefs were calculated. Possible range of scores in the survey was 10 to 50 (10 items) for teachers with teacher-centered beliefs, and 15 to 75 (15 items) for teachers with student-centered beliefs.

The following conventions were observed when entering data from the Perceptions of Computers and Technology survey (Appendix B). If participants left a single statement blank in only one section, the missing statement was replaced with the mode of that section. If, however, participants left more than one statement blank in a section, that entire section was not included in the analysis. As a result, those sections containing more than one blank statement were not entered. The number of participants included for analyses therefore varied from 103 to 113, excluding the section for 
Technical Support. For Technical Support, 91 out of 113 teachers reported to have technical support available at their schools. The remaining 22 were not included in the analysis for Technical Support as these teachers reported not having technical support available at their schools.

In addition, the following procedures were observed when entering data from the Attitudes and Technical Support sections of the Perceptions of Computers and Technology survey. When entering data from the Attitudes section, eight items (Statement 3, 4, 6, 7, 8, 9, 15, and 17) were reversed as these items were determined to be negative attitudes, but were corresponding to highest values in the survey. For example, if participants gave the value of "5" (strongly agree) for the statement "I feel pressure from others to integrate the computer more into my classroom” (Item 3), this score of 5 was reversed to 1 because strong agreement to feeling pressure to integrate technology was not an indicator of positive attitudes toward computers and technology. Similarly, the following statement, "I have to contact our specialist/coordinator several times before I get assistance” from the Technical Support section was reversed.

The number of participants, means, standard deviations, and ranges of scores for the variables are presented in Table 6. 
Table 6

Descriptive Statistics for the Interval Variables

\begin{tabular}{lcccc}
\hline Variables & $\mathrm{N}$ & $\bar{X}$ & $\mathrm{SD}$ & Range \\
\hline Student-Centered Beliefs & 113 & 51.66 & 6.34 & $38-67$ \\
Teacher-Centered Beliefs & 113 & 38.16 & 3.85 & $27-50$ \\
Attitudes & 113 & 78.65 & 7.67 & $58-93$ \\
Confidence and Comfort & 113 & 37.00 & 6.58 & $10-45$ \\
Technical Support & 91 & 20.47 & 3.20 & $12-25$ \\
General School Support & 113 & 26.80 & 4.61 & $9-35$ \\
Ratio of Computer-to-Students & 112 & 5.85 & 5.54 & $0-30$ \\
Teacher Software Use & 105 & 33.72 & 8.37 & $18-62$ \\
Student Software Use & 109 & 29.96 & 8.60 & $14-60$ \\
Instructional Strategies & 113 & 33.94 & 9.38 & $12-55$ \\
\end{tabular}




\section{Analyses of Research Questions}

Of the 10 variables used in the study, three were selected as criteria (dependent variables), and seven identified as predictors (independent variables). The criteria variables were Teacher Software Use, Student Software Use, and Instructional Strategies. The seven predictors were Student-Centered Beliefs (P1), Teacher-Centered Beliefs (P2), Attitudes (P3), Confidence and Comfort (P4), Technical Support (P5), General School Support (P6), and Ratio of Computers-to-Students (P7). These seven predictors were further divided into two groups to answer each research question. The first three (P1, P2, and P3) were used to answer Research Question 1, and the other four (P4, P5, P6, and P7) were used to answer Research Question 2.

Two separate tests, multiple regression and correlational analyses, were performed in answering the research questions. A total of six multiple regression analyses (three for each research question) were conducted to determine the extent to which a predictor (e.g., Student-Centered Beliefs) contributed to predicting the overall frequency of a criterion variable (e.g., Student Software Use). These six multiple regression analyses were performed as described in Chapter 3, Table 3.

Since these six multiple regression analyses were performed based on the total score of each section, these analyses revealed the overall frequency for a criterion variable (e.g., Teacher Software Use) without describing what types of technologies or different types of instructional strategies teachers used when integrating that technology. Thus, a separate correlational analysis was conducted to further investigate the relationship between each item on the criterion variable with the total score of a predictor variable determined for each research question. As there were three criterion variables 
(14 items on Teacher Software Use, 14 items on Student Software Use, and 12 items on Instructional Strategies) and seven predictors (P1, P2, P3, P4, P5, P6, and P7), a total of 21 sets of correlational analyses (nine for Research Question 1 and twelve for Research Question 2) were conducted as shown in Table 7. 


\section{Table 7}

Tests, Predictors, Criteria, and Analyses for Each Research Question

Research Question 1a:

How do teachers' beliefs relate to the types of technologies teachers use for instruction?

\begin{tabular}{llll}
\hline Number of Tests & Predictors & Criterion & Analyses \\
\hline $\begin{array}{lll}\text { 1 Multiple } \\
\text { Regression test }\end{array}$ & $\begin{array}{l}\text { Student-Centered Beliefs (P1) } \\
\text { Teacher-Centered Beliefs (P2) } \\
\text { Attitudes (P3) }\end{array}$ & $\begin{array}{l}\text { Teacher } \\
\text { Software Use } \\
\text { (14 items) }\end{array}$ & Regression 1 \\
14 Correlations & Student-Centered Beliefs (P1) & Correlation Set 1 \\
14 Correlations & Teacher-Centered Beliefs (P2) & Correlation Set 2 \\
14 Correlations & Attitudes (P3) & Correlation Set 3 \\
\hline
\end{tabular}

Research Question 1b:

How do teachers' beliefs relate to the types of technologies teachers have their students use for instruction?

\begin{tabular}{llll}
\hline Number of Tests & Predictors & Criterion & Analyses \\
\hline $\begin{array}{lll}\text { 1 Multiple } \\
\text { Regression test }\end{array}$ & $\begin{array}{l}\text { Student-Centered Beliefs (P1) } \\
\text { Teacher-Centered Beliefs (P2) } \\
\text { Attitudes (P3) }\end{array}$ & $\begin{array}{l}\text { Student } \\
\text { Software Use } \\
\text { (14 items) }\end{array}$ & Regression 2 \\
14 Correlations & Student-Centered Beliefs (P1) & Correlation Set 4 \\
14 Correlations & Teacher-Centered Beliefs (P2) & Correlation Set 5 \\
14 Correlations & Attitudes (P3) & Correlation Set 6 \\
\hline
\end{tabular}




\section{Table 7 (continued)}

Research Question 1c:

How do teachers' beliefs relate to the types of instructional strategies teachers use for instruction when integrating technology?

\begin{tabular}{llll}
\hline Number of Tests & Predictors & Criterion & Analyses \\
\hline $\begin{array}{lll}\text { 1 Multiple } \\
\text { Regression test }\end{array}$ & $\begin{array}{l}\text { Student-Centered Beliefs (P1) } \\
\text { Teacher-Centered Beliefs (P2) } \\
\text { Attitudes (P3) }\end{array}$ & $\begin{array}{l}\text { Instructional } \\
\text { Strategies } \\
\text { (12 items) }\end{array}$ & Regression 3 \\
12 Correlations & Student-Centered Beliefs (P1) & Correlation Set 7 \\
12 Correlations & Teacher-Centered Beliefs (P2) & Correlation Set 8 \\
12 Correlations & Attitudes (P3) & Correlation Set 9 \\
\hline
\end{tabular}

Research Question 2a:

How do factors other than teachers' beliefs relate to the types of technologies teachers use for instruction?

\begin{tabular}{llll}
\hline Number of Tests & Predictors & Criterion & Analyses \\
\hline $\begin{array}{lll}\text { 1 Multiple } \\
\text { Regression test }\end{array}$ & $\begin{array}{l}\text { Confidence and Comfort (P4) } \\
\text { Technical Support (P5) } \\
\text { General Support (P6) } \\
\text { Ratio of Computers-to-Students (P7) }\end{array}$ & $\begin{array}{l}\text { Teacher } \\
\text { Software }\end{array}$ & Regression 4 \\
(14 items) & \\
14 Correlations & Confidence and Comfort (P4) & Correlation Set 10 \\
14 Correlations & Technical Support (P5) & Correlation Set 11 \\
14 Correlations & Ratio of Computers-to-Students (P7) & Correlation Set 12 \\
\hline
\end{tabular}




\section{Table 7 (Continued)}

Research Question 2b:

How do factors other than teachers' beliefs relate to the types of technologies teachers have their students use for instruction?

\begin{tabular}{llll}
\hline Number of Tests & Predictors & Criterion & Analyses \\
\hline $\begin{array}{lll}\text { 1 Multiple } \\
\text { Regression test }\end{array}$ & $\begin{array}{l}\text { Confidence and Comfort (P4) } \\
\text { Technical Support (P5) } \\
\text { General Support (P6) } \\
\text { Ratio of Computers-to-Students (P7) }\end{array}$ & $\begin{array}{l}\text { Student } \\
\text { Software } \\
\text { Use } \\
\text { (14 items) }\end{array}$ & Regression 5 \\
14 Correlations & Confidence and Comfort (P4) & Correlation Set 14 \\
14 Correlations & Technical Support (P5) & Correlation Set 15 \\
14 Correlations & General Support (P6) & Correlation Set 16 \\
14 Correlations & Ratio of Computers-to-Students (P7) & Correlation Set 17 \\
\hline
\end{tabular}

Research Question 2c:

How do factors other than teachers' beliefs relate to the types of instructional strategies teachers use for instruction when integrating technology?

\begin{tabular}{llll}
\hline Number of Tests & Predictors & Criterion & Analyses \\
\hline $\begin{array}{l}\text { 1 Multiple } \\
\text { Regression test }\end{array}$ & $\begin{array}{l}\text { Confidence and Comfort (P4) } \\
\text { Technical Support (P5) } \\
\text { General Support (P6) } \\
\text { Ratio of Computers-to-Students (P7) }\end{array}$ & $\begin{array}{l}\text { Instructional } \\
\text { Strategies } \\
\text { (12 items) }\end{array}$ & Regression 6 \\
12 Correlations & Confidence and Comfort (P4) & Correlation Set 18 \\
12 Correlations & Technical Support (P5) & Correlation Set 19 \\
12 Correlations & General Support (P6) & Correlation Set 20 \\
12 Correlations & Ratio of Computers-to-Students (P7) & Correlation Set 21 \\
\hline
\end{tabular}




\section{Research Question 1}

Three multiple regression analyses and nine sets of correlational analyses were conducted to investigate how teachers' beliefs relate to the types of technologies and instructional strategies they used with their students for instruction. Research Question 1 is divided into three logical parts (Research Question 1a, 1b, and 1c) in order to describe what types of (a) technologies teachers used for instruction, (b) technologies teachers had their students used for instruction, and (c) the instructional strategies teachers used when integrating technology. The analytical strategies for answering each section of Research Question 1a, 1b, and 1c involved one multiple regression analyses and three sets of correlations. The number of tests, predictors, criterion, and types of analyses are described in Table 7, and the results of these analyses are presented below. Research Question 1a: How do teachers' beliefs relate to the types of technologies teachers use for instruction?

A multiple regression analysis was conducted by regressing Student-Centered Beliefs (P1), Teacher-Centered Beliefs (P2), and Attitudes (P3) on the criterion variable, Teacher Software Use. This analysis sought to determine the extent to which three predictors contributed to overall Teacher Software Use. The score ranges for these three predictor variables were 15 to 75 for P1 (15 items), 10 to 50 for P2 (10 items), 20 to 100 for P3 (20 items). The criterion variable, Teacher Software Use, was a 14 item section, and the scores for Teacher Software Use ranged from 14 to 70 in the survey.

In the simultaneous multiple regression analysis the predictors yielded nonsignificant $t$ test values for Student-Centered Beliefs (P1) and Teacher-Centered Beliefs (P2). These values were $t=.60, p>.05$ for P1 and $t=-.17, p>.05$ for P2. The $t$ value 
for Attitudes measure was (P3) $t=4.96, p<.001$, significant. The model accounted for $21 \%$ of the variance in Teacher Software Use, $\mathrm{R}^{2}=.21$, and the Attitudes (P3) were found to be the only significant predictor in the model.

When the belief predictors (P1, P2, and P3) were examined in terms of their relationship to each item of Teacher Software Use, the following items were found to be significantly correlated. Student-Centered Beliefs correlated only with spreadsheets $(r=$ $.20, p<.05)$. Teacher-Centered Beliefs correlated with word processor $(r=.21, p<.05)$ and desktop publishing $(r=.20, p<.05)$. Attitudes significantly correlated with word processor $(r=.31, p<.01)$, spreadsheets $(r=.32, p<.01)$, databases $(r=.33, p<.01)$, desktop publishing $(r=.23, p<.05)$, presentation software $(r=.43, p<.01)$, web publishing programs $(r=.40, \mathrm{p}<.01)$, graphic programs $(r=.25, p<.05)$, integrated learning systems $(r=.20, \mathrm{p}<.05)$, web browsers $(r=.38, p<.01)$, and programming/authoring tools $(r=.20, p<.05)$. The relationships of the belief predictors (Student-Centered, Teacher-Centered, and Attitudes) with a specific type of software teachers chose to use for instructional purposes are reported as Pearson $r$ values in Table 8.

These results indicated that teachers' attitudes variable is the most important factor for teachers' use of a variety of software for instructional purposes. Teacher Software Use was related to teachers’ attitudes, and their student or teacher-centered beliefs played a less significant role in their choices of instructional software for teaching purposes. 
Table 8

Means and Standard Deviations of Teacher Software Use Items and their Relationship to Student-Centered Beliefs (P1), Teacher-Centered Beliefs (P2), and Attitudes (P3) for Research Question $1 a$

Correlations

\begin{tabular}{|c|c|c|c|c|c|}
\hline Teacher Software Use Item & $\bar{X}$ & SD & P1 & P2 & P3 \\
\hline Word Processor & 4.62 & .712 & .09 & $.21^{*}$ & $.31 * *$ \\
\hline Spreadsheets & 2.38 & 1.24 & $.20 *$ & .13 & $.32 * *$ \\
\hline Databases & 2.07 & 1.34 & .08 & .14 & $.33 * *$ \\
\hline Desktop Publishing & 2.68 & 1.20 & .13 & $.20 *$ & $.23 *$ \\
\hline Presentation Software & 2.57 & 1.07 & -.09 & .19 & $.43^{* *}$ \\
\hline Web Publishing Programs & 1.89 & 1.20 & -.03 & .04 & $.40 * *$ \\
\hline Graphics Programs & 2.01 & 1.14 & .12 & .01 & $.25 *$ \\
\hline Drill and Practice & 1.88 & 1.30 & -.06 &.-07 & .00 \\
\hline Games & 2.26 & 1.45 & .06 & -.05 & .11 \\
\hline Simulations & 1.54 & .95 & .07 & .05 & .11 \\
\hline Tutorials & 1.95 & 1.05 & -.02 & .05 & .15 \\
\hline Integrated Learning Systems & 1.94 & 1.31 & -.08 & -.19 & $.20^{*}$ \\
\hline Web Browsers & 4.55 & .90 & .01 & .13 & $.38 * *$ \\
\hline Programming/Authoring Tools & 1.39 & .92 & .09 & -07 & $.20^{*}$ \\
\hline
\end{tabular}

* Correlation is significant at the 0.05 level (2-tailed).

** Correlation is significant at the 0.01 level (2-tailed). 
Research Question 1b: How do teachers' beliefs relate to the types of technologies teachers have their students use for instruction?

A multiple regression analysis was conducted by regressing Student-Centered Beliefs (P1), Teacher-Centered Beliefs (P2), and Attitudes (P3) on the criterion variable, Student Software Use. This analysis sought to determine the extent to which these three predictors contributed to Student Software Use. The scores for Student Software Use ranged from 14 to 70 in the survey.

In the simultaneous multiple regression analysis the predictors yielded nonsignificant $t$ test values for Student-Centered Beliefs (P1) and Teacher-Centered Beliefs (P2). These values were $t=1.52, p>.05$ for $\mathrm{P} 1$ and $t=1.43, p>.05$ for P2. The $t$ value for Attitudes was (P3) $t=2.96, p<.01$, significant. The model accounted for $14 \%$ of the variance in Student Software Use, $\mathrm{R}^{2}=.14$, and the Attitudes (P3) was found to be the only significant predictor in the model.

When the belief predictors (P1, P2, and P3) were examined in terms of their relationship to each item of Student Software Use, the following items were found significantly correlated with these three predictors. Student-Centered Beliefs measure was correlated only with spreadsheets $(r=.22, p<.05)$. Teacher-Centered Beliefs measure was correlated with the following items on Student Software Use: word processor $(r=.19, p<.05)$, databases $(r=.24, p<.05)$, desktop publishing $(r=.23, p<$ $.05)$, presentation software $(r=.24, p<.05)$, and web publishing programs $(r=.20, p<$ .05). Teachers' Attitudes was found to be significantly correlated with the following items on Student Software Use: word processor $(r=.33, p<.01)$, spreadsheets $(r=.28$, $p<.01)$, desktop publishing $(r=.25, p<.01)$, presentation software $(r=.29, p<.01)$, 
web publishing programs $(r=.29, p<.01)$, graphic programs $(r=.24, p<.05)$, and web browsers $(r=.28, p<.01)$. The relationships of the belief predictors (Student-Centered, Teacher-Centered, and Attitudes) with a specific type of software teachers had their students use for instructional purposes are reported as Pearson $r$ values in Table 9.

Similar to Teacher Software Use results, teachers’ attitudes variable was the most important factor for teachers having their students use a variety of software for instruction. Teachers with positive attitudes toward technology had students use word processor, spreadsheets, desktop publishing, presentation software, web publishing programs, graphic programs, and web browsers. The Teacher-centered beliefs measure was found to be a predictor for teachers having students use word processor, databases, desktop publishing, presentation software, and web publishing programs. The results indicated that teachers' attitudes toward computers and their teacher-centered beliefs to some extent are the predictors for teachers having their students use a variety of software. 
Table 9

Means and Standard Deviations of Student Software Use Items and their Relationship to Student-Centered Beliefs (P1), Teacher-Centered Beliefs (P2), and Attitudes (P3) for Research Question $1 b$

Correlations

\begin{tabular}{|c|c|c|c|c|c|}
\hline Student Software Use Item & $\bar{X}$ & $\mathrm{SD}$ & $\mathrm{P} 1$ & $\mathrm{P} 2$ & P3 \\
\hline Word Processor & 2.88 & 1.29 & .15 & $.19 *$ & $.33 * *$ \\
\hline Spreadsheets & 1.52 & .86 & $.22 *$ & .18 & $.28 * *$ \\
\hline Databases & 1.45 & .97 & .11 & $.24^{*}$ & .17 \\
\hline Desktop Publishing & 1.83 & 1.02 & .16 & $.23 *$ & $.25 * *$ \\
\hline Presentation Software & 2.08 & 1.10 & .06 & $.24^{*}$ & $.29 * *$ \\
\hline Web Publishing Programs & 1.29 & .67 & .14 & $.20^{*}$ & $.29 * *$ \\
\hline Graphics Programs & 1.76 & .94 & .15 & .15 & $.24^{*}$ \\
\hline Drill and Practice & 3.06 & 1.30 & -.01 & .02 & .01 \\
\hline Games & 2.73 & 1.44 & .05 & -.06 & -.01 \\
\hline Simulations & 1.94 & 1.27 & .14 & .14 & .01 \\
\hline Tutorials & 2.32 & 1.29 & .14 & .13 & .18 \\
\hline Integrated Learning Systems & 2.61 & 1.59 & .02 & -.08 & .01 \\
\hline Web Browsers & 3.17 & 1.45 & .06 & .15 & $.28 * *$ \\
\hline Programming/Authoring Tools & 1.30 & .79 & .14 & .13 & .18 \\
\hline
\end{tabular}

* Correlation is significant at the 0.05 level (2-tailed).

** Correlation is significant at the 0.01 level (2-tailed). 
Research Question 1c: How do teachers' beliefs relate to the types of instructional strategies teachers use for instruction when integrating technology?

A multiple regression analysis was conducted by regressing Student-Centered Beliefs (P1), Teacher-Centered Beliefs (P2), and Attitudes (P3) on the criterion variable, Instructional Strategies. This analysis sought to determine the extent to which three predictors contributed to the types of instructional strategies teachers used when integrating technology. The scores for Instructional Strategies ranged from12 to 60 in the survey.

In the simultaneous multiple regression analysis the predictors yielded nonsignificant $t$ test values for Student-Centered Beliefs (P1) and Teacher-Centered Beliefs (P2). These values were $t=.90, p>.05$ for P1 and $t=-.15, p>.05$ for P2. The $t$ value for Attitudes was (P3) $t=3.61, p<.01$, significant. The model accounted for $12 \%$ of the variance in Instructional Strategies, $\mathrm{R}^{2}=.119$, and the teachers' Attitudes (P3) measure was found to be the only significant predictor in the model.

When the belief predictors (P1, P2, and P3) were examined in terms of their relationships to each item of the Instructional Strategy items, the following items were found significantly correlated with the three predictors in the model. Student-Centered Beliefs was correlated with "as a problem solving/decision making tool” $(r=.20, p<$ .05). Teachers' Attitudes was found significantly correlated with the following items on Instructional Strategies: "small group instruction" $(r=.24, p<.05)$, "individual instruction" ( $r=.22, p<.05)$, "cooperative groups" $(r=.20, p<.05)$, "to promote student-centered learning" ( $r=.27, p<.01)$, "as a research tool” $(r=.23, p<.05)$ "as a problem solving/decision making tool" ( $r=.34, p<.01)$, "as a classroom presentation 
tool” ( $r=.44, p<.01)$, and "as a communication tool” $(r=.20, p<.05)$. Teachers' beliefs in relation to a specific type of instructional strategy teachers used when integrating technology are reported as Pearson $r$ values in Table 10.

These correlation results indicated that teachers’ student-centered beliefs are related to their choice of using technology as a problem solving/decision tool. Teachers' positive attitudes were not related to their use of technology as a reward, to tutor, or for independent learning. However, the more positive attitudes teachers had, the more likely that they would use computers for small group instruction, individual instruction, cooperative groups, student-centered learning, conducting research, and using computers as a tool for problem solving, presentation, and communication. 
Table 10

Means and Standard Deviations of Student Software Use Items and their Relationship to Student-Centered Beliefs (P1), Teacher-Centered Beliefs (P2), and Attitudes (P3) for Research Question 1c

\begin{tabular}{|c|c|c|c|c|c|}
\hline \multirow[b]{2}{*}{ Instructional Strategy Items } & \multirow[b]{2}{*}{$\bar{X}$} & \multirow[b]{2}{*}{ SD } & \multicolumn{3}{|c|}{ Correlations } \\
\hline & & & P1 & $\mathrm{P} 2$ & P3 \\
\hline Small group instruction & 2.75 & 1.14 & .04 & -.00 & $.24 *$ \\
\hline Individual instruction & 3.32 & 1.24 & .08 & -.05 & $.22 *$ \\
\hline Cooperative groups & 2.53 & 1.07 & .18 & .04 & $.20 *$ \\
\hline As a reward & 2.29 & 1.32 & .14 & .15 & -.03 \\
\hline Independent Learning & 3.34 & 1.35 & -.04 & -.07 & .18 \\
\hline To tutor & 2.82 & 1.31 & -.02 & .06 & .11 \\
\hline $\begin{array}{l}\text { To promote student centered } \\
\text { learning }\end{array}$ & 3.09 & 1.29 & -.02 & -.01 & $.27 * *$ \\
\hline As a research tool for students & 2.93 & 1.31 & .07 & .10 & $.23 *$ \\
\hline $\begin{array}{l}\text { As a problem solving/decision } \\
\text { making tool }\end{array}$ & 2.17 & 1.21 & $.20 *$ & .14 & $.34 * *$ \\
\hline As a productivity tool & 2.78 & 1.22 & .04 & .05 & .12 \\
\hline $\begin{array}{l}\text { As a classroom presentation } \\
\text { tool }\end{array}$ & 2.73 & 1.14 & .01 & .08 & $.44^{* *}$ \\
\hline As a communication tool & 3.19 & 1.64 & .09 & .05 & $.20 *$ \\
\hline
\end{tabular}

* Correlation is significant at the 0.05 level (2-tailed).

** Correlation is significant at the 0.01 level (2-tailed). 


\section{Research Question 2}

Three multiple regression analyses and 12 sets of correlational analyses were conducted to investigate how factors other than teachers' beliefs relate to the types of technologies and instructional strategies teachers use with their students for instruction. Research Question 2 is further divided into three logical parts (Research Question 2a, 2b, and 2c) in order to describe the types of (a) technologies teachers use for instruction, (b) technologies teachers have their students use for instruction, and (c) the instructional strategies teachers use when integrating technology. The analytical strategies for answering each section of Research Question 2 a, 2b, and 2c include one multiple regression analyses and four sets of correlations. The number of tests, predictors, criterion, and types of analyses are described in Table 7, and the results of these analyses are presented below.

Research Question 2a: How do factors other than teachers' beliefs relate to the types of technologies teachers use for instruction?

A multiple regression analysis was conducted by regressing four predictors Confidence and Comfort (P4), Technical Support (P5), General School Support (P6), and Ratio of Computers-to-Students (P7) - on the criterion variable, Teacher Software Use. This analysis sought to determine the extent to which four predictors contributed to the overall score of Teacher Software Use. The score ranges for the four predictor variables were for 9 to 45 for P4 (9 items), 5 to 25 for P5 (5 items), 7 to 35 for P6 (7 items), and 0 to 30 for P7 (1 item). 
In the simultaneous multiple regression analysis the predictors yielded nonsignificant $t$ test values for Technical Support (P5), General School Support (P6), and Ratio of Computers-to-Students (P7). These values were $t=.14, p>.05$ for P5, $t=.33$, $p>.05$ for P6, and $t=1.06, p>.05$ for P7. The $t$ value for Confidence and Comfort (P4) was $t=2.25, p<.05$, significant. The model accounted for $12 \%$ of the variance in Teacher Software Use, $\mathrm{R}^{2}=.12$, and Confidence and Comfort (P4) measure was found to be the only significant predictor in the model.

Results for Correlation Set 7 through 9 of Teacher Software Use items are reported if they are significantly correlated with one of the four criteria: Confidence and Comfort (P4), Technical Support (P5), General School Support (P6), and Ratio of Computers-to-Students (P7). Teachers' Confidence and Comfort measure was correlated with presentation software $(r=.47, p<.01)$, web publishing programs $(r=.35, p<.01)$, graphic programs $(r=.24, p<.05)$, integrated learning systems $(r=.20, p<.05)$, and web browsers $(r=.23, p<.05)$. Technical Support was found to be correlated only with web publishing $(r=.22, p<.05)$. General School Support was correlated with the following items: word processor $(r=.21, p<.05)$, web publishing programs $(r=.25, p<$ $.05)$, and integrated learning systems ( $r=.22, p<.05)$. Finally, Ratio of Computers-toStudents measure was found to be correlated with spreadsheets $(r=.21, p<.05)$, databases $(r=.22, p<.05)$, and web publishing programs $(r=.24, p<.05)$. The relationships between individual items of the Teacher Software Use and other four factors are reported as Pearson $r$ values in Table 11.

These results indicated that among the four variables, the Confidence and Comfort measure was the most important factor for teachers' selection of a variety of 
computer applications for instruction. Specifically, teachers’ confidence and comfort played a significant role in their use of presentation software, web publishing software, graphic programs, integrated learning systems, and web browsers. General School Support and Ratio of Computers-to-Students were the second most important factors in teachers' selection of a variety of instructional technologies. Technical support was found not to be a significant factor for teachers' selections of technologies for instruction except for web publishing programs. These results indicated that teacher confidence and comfort was the primary factor in the order of importance of teachers' selection and frequent use of a variety of instructional software. Following confidence and comfort, general school support and ratio of computers-to-students in the classroom were the main predictors of teachers' selection of instructional software. 
Table 11

Means and Standard Deviations of Teacher Software Use Items and their Relationship to Confidence and Comfort (P4), Technical Support (P5), General School Support (P6), and Ratio of Computers-to-Students (P7) for Research Question $2 a$

\begin{tabular}{|c|c|c|c|c|c|c|}
\hline \multirow[b]{3}{*}{ Teacher Software Use Item } & \multirow[b]{3}{*}{$\bar{X}$} & \multirow[b]{3}{*}{$\mathrm{SD}$} & \multicolumn{4}{|c|}{ Correlations } \\
\hline & & & $\mathrm{P} 4$ & P5 & P6 & P7 \\
\hline & & & & & & \\
\hline Word Processor & 4.62 & .712 & .13 & .12 & $.21^{*}$ & .14 \\
\hline Spreadsheets & 2.38 & 1.24 & .17 & -.09 & -.10 & $.21^{*}$ \\
\hline Databases & 2.07 & 1.34 & .15 & .03 & -.05 & $.22 *$ \\
\hline Desktop Publishing & 2.68 & 1.20 & .14 & .10 & .09 & .07 \\
\hline Presentation Software & 2.57 & 1.07 & $.47 * *$ & .19 & .05 & .19 \\
\hline Web Publishing Programs & 1.89 & 1.20 & $.35 * *$ & $.22 *$ & $.25 *$ & $.24^{*}$ \\
\hline Graphics Programs & 2.01 & 1.14 & $.24^{*}$ & .02 & .06 & .06 \\
\hline Drill and Practice & 1.88 & 1.30 & .03 & .05 & -.04 & .02 \\
\hline Games & 2.26 & 1.45 & .04 & .03 & .10 & -.06 \\
\hline Simulations & 1.54 & .95 & .19 & .01 & -.12 & .08 \\
\hline Tutorials & 1.95 & 1.05 & .16 & .09 & .02 & .06 \\
\hline Integrated Learning Systems & 1.94 & 1.31 & $.20 *$ & .21 & $.22 *$ & .02 \\
\hline Web Browsers & 4.55 & .90 & $.23^{*}$ & -.03 & .02 & .16 \\
\hline Programming/Authoring Tools & 1.39 & .92 & .07 & -.11 & .13 & .13 \\
\hline
\end{tabular}

* Correlation is significant at the 0.05 level (2-tailed).

** Correlation is significant at the 0.01 level (2-tailed). 
Research Question 2b: How do factors other than teachers' beliefs relate to the types of technologies teachers have their students use for instruction?

A multiple regression analysis was conducted by regressing four predictors Confidence and Comfort (P4), Technical Support (P5), General School Support (P6), and Ratio of Computers-to-Students (P7) - on the criterion variable, Student Software Use. This analysis sought to determine the extent to which four predictors contributed to the overall score of Student Software Use.

In this simultaneous multiple regression analysis, the predictors yielded nonsignificant $t$ test values for Technical Support (P5), General School Support (P6), and Ratio of Computers-to-Students. These values were $t=-.29, p>.05$ for P5, $t=1.14, p$ $>.05$ for P6, and $t=.90, p>.05$ for P7. The $t$ value for Confidence and Comfort (P4) showed a trend toward significance $(t=1.74, p=.086)$. The model accounted for $10 \%$ of the variance in Student Software Use, $\mathrm{R}^{2}=.10$, and the Confidence and Comfort (P4) measure was found to be the only variable with a trend toward significance in the model.

Only those Student Software Use items that were found significantly correlated with one of the four predictors are reported below. Teachers' Confidence and Comfort measure was correlated with five items of the Student Software Use: presentation software $(r=.30, p<.01)$, web publishing programs $(r=.21, p<.05)$, simulations $(r=$ $.23, p<.05)$, tutorials $(r=.19, p<.05)$, and web browsers $(r=.25, p<.05)$. Technical Support was found to be correlated with two items: presentation software $(r=28, p<$ $.01)$ and integrated learning systems $(r=.30, p<.01)$. General School Support was only correlated with integrated learning systems $(r=.24, p<.05)$. Finally, the Ratio of 
Computers-to-Students measure was found to be correlated with the following seven items: word processors $(r=.29, p<.01)$, spreadsheets $(r=.25, p<.05)$, databases $(r=.19, p<.05)$, presentation software $(r=.24, p<.05)$, web publishing programs $(r=$ $.21, p<.05)$, graphic programs $(r=.20, p<.05)$, and web browsers $(r=.22, p<.05)$. The relationships between individual items of the Student Software Use and factors other than beliefs are reported as Pearson $r$ values in Table 12.

These results indicated that the Ratio of Computers-to-Students measure was the most important factor for teachers having their students use a variety of computer applications. The significant role of Ratio of Computers-to-Students in teachers’ selection of software for student use was evident in seven of 14 Student Software Items. The Confidence and Comfort measure was the second most important factor for teachers' selection of a variety of software for student use. Except for one item (integrated learning systems) for General School Support and two items (presentation software and integrated learning systems) for Technical Support, teachers’ selection of instructional software for student use tended to be more related to the availability of computers in the classroom and their confidence and comfort with using technology. 
Table 12

Means and Standard Deviations of Student Software Use Items and their Relationship to Confidence and Comfort (P4), Technical Support (P5), General School Support (P6), and Ratio of Computers-to-Students (P7) for Research Question $2 b$

\begin{tabular}{|c|c|c|c|c|c|c|}
\hline \multirow[b]{3}{*}{ Student Software Use Item } & \multirow[b]{3}{*}{$\bar{X}$} & \multirow[b]{3}{*}{$\mathrm{SD}$} & \multicolumn{4}{|c|}{ Correlations } \\
\hline & & & $\mathrm{P} 4$ & P5 & P6 & P7 \\
\hline & & & & & & \\
\hline Word Processor & 2.88 & 1.29 & .19 & .05 & .15 & $.29 * *$ \\
\hline Spreadsheets & 1.52 & .86 & .16 & .01 & -.08 & $.25 *$ \\
\hline Databases & 1.45 & .97 & -.05 & -.02 & -.13 & $.19 *$ \\
\hline Desktop Publishing & 1.83 & 1.02 & .14 & .04 & .02 & .09 \\
\hline Presentation Software & 2.08 & 1.10 & $.30 * *$ & $.28 * *$ & .18 & $.24^{*}$ \\
\hline Web Publishing Programs & 1.29 & .67 & $.21^{*}$ & .06 & .07 & $.21^{*}$ \\
\hline Graphics Programs & 1.76 & .94 & .13 & -.03 & .06 & $.20^{*}$ \\
\hline Drill and Practice & 3.06 & 1.30 & .02 & .01 & .03 & .03 \\
\hline Games & 2.73 & 1.44 & -.00 & .10 & .14 & -.09 \\
\hline Simulations & 1.94 & 1.27 & $.23 *$ & .20 & .06 & -.00 \\
\hline Tutorials & 2.32 & 1.29 & $.19 *$ & .01 & .04 & -.00 \\
\hline Integrated Learning Systems & 2.61 & 1.59 & .16 & $.30 * *$ & $.24^{*}$ & -.12 \\
\hline Web Browsers & 3.17 & 1.45 & $.25 *$ & -.02 & .11 & $.22 *$ \\
\hline Programming/Authoring Tools & 1.30 & .79 & .13 & .07 & .15 & .14 \\
\hline
\end{tabular}

* Correlation is significant at the 0.05 level (2-tailed).

** Correlation is significant at the 0.01 level (2-tailed). 
Research Question 2c: How do factors other than teachers' beliefs relate to the types instructional strategies teachers use for instruction when integrating technology?

A multiple regression analysis was conducted by regressing four predictors Confidence and Comfort (P4), Technical Support (P5), General School Support (P6), and Ratio of Computers-to-Students (P7) - on the criterion variable, Instructional Strategies teachers used when integrating technology. This analysis sought to determine the extent to which four predictors contributed to the overall score of Instructional Strategies.

In this simultaneous multiple regression analysis, the predictors yielded nonsignificant $t$ test values for Confidence and Comfort $(t=1.65, p>.05)$ and Technical Support $(t=-.95, p>.05)$. Ratio of Computers-to-Students $(t=2.46, p<.05)$ and General School Support $(t=2.10, p<.05)$ yielded significant $t$ values. The model accounted for $21 \%$ of the variance of Instructional Strategies that teachers used when integrating technology, $\mathrm{R}^{2}=.205$. General School Support (P6) and Ratio of computers-to-Students (P7) were found to be the significant predictors in the model.

Only those Instructional Strategy items that were found significantly correlated with one of the four predictors are reported below. Teachers' Confidence and Comfort measure was correlated with four items of the Instructional Strategies measure: “independent learning" $(r=.21, p<.05)$, "to promote student-centered learning” $(r=$ $.30, p<.01)$, "as a productivity tool” ( $r=.21, p<.05)$, "as a classroom presentation tool” $(r=.43, p<.01)$. Only one Instructional Strategy item, "as a communication tool" was significantly correlated with the Technical Support measure $(r=.21, p<.05)$. General School Support was correlated with three items: "independent learning” $(r=.21$, $p<.05)$, "to tutor" $(r=.22, p<.05)$, and "to promote student-centered learning" ( $r=.19$, 
$p<.05)$. Finally, the Ratio of Computers-to-Students measure was found to be correlated with the following seven items: "individual instruction" $(r=.26, p<.01)$, "to promote student-centered learning” ( $r=.24, p<.01)$, “as a research tool for students” $(r=.25$, $p<.01)$, "as a problem solving/decision making tool” $(r=.44, p<.01)$, "as a productivity tool” ( $r=.20, p<.05)$, “as a classroom presentation tool” $(r=.35, p<.01)$, and "as a communication tool" $(r=.27, p<.01)$. The relationships between individual items of the Instructional Strategies and factors other than beliefs that relate to teachers' selection of instructional strategies are reported as Pearson $r$ values in Table 13.

These results indicated that the Ratio of Computers-to-Students measure was the most important factor for teachers' selection of a variety of instructional strategies when integrating technology. The Ratio of Computers-to-Students measure was found to be significantly correlated with seven Instructional Strategy items. Following the Ratio of Computers-to-Students, teachers’ Confidence and Comfort and General School Support were the other two most important factors for teachers' selection of a variety and frequency of instructional strategy selection. With the exception of one Instructional Strategy item (as a communication tool), Technical Support availability at schools was not related to teachers' use of a variety of instructional strategies when integrating technology. These results indicated that teachers' selection of instructional strategies tended to be more related to the availability of computers in the classroom. Teachers’ confidence and comfort for using these technologies and the availability of general school support availability played less of a significant role compared to ratio of computers-tostudents in teachers instructional strategy decisions when integrating technology. 
Table 13

Means and Standard Deviations of Instructional Strategies Items and their Relationship to Confidence and Comfort (P4), Technical Support (P5), General School Support (P6), and Ratio of Computers-to-Students (P7) for Research Question 2c

\begin{tabular}{|c|c|c|c|c|c|c|}
\hline \multirow[b]{3}{*}{ Instructional Strategy Items } & \multirow[b]{3}{*}{$\bar{X}$} & \multirow[b]{3}{*}{$\mathrm{SD}$} & \multicolumn{4}{|c|}{ Correlations } \\
\hline & & & P4 & P5 & P6 & P7 \\
\hline & & & & & & \\
\hline Small group instruction & 2.75 & 1.14 & .11 & -.05 & .07 & .17 \\
\hline Individual instruction & 3.32 & 1.24 & .07 & .20 & .14 & $.26 * *$ \\
\hline Cooperative groups & 2.53 & 1.07 & .12 & -.02 & .08 & .10 \\
\hline As a reward & 2.29 & 1.32 & -.00 & .08 & .15 & -.12 \\
\hline Independent Learning & 3.34 & 1.35 & $.21 *$ & .20 & $.21^{*}$ & .12 \\
\hline To tutor & 2.82 & 1.31 & .13 & .12 & $.22 *$ & .11 \\
\hline $\begin{array}{l}\text { To promote student centered } \\
\text { learning }\end{array}$ & 3.09 & 1.29 & $.30 * *$ & .10 & $.19 *$ & $.24 * *$ \\
\hline As a research tool for students & 2.93 & 1.31 & .14 & -.04 & .06 & $.25 * *$ \\
\hline $\begin{array}{l}\text { As a problem solving/decision } \\
\text { making tool }\end{array}$ & 2.17 & 1.21 & .16 & -.12 & -.02 & $.44 * *$ \\
\hline As a productivity tool & 2.78 & 1.22 & $.21 *$ & -.00 & -.05 & $.20 *$ \\
\hline $\begin{array}{l}\text { As a classroom presentation } \\
\text { tool }\end{array}$ & 2.73 & 1.14 & $.43^{* *}$ & .00 & .07 & $.35 * *$ \\
\hline As a communication tool & 3.19 & 1.64 & .17 & $.21 *$ & .09 & $.27 * *$ \\
\hline
\end{tabular}

* Correlation is significant at the 0.05 level (2-tailed).

** Correlation is significant at the 0.01 level (2-tailed). 


\section{Intercorrelations of the Ten Variables in the Study}

Pearson product moment bivariate correlational analyses were performed to examine the relation between the 10 continuous variables (seven predictor variables and three criterion variables) used in the study. Reported below are the variables that were found to be significantly correlated with the greatest number of other variables in the study.

The result indicated the teachers' Attitudes (P3) measure was positively correlated with seven variables in the study. The teachers' Attitudes measure was related to their Teacher-Centered Beliefs ( $r=.22, p<.05)$, Confidence and Comfort $(r=.59, p<.01)$, Technical Support $(r=.23, p<.05)$, Ratio of Computers-to-Students $(r=32, p<.01)$, Teacher Software Use $(r=.45, p<.01)$, Student Software Use $(r=.32, p<.01)$, and Instructional Strategies $(r=.34, p<.01)$. The teachers who reported having positive attitudes toward computers also reported having higher confidence and comfort using computers and having teacher-centered beliefs. Teachers with mainly teacher-centered beliefs, high confidence and comfort, and positive attitudes integrated technology more frequently into curriculum with a variety of approaches, and had more computers in the classroom as well as technical support available at their schools.

Similarly, Confidence and Comfort (P4) measure was found to be positively correlated with seven variables in the study. The Confidence and Comfort measure had a significant relationship with Attitudes $(r=.59, p<.01)$, Technical Support $(r=.24, p<$ $.05)$, General School Support ( $r=.29, p<.01)$, Ratio of Computers-to-Students ( $r=27$, $p<.01)$, Teacher Software Use $(r=.34, p<.01)$, Student Software Use $(r=.27, p<$ $.01)$, and Instructional Strategies $(r=.28, p<.01)$. Teachers who were more confident 
about using technology also had positive attitudes toward technology. These teachers integrated technology for teaching and learning more frequently with a variety of instructional strategies, and had more computers in their classroom in addition to technical and general support availability at their schools.

Similar results were obtained for the criterion variables of Teacher Software Use, Student Software Use, and Instructional Strategies. Each of these criterion variables were correlated with five predictors in the study. Again teachers' attitudes and confidence and comfort were the most common predictable variables for teachers using and having their students use instructional technologies with a variety of approaches. The Ratio of Computers-to-Students measure had a significant relationship with teachers' selection of a variety of instructional technology and instructional strategies. Finally, the teachercentered beliefs measure had a significant relationship with teachers' having their students use a variety of educational software in class.

Table 14 below reports the Pearson bivariate correlation results for all the variables used in the study. 
Table 14

Intercorelations of the Ten Variables Used in the Study

\begin{tabular}{|c|c|c|c|c|c|c|c|c|c|c|}
\hline & P1 & P2 & P3 & P4 & P5 & P6 & P7 & C1 & C2 & C3 \\
\hline $\mathrm{P} 1$ & & .17 & .07 & -.01 & -.16 & -.11 & -.14 & .08 & .19 & .10 \\
\hline P2 & .17 & & $.22 *$ & .14 & .12 & -.07 & -.14 & .09 & $.22 *$ & .07 \\
\hline P3 & .07 & $.22 *$ & & $.59 * *$ & .15 & $.23^{*}$ & $.32 * *$ & $.45^{* *}$ & $.32 * *$ & $.34^{* *}$ \\
\hline P4 & -.01 & .14 & $.59 * *$ & & $.24 *$ & $.29 * *$ & $.27^{* *}$ & $.34 * *$ & $.27^{* *}$ & $.28^{* *}$ \\
\hline P5 & -.16 & .12 & $.23^{*}$ & $.24 *$ & & $.59 * *$ & .11 & .12 & .13 & .11 \\
\hline P6 & -.11 & -.07 & .15 & $.29 * *$ & $59 * *$ & & .07 & .11 & .16 & .17 \\
\hline P7 & -.14 & -.14 & $.32 * *$ & $.27^{* *}$ & .11 & .07 & & $.20 *$ & .19 & $.32 * *$ \\
\hline C1 & .08 & .09 & $.45^{* *}$ & $.34 * *$ & .12 & .12 & $.20^{* *}$ & & $.54 * *$ & $.60^{* *}$ \\
\hline C2 & .19 & $.22^{* *}$ & $.32^{* *}$ & $.27^{* *}$ & .13 & .16 & .19 & $.54^{* *}$ & & $.60^{* *}$ \\
\hline C3 & .10 & .07 & $.34 * *$ & $.28 * *$ & .11 & .17 & $.32 * *$ & $.60^{* *}$ & $.60^{* *}$ & \\
\hline
\end{tabular}

P1: Student-Centered Beliefs

P2: Teacher Centered Beliefs

P3: Attitudes

P4: Confidence and comfort

P5: Technical Support

P6: General Support

P7: Ratio of Computers-to-Students

C1: Teacher Software Use

C2: Student Software Use

C3: Instructional Strategies 


\section{Method 2: Case Study Results}

\section{Sampling}

The maximum variation sampling strategy was employed to carefully select the cases representing the greatest differences in the phenomenon. Based on the beliefs survey (Inventory of Philosophies) two teachers with student-centered beliefs and two with teacher-centered beliefs were identified. Figure 1 and Figure 2 on the following page represent the distribution of the teacher-centered and student-centered scores of the research population. The mean scores were 38 for teacher-centered beliefs and 52 for student-centered beliefs. As shown in Figure 1, 71\% $(n=80)$ of teachers beliefs were clustered around the scores of 35 and 42 . This indicates $71 \%$ of the teachers who responded to the beliefs survey self-reported having mainly teacher-centered beliefs. At the same time as shown in Figure 2, teachers' scores were even more broadly distributed when it came to student-centered beliefs. Although the beliefs of the participants mainly clustered around the scores of representative of teacher-centered, population scores were also broadly distributed all across the scores representative of student-centered beliefs.

Given the distribution of the scores indicating a mixed of beliefs for the teachers in this research population, the following procedures were employed in the selection of the four cases. Based on the mean score of 38 for teacher-centered beliefs and the mean score of 52 for student-centered beliefs, the entire research population $(\mathrm{N}=113)$ was investigated to determine the four cases. The selection method considered the variability of the teacher beliefs' scores between teacher-centered and student-centered and consistency of teachers' responses to the statements in the survey. Variability of 


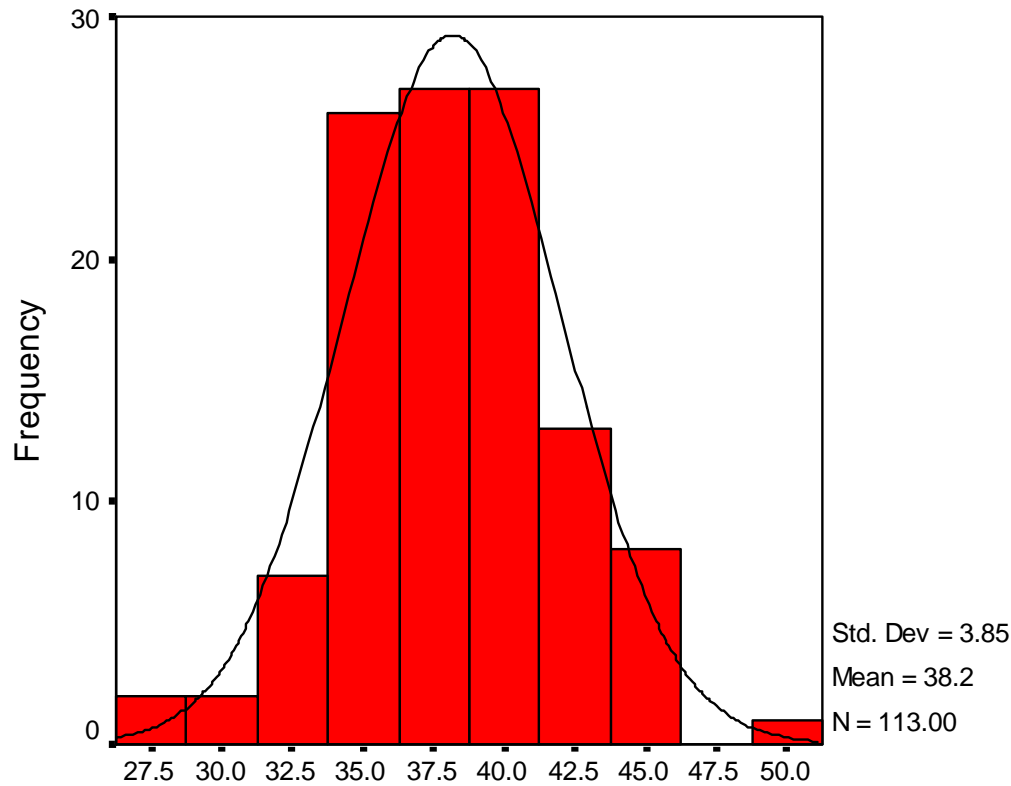

Teacher-Centered Scores

Figure 1

Distribution of Teacher-Centered Scores of the Participants $(N=113)$

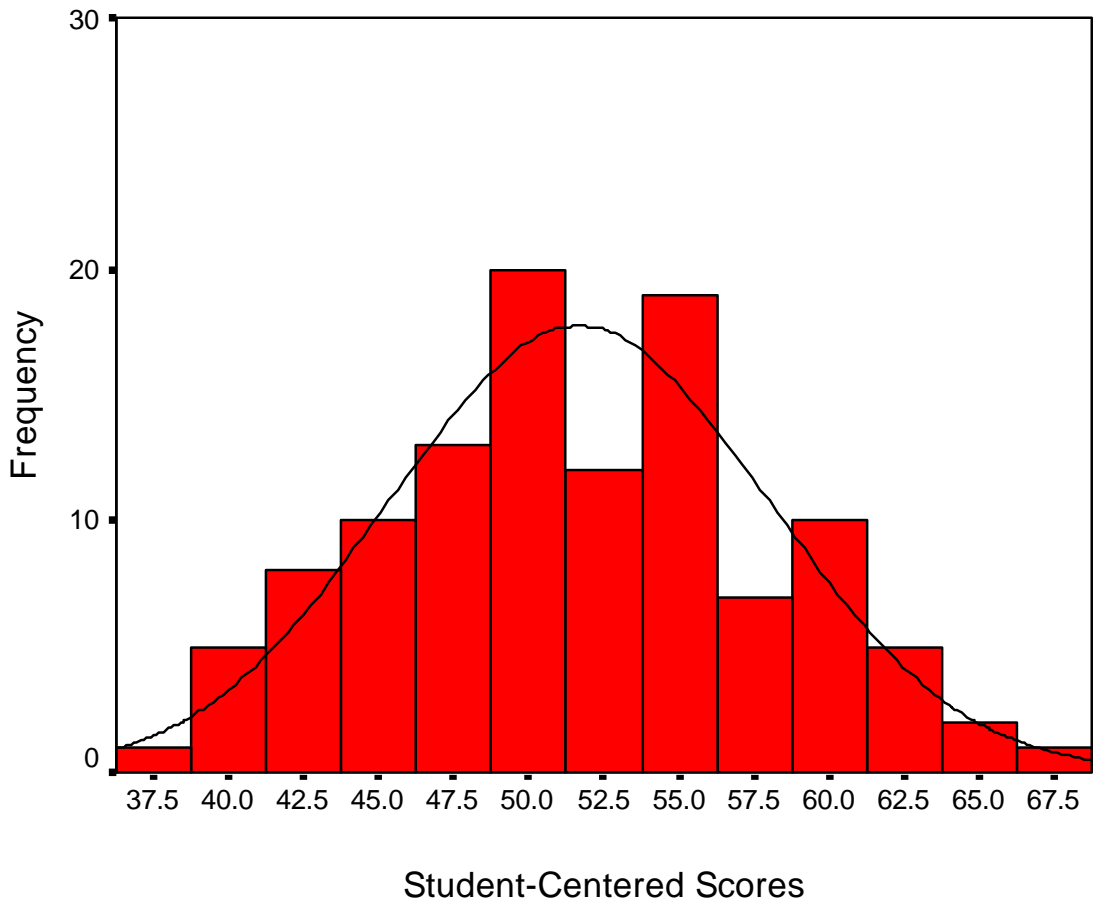

Figure 2

Distribution of Student-Centered Scores of the Participants $(N=113)$ 
teachers' scores were assured by selecting two cases for teacher-centered beliefs and two for student-centered beliefs based on the following criteria: (1) the pairs had the most varied mean scores in terms of their teacher-centeredness and student-centeredness, (2) the pairs had the mean scores that were higher than the average of that representative tenet, and (3) the two pairs had consistent responses to the survey statements that qualified them to be the representative of teachers with student and teacher-centered beliefs.

The selection criteria described above did not consider other variable other than teachers' beliefs. In other words, no differences were made in the selection of teachers in terms of gender, age, years of teaching or computer experience, grade level, and subject matter taught. Table 15 presents the demographics of the four teachers.

Table 15

Demographics of the Four Cases

\begin{tabular}{|c|c|c|c|c|c|c|}
\hline Name* & Beliefs & Grade Level & $\begin{array}{l}\text { Number } \\
\text { of } \\
\text { Students }\end{array}$ & $\begin{array}{l}\text { Number } \\
\text { of } \\
\text { Computers }\end{array}$ & $\begin{array}{l}\text { Teaching } \\
\text { Experience }\end{array}$ & $\begin{array}{l}\text { Computer } \\
\text { Experience }\end{array}$ \\
\hline Kate & $\begin{array}{l}\text { Teacher- } \\
\text { centered }\end{array}$ & $\begin{array}{l}\text { Cross } \\
\text { curriculum } \\
\text { Grade } 1\end{array}$ & 24 & 4 & 39 years & 14 years \\
\hline Sandy & $\begin{array}{l}\text { Teacher- } \\
\text { centered }\end{array}$ & $\begin{array}{l}\text { Special } \\
\text { Education } \\
\text { Grade } 8\end{array}$ & 10 & 1 & 5 years & 2 years \\
\hline Anne & $\begin{array}{l}\text { Student- } \\
\text { centered }\end{array}$ & $\begin{array}{l}\text { Gifted } \\
\text { Children } \\
\text { Grades 6-8 }\end{array}$ & 5 & 4 & 9 years & 9 years \\
\hline Tina & $\begin{array}{l}\text { Student- } \\
\text { centered }\end{array}$ & $\begin{array}{l}\text { Special } \\
\text { Education } \\
\text { Grades K-5 }\end{array}$ & 8 & 2 & 3 years & 3 years \\
\hline
\end{tabular}

* Pseudonyms 


\section{Research Design}

The research design for the case study called for hermeneutic inquiry to describe teachers' beliefs in relation to their instructional technology practice within the contextual conditions under which teachers' practice took place or a product was produced that make it possible to interpret its meaning. The literature review posits that it is important to examine teachers' beliefs within their school context because teachers' beliefs tend to be more experience-based than theory-based (Orton, 1996); teachers’ beliefs are ill-structured (Nespor, 1987); they are context-bound (Tobin \& LaMaster, 1995), and beliefs are implicitly defined (Clark, 1988). Because the hermeneutic qualitative inquiry perspective interprets meaning based on the cultural context in which the meaning was created, as well as the cultural context within which it is subsequently interpreted (Patton, 2002), the design and interpretation of this study considered the context of teachers' technology practices.

The hermeneutic qualitative research perspective was selected as several other studies in literature pointed to the importance of studying teachers beliefs' in the context within which their actions took place (Borko \& Putnam, 1996; Calderhead, 1996; Cuban, 2002; Putnam \& Borko, 2000; Tobin \& LaMaster, 1995; Tobin, Tippins, \& Gallard, 1995). Consequently, teachers' beliefs in relation to their instructional technology practices were interpreted in the context of their school environment and culture by taking organization into account. The organizational and contextual factors included both the tools as well the infrastructure at teachers' schools, and the human support teachers might have received from colleagues and administration at their school site. 
The case study design called for multiple sources of data and included the following: (1) an interview, (2) a lesson plan, (3) classroom observation, (4) teacher reflections, and (5) survey results. An interview protocol was created to elicit more indepth information from teachers regarding their beliefs and practices within the context of their school. A lesson plan was requested from the teachers. This lesson plan was used during the interview as a prompt so that teachers would be able to walk the researcher through a specific lesson in which they typically used technology. Similarly, a classroom observation was requested in order to better interpret and place teachers’ practices and actions in the context of their teaching. Finally, teacher reflections were developed to prepare teachers for the interview questions. Through these multiple sources of data given the perspective of the hermeneutic inquiry, the following procedures were employed during data collection and data analysis.

\section{Procedure}

Four participants were identified based on the maximum variation sampling strategy to describe the phenomenon of teachers' beliefs in relation their instructional technology practices within the context of their practice. Before visiting teachers, two letters were prepared (Appendix D). The first letter informed the teachers of the nature of the study and listed types of data sources the researcher requested from them. The second letter was designed to elicit teacher reflections. Once the researcher identified the four cases, the researcher visited three teachers who taught at nearby schools and called the fourth teacher who taught at a distant school to (1) request their participation and (2) explain the nature of the study. Once the teachers agreed to participate in the study, the researcher made an appointment for an interview meeting and left the letters with the 
three teachers who were visited. After scheduling an interview date over the telephone with the fourth teachers, the two letters were sent as an email attachment to this teacher who taught at a distant school.

Interviews were conducted at the schools of each participant on the scheduled days. All four interviews took place in the classrooms of the teachers and lasted between 60 to 90 minutes. The interview protocol (Appendix C) was read to the participants and the interviews were recorded upon receiving approval from the teachers. Both the lesson plan and teachers reflections were used during the interview to prompt teachers in order to elicit more in-depth information in regards to their thinking and practice. The lesson plans and teacher reflections were not collected from the teachers if they wished not to do so. Classroom observations took place on the same day of the interview for three of them and on another day for one of the teachers upon her request. Field notes were taken during the observation.

\section{Analysis}

The researcher transcribed all the interviews and brought all case study data sources together. These data sources included the following: two surveys, interview transcripts, observations, a lesson plan, and reflections. Because the teachers talked about their lesson plans and about their reflections during the interview, the interview transcripts in three of the cases included these two sources of data.

The researcher read the entire content of the each transcript to identify the units of analysis in order to construct categories for case description. The categories of units of analysis were identified deductively as the researcher read the transcripts for the second time. The units of meaningful pieces of data were coded as the following: (1) teacher 
philosophies, (2) the role of curriculum, (3) the role of a teacher, (4) teacher confidence and comfort, (5) attitudes toward using technology (6) the role of technology in education, (7) types of technology use for instruction, (8) technology availability at school, (9) incentives, (10) barriers to using technology at the school, and (11) impact of technology integration in general. These were identified as units of analysis because they were meaningful bits of information that captured the recurring themes throughout data (Merriam, 1998; Maykut \& Morehouse, 1994). Once the units of data were coded, these units were constantly compared throughout the transcripts and with all other sources of data: teacher reflections, classroom observations, and a lesson plan teachers talked about during the interview.

To enhance the interpretation of the cases survey results were added in the final interpretation and development of the cases. Specifically, the following factors from the two surveys were included: (1) philosophies of education score, (2) teacher confidence and comfort score, (3) attitudes score, (4) instructional strategy items, (5) student software use items, and (6) teacher software use items. These six factors from the surveys were combined with all the other sources of qualitative data. Table 16 presents a summary of sampling, data collection, and analysis.

Upon collective revisions and analysis of multiple sources of data, the case studies were described under the following subheadings: (1) Beliefs and practices, (2) incentives and barriers, and (3) impact of technology, and (4) a summary. Each case was described individually within the above subheadings. At the end of description of individual cases, a summary table, Table17, was provided to outline the most important characteristics across cases. 
Documenting case study results ends with within-case and cross-case comparisons. The within-case comparisons were conducted to portray how teachers with similar beliefs are likely to integrate instructional technology practices and how factors other than beliefs relate to teachers' instructional technology practices. Similarly, the cross-case comparisons were conducted to portray how teachers, across four cases, are likely to integrate instructional technology practices and how factors other than beliefs relate to their instructional technology practices. 
Table 16

Summary of Case Study Design and Analysis

Sampling

- Select four teachers using the maximum variation sampling technique

- Identify two with teacher-centered beliefs and two with student-centered beliefs based on the Inventory of Philosophies of Education survey

Pre-Data Collection

- Create the interview protocol (Appendix C)

- Create teacher reflections (Appendix D)

- $\quad$ Create the letter for the selected teachers (Appendix D)

- Enclose the letter with the reflection questions and deliver it to the teachers.

Data Collection

- Visit or phone teachers to (1) request their participation and (2) set up the appointments

- Visit schools again to conduct the interviews and observe a lesson

- Transcribe the interviews

Data Analysis

- $\quad$ Read the entire transcript to identify the units of data

- Read it again to code the units of data as follows:

- Teacher philosophies

- The role of curriculum

- Assessment methods

- The role of a teacher

- Teacher confidence and comfort and attitudes

- The role of technology in education

- Types of technology use for instruction

- Technology availability at school

- Barriers and incentives for using technology at school

- Impact of technology

- Bring the following factors from the two surveys

- Confidence and comfort

- Philosophies of education

- Attitudes

- Instructional strategies

- Teacher Software Use items

- Student Software Use items

- Combine all sources of quantitative (6 factors above) and qualitative data

- Constantly compare and contrast recurring themes throughout all data sources

- Develop and write the cases

- Conduct a within-case analysis between two cases with the same beliefs

- Conduct a cross-case analysis among four cases with different beliefs 


\section{Case 1: Kate}

Kate is an experienced teacher with 39 years of teaching experience. She is a Grade 1 teacher at a rural elementary school. Visitors to this school will observe a friendly, yet professional atmosphere at this mid-sized rural elementary school. Visuals and children's work are displayed on the walls throughout the school. The school building is new, and the school appears to have abundant resources for student use. The library and the computer lab look well-provided and up-to-date. The equipment in Kate's classroom reflects this school's level of resources. There are four computers in Kate's room, one of which was an XP machine, a color printer, and a scanner in addition to several books and CR-ROMs.

A student-teacher was helping Kate when the researcher walked in to observe her class. She was sitting at her desk checking student work while the student-teacher was conducting a whole class activity on writing. Students were copying sentences from their book onto their worksheets. Once students finished their work, they would walk to Kate's desk to have her approve. She sent those few students who finished early over to the computer stations to play games or work on Compass (a skill-based learning system) for further practice. When children came to Kate’s desk, she checked to see completion of student work and approved children's work even if they had spelling errors. She later said she did not wish to make students conscious of their spelling so they cannot produce anything. During the rest of the hour, students in Kate's class continued to practice writing independently while a few worked on the computer stations. 


\section{Beliefs and Practices}

Kate's scores in the Inventory of Philosophies of Education survey revealed that Kate was a teacher with teacher-centered beliefs. Her philosophy of education was that "Every child can learn. If children were given opportunities and a variety of approaches, you will find one that makes the child successful.” Kate described herself as a "leader, facilitator, guide, and a counselor sort of" and defined her role in the curriculum "to introduce and re-teach so that kids master what it is that I am trying to teach.” She said "I have 24 students here at all levels... I have a child here who has not mastered the alphabet yet another child reading on the second grade. You have to adjust. You cannot teach the masses and hope that those children will fall in. It does not work that way.”

Kate believed that the curriculum should include the essential skills children needed to learn to be successful. She stated that the focus of the curriculum in the early grades was reading, writing, and math. While showing an example of a curriculum, she said "these are the things they must accomplish in Kindergarten and Grade 1. These are our essential skills. We have to build these skills.” Kate often stated the mastery of skills, dictated by the state, was essential for children's success. Kate said "the state says we must have the CSO in all subject areas... We use those as guidelines... and prioritize them." She defined prioritizing the curriculum with the following sentence: "We sit down and ask what is going to make the child successful.” Since Kate believed that mastery of basic skills was essential for students’ success, she taught and re-taught the basic skills until students mastered them.

Kate acknowledged that tests were the means for determining student mastery or degree to which students learned. Because mastery of essential skills was measured with 
tests, passing tests was the gateway to success. She said "I tailor the curriculum into each child's needs so that child has been able to pass the test. He can move along and go ahead.” Based on the test results she said, "If they have not mastered, I go back and reteach for that child.” Technology came into play in her teaching as she used technology to reinforce skills when she was re-teaching for mastery.

Because Kate believed every child could learn given a variety of approaches, she stated employing several approaches through which she chose to use technology to help her re-teach the skills. Uses of variety of approaches were reflected in the Perceptions of Computer survey. Kate indicated she used the following instructional strategies most frequently when integrating technology: “individual instruction”, “independent leaning”, “to tutor”, "to promote student-centered learning”, “as a communication tool, and "as a reward.” Contrary to her employment of a variety of approaches, Kate marked one technology for most frequent student use in the survey. This technology was the “Integrated Learning Systems.” Compass, the integrated learning system recommended by the state, was the technology she most frequently cited during the interview as well. Kate liked Compass because it allowed her to program instruction and to teach basic skills. Kate could set up Compass where she wanted students to start. With Compass, she could check student progress, time the instruction, record the time it took students to complete the task, and keep the record of their practice as a printout.

“Drill and practice” and "games” were the in the second most frequent types of software that Kate had her students use. This type of use was also evident throughout the interview. Kate said "I use technology as a second teacher because it can reinforce by playing a game or whatever, the skills I have just taught, provides them practice, records 
testing that I can go and check and I know what they are doing and that guides what we are doing next.” Technology was a "fun reinforcement” because children enjoyed working with different games and different concepts. Technology was also like "extra pair of hands" for helping children to succeed because there were 24 children in the classroom making it difficult to attend their needs individually. Kate also considered that technology taught children to think logically because computers were very logical.

Kate’s technology decisions were based on her judgments if "it (technology) is going to help, make the concept clear to what I am trying to get through, aid their understanding... not going to take the time away from what we are trying without them.” For Kate, it was important that technology “did not disturb” her regular classroom activities. In summary, given the evidence above, Kate used technology to reinforce student mastery, record student grades, and to check student progress.

Kate was extremely comfortable with technology as reflected in the survey results and in the interview. Kate had given herself the highest score (45) in the nine item Confidence and Comfort section of the Perceptions of Computer survey. She had taken all three technology integration professional development courses (Trek 21, Phase 9, and Reinvent) that became available. In terms of her attitudes, Kate scored 85 out of 100 compared to other teachers whose attitude scores ranged between 58 and 93 in the survey. Her positive attitudes toward computer use and high comfort and confidence to use computers were also evident throughout the interview. Kate was the technology support person at her school and was in charge of delivering professional development at her school site regarding technology use. Kate described herself as the technical support person at this school. She was the chair of the technology committee and responsible for 
anything to do with technology at this school. Her responsibilities included setting up email accounts for teachers, installing software to school computers, training teachers how to use new educational software, training them how to search and evaluate educational websites, and help teachers manage electronic resources. Incentives and Barriers

Kate made references to her progressive principal, the county, and after school classes where she taught computer integration to the other teachers at this school. When asked about availability of equipment, Kate pointed to the computer lab with $30 \mathrm{XP}$ machines and the equipment in her room: four computers, the color printer, and the scanner. The technology committee had a budget of $\$ 7000$ to spend this year and the committee voted to spend this money on renewing licenses and buying new software. Because Kate was the technology person at this school, other teachers contacted her if they run out of computer ink or any other equipment they needed. Kate said "we never fall behind we have four digital cameras, a big TV screen, and several LCD projectors.” All this equipment was available to check out from the library. At the same time, however, Kate laughed and said equipment was a barrier because there were some old machines and they had to continually deal with old equipment. Few teachers at this school did not have personal computers at home, so Kate indicated that that this was a barrier for them to use technology more frequently in their teaching. At the end, Kate pointed out that teachers were now expected to use technology since technology had become both a content standard and one of the factors teachers were evaluated at the end of the school year. 


\section{Impact of Technology}

Kate's responses to the impact of technology can be summarized as being on her instruction, relationship with colleagues, and her professional status. In regards to technology’s impact on her instruction, she said "technology created independent learners" and allowed her to "individualize learning” because she could use the State's basic skills program, Compass, and thus re-address the needs of a particular student without disturbing the whole class activity. When she was prompted whether she observed any changes in her instructional approaches, she pondered few seconds and first said "What changed? I will have to see... and continued "As a matter of fact somebody is doing different than someone else has made me be more flexible.” Also she said her assessment methods changed, because she now collected the evidence of student learning not only paper and pencil based, but through Compass.

In terms of technology's impact on the relationship of colleagues at this school, Kate said they now collaborated with each other more frequently. Before, “we were locked in our classrooms.” Now they asked each other for help because they attended professional development classes together and had the opportunity to work with each other in the same classroom. Because of the interactions they developed in professional development sessions, she believed some of the timid teachers were no longer timid and asked questions in the faculty senate. Kate mentioned that now almost everybody used their school email and this also helped them strengthen their relationships.

Kate both directly and indirectly mentioned the impact of technology on her professional standing. She had gained additional status at this school due to being the technology coordinator and teacher training person. In fact, she often referred to her 
responsibility to train her fellow teachers to use technology throughout the interview.

Kate stated that her responsibilities included training teachers how to use technology and providing technical support. Due to these additional responsibilities, Kate often referred to her technology use specifically for the purposes of professional development during the interview. This trend was also observed in the Perceptions of Computers survey. Kate stated using the following Teacher Software Use items: “word processing”, “desktop publishing programs”, “presentation software”, “web publishing programs”, “integrated learning systems”, and "web browsers". However, when it came to types of Student Software Use items, she stated using “integrated learning systems”, Compass, most frequently that was followed by "games” and “drill and practice” software.

\section{Summary}

Kate self-reported being a teacher with teacher-centered beliefs and demonstrated using technology for drill and practice and reinforcement as she believed mastery of basic skills was essential for her students’ success. Despite her positive attitudes, high comfort and confidence, and the availability of computer hardware and software, she mainly used technology to support her existing ways of teaching. Kate was a frequent user of technology for only those student software items that she used to support her teaching. She used computers even more frequently for preparation and management: to keep records, to check student progress, and to post grades. In conclusion, neither of the following factors - the frequency and comfort of her computer use, her attitudes, nor availability of technology - transformed her teaching. She made her technology decisions in line with her beliefs given the limitations in the context of her teaching in terms of the number of students, the academic ability, and the chronological age of her students. 
Case 2: Anne

Anne, a teacher of the gifted, has nine years of teaching experience, and currently is teaching $8^{\text {th }}$ Grade. The middle school where Anne teaches is a large town school and is located near the University. The school is serving ethnically and linguistically diverse students whose parents are usually affiliated with the University. The school's library and the computer lab look well-appointed and up-to-date.

In Anne’s classroom, there had three mid-sized round tables for student seating, her small table, and a wall unit that was loaded with books and games. She had four computers in her classroom, all of which looked very old compared to the computers in the library and the ones in the computer lab. Anne was working on a poetry unit with six students for the class the researcher observed. She began the lesson passing out a-onepage handout (double-sided) to each student and then discussed the new poetry unit with her students in the round table where everybody was sitting referring her students to the handout. She had a student read each section and then she raised a few questions for interaction and clarification of ideas while insuring everybody’s participation. For today’s lesson, Anne wanted students to arrange lines and alter spacing to convey how poets and students could give special emphasis to the certain parts of a poem. She had an example of a poem on one side of the handout illustrating the effect of emphasis. On the other side of the handout, she had given the instructions for completing this assignment. After about 20 minutes, they all went to the library to use the computers there. Students worked on their line arrangement assignment using word processing while Anne walked around and helped students with their work until the end of class hour. 


\section{Beliefs and Practices}

Anne was sampled because her scores in the Inventory of Philosophies of Education revealed that she was a teacher with student-centered beliefs. Anne often used the pronoun "we" as opposed to "I" when describing her work. When she was asked who "we” referred to, Anne said "we” referred to the teachers who taught gifted students at this school. She described her role of teaching "as a facilitator because we have a different type of classroom and the way we work is different... and it is more studentcentered.” Modestly, Anne said she was able be a facilitator because "we have small groups and we are able to do that." She said "we cannot be the expert in class because we have kids who have expertise beyond us in some subjects.” Anne continued "we teach them how to learn... The process is more important than product ... It (the process) can be applied in so many different ways. The product they produce initially is not as important as many different ways that they can apply that.”

Anne often defined the role of the curriculum and her role in the curriculum using phrases such as “process”, "thinking skills”, "having choices”, and “multiple ways for looking at things." She stated "they (students) need to be learned to be life long learners and learn those processes that they can apply to other places.... They need to learn how to learn and enjoy it.” She said "We are content based. We are required to use full content areas... We teach the process...We deliver the content through thinking skills and processes." Anne wanted her students to see the "how things work and reasons behind that." She gave students lots of choices within the content and allowed students to “make some decisions either right or wrong because I think that is how we learn.” She said "We know what we are going to deliver, within that there is a whole a lot choices." 
Consequently, she described herself more of an "organizer" than the leader of the class because she believed "sometimes kids need to do little leading"... I think if they do not learn to make decisions, they will be always expecting someone else to do that for them.”

Anne referred to the fact that their curriculum was individualized based on the IEP. This is how she explained the individualized curriculum: "We start from the testing that they have and present levels of performance that we observe and from there we go to goal areas." She then explained that based on the student's level and content objectives, she asked "what units can we do to satisfy those goals?” Within the same unit she individualized the curriculum as students work at different levels, "maybe one student working on a journal and the other might be working in higher level thinking."

Anne’s delivery and assessment methods reflected her curricular goals. She said "most of the times, kids work on projects. We are walking around. A lot of times, we work at different levels.” She referred to student journals throughout the interview and mentioned two types of uses for them: (1) to have students continually record their work and (2) to assess student performance. When asked if she gave any tests, she said "just because you do not give a test does not mean you do not evaluate performance.” With examples, she explained how she evaluated student performance everyday through the student products. The journals were a part of student projects, where students used technology to complete their assignments and recorded their work. Although she used the journals to assess student progress, she cautioned that she was very careful when grading them. Without using the word "portfolio", Anne talked about a CD that each student burned at the end of the $8^{\text {th }}$ grade. The CD stored the student work collected Grades 6 through 8 "as a digital portrait of what they have done in middle school.” 
Multiple data sources pointed that Anne used technology as a learning tool when it best fit what she wanted to accomplish. She said her decisions to use technology or not depended on "what I want to accomplish and technology is the best way I can do it. I do not always use technology. But when I use it, I use it as a book. You use a particular book because it is the best way.” Anne’s eclectic approach to technology as a tool for learning was evident in the survey. In the Perceptions of Computers survey, she marked 10 of the 12 Instructional Strategy items using equally. She had a note in the survey to support her eclectic approach. She wrote "many activities in my room fit to serve several of these objectives” that included small group instruction to cooperative groups. However, she stated two Instructional Strategy items were not applicable or not used at all. These two items were: using computers "as a reward" and using the computer "to tutor." In the survey beside the statement of computer use as a reward, she had dropped the following note: "no, it is a regular part of curriculum."

Anne had marked using the following Teacher Software Use items most frequently in the Perceptions of Computers survey: “word processing”, "spreadsheets”, and “web browsers” followed by “databases”, “desktop publishing programs”, and “graphic programs.” As for the Student Software Use items, Anne’s students used a variety of software excluding these two: "integrated learning systems" and "programming /authoring tools.” In the interview, Anne described how natural for her students to complete their assignments with using computers and how her students were technology savvy. They were using instant messaging for communicating with each other to complete class assignments even when she did not require. Her students were more comfortable with sending her email messages instead of calling her. 
Anne's view of instructional technologies is summarized by the following:

“Technology is really incorporated in everything we do.” She then immediately turned on one of the really slow computers in her classroom to show the researcher the main technology tool, EdLine, which she used everyday. Anne proudly showed how each teacher at the school had a page on their own where they could post news, post class notes/handouts, communicate with parents and students, post grades, post articles, and so forth. She said "EdLine program is a big part of what we do... EdLine gives you the format... All the different parts are here...It is ready to post your classroom materials.” In Anne’s words EdLine enabled her to “be connected to students inside and outside school." With EdLine she was able to post word documents as links to her page without going through the hustle of developing web pages. EdLine made her units web-based because "students have to visit certain links to do certain things to complete their assignments.” On EdLline, students could check the calendar for class agendas, email her for questions, and pull out class handouts when they needed.

Anne marked herself at the top $80 \%$ (36 out of 45) rate for her confidence and comfort using instructional technologies in the survey of Perceptions of Computers. In the interview, Anne stated that "I have taken lots of classes because I was interested in technology. I have taken anything related to technology. I like new things. I am always looking for something new.” Anne rated herself with $80 \%$ positive attitudes in the survey. In the interview it became even more apparent that Anne had been a serious home computer user for sometime. She bought her first computer in 1986 and learned how to work on them with her two sons who studied engineering. She even built one computer with her sons and then built the two computers in her classroom with her students. 


\section{Incentives and Barriers}

Anne pointed that time was a limitation or barrier for using technology. She said “there is not enough time during the school day to do the kinds of things we wish to achieve.” Hardware was another barrier. Anne had a scanner in her room, but that was passed on to her when the teacher had left the building. Pointing to the old computers in her room, one of them was her home computer bought back in 1986 and had only word processing. The other two other on the other end of the room were built together with her students. Anne said "I was not willing to wait 12 years to get computers, so we raised funds and with that fundraising we bought parts and built the computers” together in class with her students. Because Anne was a special education teacher, funds were limited. To overcome the problems of old hardware in her classroom, Anne raised funds with her students and built two computers while incorporating this work into one of the class projects. Anne often resorted to fundraisers to supply the equipment she needed in the classroom.

As for the support at school, Anne mentioned Janet, the technology teacher at school, and described how those “JanetTech" days turned from Janet showing them computer tricks to sessions for collaboration and information exchanges among each other. Anne argued the lack of hardware in her room was not a barrier as they had computers in the library and in the lab. Neither did she use technology due to the availability of computers at school and administrative expectations. Anne used technology with her students because she believed students needed to use technology. "We are moving technological” and it would be unfair not providing this service to the students. For her, technology was an important "learning tool” and sometimes was the 
best teaching and learning tool. She used technology in her instruction despite the limitations because she believed her students needed to be able use technology to search, withdraw, and produce for what they needed. It was important that the students see the connections and realize what they can do with technology to be successful life-long learners.

Impact of Technology

Anne's responses to impact of technology can be summarized as affecting (1) her students, (2) her preparation and management, and (3) expectations on how they were supposed to teach. As for the changes on students, she said "my students are probably more independent because I construct my units more so they work more independently.” Anne gave the following reasons for this. Her students accessed information on their own through the web-based lessons she created.

As for the changes on her preparation, she said "I remember doing a lot less that I do now." Anne pointed to increasing numbers of available resources for educators over the last couple of years and said she often searched and collected ideas from the Internet and stated "I rarely go to the library, and if I do, I access it from home." She checked her email at home in the evenings and thus communicated with her students in and out of school. As for management, Anne said she would not have been able to get along without a computer now as stated “I couldn’t do the job I do.”

Finally, Anne argued that the expectations from the administration and the county for having teachers use technology had an impact on the practices of some teachers who were not as comfortable with using technology. Anne stated that there were different levels of integrating technology. Anne was able to do the things that she did with 
computers because over the years "I learned more ways to implement it and got better with technology." There were few teachers at this school who were not as comfortable and were not as trained. Those teachers too were also expected to use technology because technology use was judged in yearly evaluations. Anne said "I worry about those people who are beginning to learn, but they are evaluated on that poorly.” Anne found the administration's expectation to have teachers use technology sometimes “frustrating.” Despite these teachers spending more time to learn to use technology, their use was limited and "with increasing pressure from the administration, I see some teachers use it not in useful ways." She almost described this as a double edged sword. On the good side, expectations from the administration was increasing the use technology, but sometimes this was not an appropriate expectation as it took longer time for novices to learn technology and would take even more time to use it appropriately.

\section{Summary}

Anne self-reported being a teacher with student-centered beliefs and demonstrated using technology as a learning tool when appropriate. Despite the lack of computer hardware in her classroom, she was able to transform her teaching face-to-face only to web-based with active student involvement. Anne was a frequent user of technology for both student and teacher software items, and she used technology to support her projectbased units. In conclusion, Anne made her technology decisions based on her beliefs and her positive attitudes, confidence and comfort, and the favorable teaching context helped Anne transform traditional teaching practices. She acted in line with her beliefs given the favorable conditions in her teaching context: small number of high achieving academically motivated technology savvy students. 


\section{Case 3: Sandy}

Sandy is a young teacher with five years of teaching experience. She has been a special education teacher for Grades 9 through 12 for three years. Sandy had a very small classroom with limited room to walk around. Individual student chairs are placed in four rows. There is a wall unit by the door where all course books for student use are kept. Because of lack of space in the room, most other classroom materials are kept in big containers, and these containers are placed on one large shelf way high on the wall. There is a small shelf of story books and CDs beside her table. Sandy's classroom has a TV with a VCR/DVD player in the upper corner of the room, and the room has only one computer.

Sandy was working in a language arts lesson on the day the researcher observed her class. She had about 10 students in her room. When the students came in to the class, she advised them to pick the course textbook from the book shelf by the door. As soon as the students were seated, she pointed them to the blackboard where she had written forms of language she wished to cover in this class hour. She talked briefly about what these language forms or parts of speech were and asked the students to open a specific page on their book to complete today's lesson. The students started working individually on that page of the book. In this exercise, two choices were given and the students were to choose the correct form appropriate for the given sentence. The correct answers were then copied from the book to a blank sheet of paper. Sandy walked around the student desks and sat down once in a while to help individual students during the rest of the class hour. Sandy collected students' work at the end of the class. 


\section{Beliefs and Practices}

Sandy was sampled because her scores in the Inventory of Philosophies of Education revealed that she was a teacher with teacher-centered beliefs. Sandy's responses regarding her teacher-centered philosophy was consistent throughout the interview and in her reflections. Sandy indicated that her philosophy in education was that "all children need to be educated but we need to educate them in areas that will be helpful and beneficial to them." Her main goals were "to prepare the students for life after high school.... To make them help themselves." She wanted "to make sure each one of my kids are going to be able to go out from here and get a job, maintain a job, and be able to support themselves." She defined her role of teaching as "one who educates all students to reach their absolute potential while modeling respectful and appropriate behavior." Pointing to the special needs of her students, Sandy said "I have kids who cannot read. They read at first grade level and they are in $11^{\text {th }}$ and $12^{\text {th }}$ grade. I accept that they read on that level. I am working toward getting them at a higher level. I want them as high as I can as educated as they can be before they leave high school.”

Sandy argued that the role of the curriculum should also have been to prepare students for life after school. She believed that the curriculum should include "life skills, i.e., conceptual math such as how to budget, balance a check book, write a check with correct spelling and numbers, resume writing, and interview skills. Sandy, however, saw a conflict between her belief what curriculum should have included and what it actually covered. She described this as a "sore spot" and said "credit generation for high school graduation should not be the focus of education.” Her students had to earn certain credits from certain courses to comply with the increasing requirements before graduating. Her 
students with special needs were not able to use these advanced courses in life. Instead, she wished to see the curriculum to include survival life skills to make them successful in life. When asked if she could tailor the curriculum into what she taught the students needed to learn, she responded "I have to teach what it is in the curriculum. I can tailor into a point, but I still have to teach the content standards that are dictated.”

Sandy believed that tests were the best means to measure student success, but she did not agree that the standard tests were appropriate for her student population. "The special education kids are taking the same tests. You cannot read the standardized test orally for Reading and Language Arts. If they have a reading disability, they cannot read the test.” Although Sandy acknowledged the importance of measuring student success through the student products, the student products she collected overtime appeared not to serve this purpose. She said "Work samples, I keep portfolios of my kids. I have tons and tons of work. As a matter of fact last week, I emptied some staff and gave one of my senior students a bunch of her work that she did when she was in $9^{\text {th }}$ grade.”

Sandy mainly saw two important purposes of using technology with her students: to reinforce what she taught and to help students prepare life after school. These themes were consistent in the interview, in her reflections, and the reasons she gave for her technology use. Sandy used Inspiration if she wanted to reinforce what she taught. She said this program reinforced the concept of how to make an outline. The other program she often used for reinforcement and student mastery was Plato, an integrated learning system. Sandy said “with Plato you can do Math, English, and Science. It has everything. I can set it so I do a diagnostic preview, and so I can put it down to a $5^{\text {th }}$ grade level. It keeps going until they mastered the concepts.” Likewise, with Plato she 
could determine what students did not need because they had already mastered the concept. "With this program, I can get reports to see how long they were on. It comes with drill and practice and a mastery test.” Sandy called Plato "a great program” because it was multifunctional, applicable to multi subjects, and reinforced the concepts for student mastery. In line with her philosophy statement, Sandy used Microsoft Word wizard to show students how they to write and update their resume before they applied for jobs.

Sandy self-reported using the following Teacher Software items in the Perceptions of Computers survey: "Drill and practice”, "games”, and “web browsers.” In addition to several of the following software: “word processors”, "presentation software”, “simulations”, and “integrated learning systems.” As for her Student Software Use items, Sandy marked a variety of software for most frequent use: “games”, “simulations”, “web browsers”, “word processing”, “presentation software”, “drill and practice”, and “integrated learning systems.” Although Sandy had marked her students used a variety of software in the survey and stated that using computers as a reward was not applicable, throughout the interview it appeared that Sandy had her students use computers sometimes as a reward and other times for drill and practice and reinforcement. In the interview, Sandy summarized her students’ computer use with the following sentence” I kind of use it (computers) sort of a reward.”

In the interview, Sandy mentioned EdLine only when she was prompted if their school had EdLine. She said “yes, we use EdLine, but EdLine is only for grades.” Sandy explained that she used EdLine to post her grades online so that parents could check how their children were doing. She continued "we can also post reports and 
announcements that are due to help the parents to see.” However, she did not give any examples of her posting. Sandy sometimes used EdLine "communicating with parents and students if they have computers.”

Non-computer technologies such as video and audio CDs were used in class because the videos helped students to see the connections with the book and helped her with the English content that she taught after reading stories. Sandy used audio CDs as they helped her students with reading disabilities. When Sandy was asked if students checked out the CDs or videos to listen or watch them on their own, she said "no, each kid gets the book. I am the only one who has the CDs, so we have to do it class” as a whole class activity.

Although, Sandy had marked using computers as "cooperative groups” and "to promote student-centered learning”, these types of uses were neither brought up as examples in the interview nor observed in the class she taught. Her use of computers as an “independent learning”, “as a research tool for students”, “as a productivity tool”, "to tutor" "as a communication tool" and for "individual instruction" were brought with the following examples. She talked about posting grades to EdLine and communicating with students and parents if they had computers. She used the Internet herself to retrieve ideas and sometimes she had her students use the Internet for research purposes to complete their assignments. In these situations, she supervised her students' access to the Internet sites as she stated "I do not want them to go and do anything (on the computer) they should not be doing" and said "they could not go online to play games or check their emails. I am always in the room and watching computers.” 
Sandy had attended only one of the three professional development initiatives (Phase 9) through which she learned how to integrate technologies. Sandy was comfortable with using computers as she explained that she was not that old so, computers were around when she was growing up. Sandy pointed her husband as the main support person to help her learn technologies. Her confidence and comfort with using technology was reflected in the Perceptions of Computers survey. Sandy had given herself a high score of 37 out of 45 for using computers for instruction in the survey. In the interview, Sandy mentioned that she was the "delegated" teacher on her floor so that other teachers on the floor could come and ask her questions. Sandy showed teachers from time to time how the drill and practice component of Plato worked. She also showed some teachers on this floor how to post grades to EdLine.

Sandy's Attitudes score toward computer use for instruction was relatively low, 66 out of 100, compared to the population range of 58 to 93, and population average 78 in the survey. Technology "is a wonderful aide to education that I use to supplement what I have already done.” Although she acknowledged the fact that "whatever they are doing in life, they will be using some type technology”, she was cautious about using computers. The fact that students were given opportunities to work on computers was “a privilege” and "it (computers) should only be used as an aide to reinforce what is taught." Incentives and Barriers

Although Sandy had only one computer in her room, it became clear later that this school had abundant hardware and software, technical help, and funds. The school had a mini lab on her floor with ten computers in addition to three other labs on other floors. The school also had portable wireless laptop computers for teachers to check out and use 
them in their rooms. These laptops and the computer labs were available on sign-up bases. As for technical assistance, one full-time and one half-time technical help people were available at the school. As far funding ongoing needs, Sandy said "we usually get about \$5200 per year to spend on what we need.” This money was allocated to each teacher and it was up to the teachers however way they wished to spend it. Sandy spent some of this money last year on the DVD/VCD player that she bought for her room and also used some of it to purchase audio CDs (literature series) that matched with the content of the stories that students read for English.

As far as administrative support and encouragement at this school, “The administration is really helpful. They (the administration) will support anything we want to try." Because technology became a content standard, "We are expected to use it. They want us to show technology in our lessons.” Technology also had become a part of their evaluations, and so teachers had to use it. Sandy said some teachers at the school were not using it to the extent that she was using technology, but every teacher at the school was using it into some capacity "because they will have to send their attendance, send their grades, and use EdLine.”

Sandy indicated the following as barriers. Using the computer lab and the laptop computers from the virtual lab was sometimes a problem because there were times "you are fighting with all other faculty to get in there.” Although she said this problem was infrequent, when it occurred, she had to rearrange her lesson plan for that day. Sandy wished to have more licenses for Plato, the integrated learning system, she most frequently used. Because of limited licenses, sometimes, she could not use Plato when she wanted. Finding time to learn and use new technologies was more of a bigger 
problem than availability of software and hardware. She gave an example of a new learning system at the school. They were given only an hour of training. Teachers had to learn to use this system on their own time until they were comfortable enough to use it with their students.

Impact of Technology

Sandy did not observe any changes in her teaching due to using technology. She said "I use technology mainly to reinforce what I have already done. They all like the computer. I kind of use it sort of a reward. So, I do not use it so much as a teaching tool as I do for reinforcement.” Immediately after this statement the researcher prompted Sandy if this meant she did not observe any changes. Sandy responded "No, I have not. Because the way I use it, the students like it and I do not want to overdue it because it just becomes the same route task, memory, and drill and practice thing that they have been doing. Student access to computers was “a privilege” and students liked to use computers, Sandy used them as a reward and for drill and practice to reinforce skills.

\section{Summary}

Sandy stated being a teacher with teacher-centered beliefs and demonstrated using technology as a reward for drill and practice and reinforcement for mastering skills. Although Sandy had high comfort and confidence and abundant technology in her school, she limited her students’ technology use as a reward and for reinforcement because of her beliefs about technology and teaching. She was a frequent user of technology for only those technologies she used to support her teaching. In conclusion, Sandy acted in line with her beliefs and attitudes toward computers given the limitations in the context of her teaching in terms of the number of students and the academic ability of her students. 


\section{Case 4: Tina}

Tina is a recent graduate with three years of teaching experience. She is a special education teacher for grades Kindergarten through Grade 5 at a large elementary school. The school building where Tina works looks very new. Both the school and classroom of each teacher are very spacious. The friendly atmosphere of this school was evident not only on the artifacts displayed all over the school, but also with the administrator's approach. The assistant principal welcomed the researcher at the door and took her to the classroom of Tina.

Tina was working on a low desk with a student one-on-one when the researcher walked in to her class to observe first and then to interview her. Tina had two teaching aids for about 12 students she had in the class. Her classroom was spacious and colorful. She had a variety of word arts, student works, and signs posted all over the classroom. Two medium sized boards on the two walls of the classroom displayed the group activities for today. Some students were working in their writing and reading groups supervised by teaching aids. Two students were working on the computers, and few were working on their own copying the sentences from the board to their paper. She had a bag of words hang on a magnetic clip. She asked one student to take that word bag and using the words in the bag write the exact sentence written on the board. Tina asked another student who finished her work early to help her friend who was working on building a sentence with the words he had. During the same class hour, Tina looked extremely busy changing students and changing activities that she did with the group or individual students that she was with. 


\section{Beliefs and Practices}

Tina was the other teacher whose scores in the Inventory of Philosophies of Education revealed that she was a teacher with student-centered beliefs. Tina's studentcentered approach to teaching was evident not only in her reflections and statements, but also in the class she was observed. In her written reflections Tina stated her philosophy as "Children have a right to learn in an environment that gives them the chance to grow and feel safe. Every child needs to have the opportunity to take risks and be himself. Every child also has a right to be taught in such a way that will allow him to achieve his fullest potential without the fear of being ridiculed.”

During the class Tina was observed, students were working in groups. When Tina was asked if she had always taught in groups and if she conducted any whole class activity, Tina responded "sometimes, we do (a whole class activity), but generally we are in groups.” Tina believed classroom interactions were very important for students to learn and grow. As she cautioned "technology should not be used in place of direct teacher/student interactions”, Tina found it troubling that a lot of her children did not know how to work together or play together. Part of her responsibility was to help her students build social skills in the classroom and help them learn to cooperate with one another. Her emphasis on cooperative learning was evident in the class she was

observed. She had sent a child to help another child. In the interview she said "we do a lot of cooperative groups... You go help this one and help him with this. I do that for a variety of reasons.” Another reason for her having student to help one another was to "boost their confidence” and "make them feel good.” 
Tina defined her role as "to create a warm and nurturing environment that will allow my students to grow and learn.” She viewed it was her responsibility "to help raise the self-esteem and confidence of my children and challenge them into exploring to unknown.” Tina aimed at "preparing students for the challenges of life.” Students would be able to meet the challenges of life if she could "improve their critical thinking skills, provide opportunities for them to work with their peers in cooperative groups, and make compromises” in the cooperative groups they worked with their peers. The purpose of schooling was to "prepare all students to succeed in life, to prepare students to become productive members of society, and to help students achieve to their fullest potential.”

Tina maintained that the curriculum should have included “self-exploration” and “critical thinking skills” in addition to "basic skills to succeed in life.” These basic skills covered the content areas in reading, writing, and math. Tina stated that "the role of the teacher is to excite the kids about the learning and help kids move along." When she was asked if the curriculum that she taught gave her this flexibility, Tina answered: "I think so. I think the role of the teacher is to help them learn and grow and help them become citizens of that community. So no matter what the curriculum is as long as the teacher helped students achieve and grow, I think they are doing their job.”

Tina gave herself 33 out of 45 (about 74\%) for her comfort and confidence using technology for instruction. In the interview, she pointed that she was a recent graduate and technology had been part of her personal and academic life as long as she remembered. She said "I am proficient in what I need.” As for her attitudes toward using computers for instruction, Tina stated having positive attitudes toward using computers for instruction given the high score of 75 . 
Tina stated using the following items for teaching purposes: "word processors" and "web browsers” followed by desktop "publishing programs”, “games”, “simulations”, and “programming/authoring tools.” Her self-stated use of these technologies aligned with her responses in the interview. She was working on web pages to post homework for children and communicate with the parents. She was using the Internet to retrieve information to use it with her students.

Tina's responses to the Perceptions of Computers survey included several types of software and instructional strategies that could be associated with both studentcentered and teacher-centered approaches. Tina marked the following items for her student use: “drill and practice”, “games”, and “web browsing” most frequently followed by "simulations" and "tutorials." In the same survey, Tina said she used computers "as a reward” for “small group instruction”, “individual instruction”, “cooperative groups”, “independent learning”, “to tutor”, and “as a classroom presentation tool.”

In the interview, Tina gave more details about her mixed approaches despite the fact that she held mainly student-centered beliefs. Technology was "as an assistant”, "the tutor” and "a bit of everything." Technology was great "to give the students an opportunity to learn and explore concepts on their own.” Students should use technology to allow them work at their own pace and to explore their knowledge and to help the students to learn and grow at their own pace.” Tina mainly used software programs such as Curious George, Jump Start, and Reader Rabbit to help reinforce the concepts that she had covered in class. She said she never sent children to do something that they had never seen or heard the content. Pointing to the special needs of her children, Tina stated that "my kids really need a lot of repetition, going over and over again and again." She 
believed the software programs she used were well suited for this purpose, and they reinforced what she had taught and presented information "in a colorful, bright, and fun way.” She pointed that "as a teacher of special needs students I have a lot of diverse needs and abilities within my classroom. Technology helps me meet the needs of each student and helps me challenge each student on their own individual levels and reinforcing concepts in a new and exciting way."

Tina mainly used the above named three pieces of software as opposed to Compass for following reasons. Her students used Compass in their regular classes and there was not a need for her to use it again in her class. Also, the software that she used was more developmental as opposed to attaining mastery. Curios George, Jumps Start, and Reader Rabbit were at Kindergarten level, but given the special needs of students, these software programs were well suited to her student population. Tina said "mastery" was difficult to determine with her students as they looked they had mastered one day and not mastered on the next day. Instead, she chose to use more of a developmental types of software because they gave her more flexibility and they were not as rigid as Compass.

Although Tina was confident, had high attitudes, and could have had more equipment if she needed, she used only three developmental software programs with her students for mainly reinforcement, and used the Internet herself to retrieve ideas. When she was directly asked what factors then influenced her technology decisions and the way she used technology with her students, she stated the following: "My kids have a hard time with spelling and writing. My kids do not have the necessary skills to be in the Internet. They would be frustrated if I tell them go to this site and tell me what you 
found.” Tina would use technology if she thought technology would support her students or help them with their problems (disabilities) as opposed to frustrate them even more. Tina said "I have a kid who can tell a good story, but has a difficulty in spelling. If I show him Word and show him how to use spell checkers, he can write stories and he can succeed just like anyone else.”

\section{Incentives and Barriers}

Tina described her school as being a great place with a very supportive administration. There was a technology teacher at the school and this teacher was very helpful. As for the resources, the administration would generally provide what she needed. When the researcher pointed that she had two computers in the class and one of which was her personal laptop, she said "if I had couple of these computers that would be great and my principal is working on getting me one or two computers.” The school had a computer lab and it was available if she wanted to use it. However, she hardly took her children to the computer lab because she said "my program is pretty intensive and goal is to get them up to where they need to be so I can put them back to regular education.”

Although the resources at her school for using technology appeared to be limited, Tina thought neither lack of equipment nor money was a barrier. The school had a technology budget but she did not use any money from that budget. The school was adapting a new system, Reading Counts, and the administration also had a lot of other things to take care with that money. Tina said she did not need a digital camera and a scanner in her class. That kind of equipment was available at the school if she needed. When she was prompted if she wished to have some equipment, she answered: "If I think I need something, I get it. I wanted Curious George phonics so I bought it.” She 
continued "if my kids need it as long as I can get, I buy it. I am sure I can get it through the school if I had asked.” Although Tina did not mention "time” as a barrier during the interview, in her self-stated responses to the survey, she stated she did not have enough time to learn more computer skills. Impact of Technology

Tina indicated that technology had the most impact on creating "independent learners." This was very important for her to achieve as she stated "a lot of my kids cannot do independent staff. The computer allows them to work on their own and to succeed on their own at their own paste in a bright and colorful way more than I can.” She stated that she cannot "imagine doing my job without technology.” Tina mentioned the student progress charts she received from the software she used and a computer program that she used to rate IEPs instead of handwriting them. Upon prompting, Tina did not think technology had any impact on the relationship of teachers at this school. As far as she knew everybody was using it and talked about different ways they used it.

\section{Summary}

Tina self-reported being a teacher with student-centered beliefs and demonstrated using technology with mixed approaches. Although Tina held student-centered beliefs, had positive attitudes and high confidence and comfort, she used technology with a variety of mixed student-centered and teacher-centered approaches given the limitations in her teaching context. Tina had an average of 12 students who were both chronologically young and challenged with their disabilities. Given these limitations, Tina employed mixed approaches and used instructional technologies to raise her students up to their chronological level and help them with their disabilities. 
Table 17

Summary of Case Study Analysis

\begin{tabular}{|c|c|c|c|c|}
\hline Variable & Kate & Anne & Sandy & Tina \\
\hline $\begin{array}{l}\text { Beliefs about } \\
\text { education }\end{array}$ & $\begin{array}{l}\text { Mastery of skills } \\
\text { for student } \\
\text { success }\end{array}$ & $\begin{array}{l}\text { Life long } \\
\text { learning } \\
\text { Learning how } \\
\text { to learn }\end{array}$ & $\begin{array}{c}\text { Preparing } \\
\text { students life } \\
\text { after school }\end{array}$ & $\begin{array}{c}\text { Creating a safe } \\
\text { environment to } \\
\text { grow, learn, and } \\
\text { cooperate }\end{array}$ \\
\hline $\begin{array}{l}\text { Beliefs about } \\
\text { curriculum }\end{array}$ & $\begin{array}{c}\text { Basic skills } \\
\text { Guidelines for } \\
\text { evaluation and } \\
\text { mastery }\end{array}$ & $\begin{array}{c}\text { Process } \\
\text { Thinking skills } \\
\text { Giving choices } \\
\text { and allowing } \\
\text { decision making }\end{array}$ & $\begin{array}{l}\text { Teach basic life } \\
\text { skills that } \\
\text { would be } \\
\text { helpful for life } \\
\text { after school }\end{array}$ & $\begin{array}{l}\text { Learn to work } \\
\text { together } \\
\text { Critical thinking } \\
\text { skills }\end{array}$ \\
\hline $\begin{array}{l}\text { The role of a } \\
\text { teacher }\end{array}$ & $\begin{array}{c}\text { A leader } \\
\text { Teacher of } \\
\text { essential skills }\end{array}$ & $\begin{array}{l}\text { A facilitator } \\
\text { An organizer } \\
\text { Not an expert }\end{array}$ & $\begin{array}{l}\text { Educator } \\
\text { A model for } \\
\text { appropriate } \\
\text { behavior }\end{array}$ & $\begin{array}{l}\text { Nurturing } \\
\text { Raising the self- } \\
\text { esteem }\end{array}$ \\
\hline $\begin{array}{l}\text { Beliefs about } \\
\text { technology }\end{array}$ & $\begin{array}{l}\text { A second teacher } \\
\text { Fun } \\
\text { reinforcement }\end{array}$ & $\begin{array}{c}\text { A learning tool } \\
\text { used when } \\
\text { appropriate }\end{array}$ & Privilege & $\begin{array}{c}\text { A learning tool } \\
\text { to help students } \\
\text { with their } \\
\text { disabilities }\end{array}$ \\
\hline $\begin{array}{l}\text { Instructional } \\
\text { Strategies }\end{array}$ & $\begin{array}{c}\text { Drill \& Practice } \\
\text { Reward } \\
\text { Independent } \\
\text { learning }\end{array}$ & $\begin{array}{c}\text { Multiple } \\
\text { approaches } \\
\text { except using } \\
\text { computer as a } \\
\text { reward }\end{array}$ & $\begin{array}{c}\text { Drill \& Practice } \\
\text { Reward }\end{array}$ & $\begin{array}{c}\text { Drill \& Practice } \\
\text { Reward } \\
\text { Cooperative } \\
\text { learning }\end{array}$ \\
\hline Attitudes & Beyond average & Beyond average & Below average & Average \\
\hline $\begin{array}{l}\text { Student } \\
\text { Software Use }\end{array}$ & $\begin{array}{l}\text { Compass } \\
\text { Games }\end{array}$ & $\begin{array}{l}\text { Web-based } \\
\text { communication } \\
\text { tools and other } \\
\text { applications }\end{array}$ & $\begin{array}{c}\text { Plato } \\
\text { Internet } \\
\text { Video and } \\
\text { Audio CDs }\end{array}$ & $\begin{array}{c}\text { Curious George } \\
\text { Reader Rabbit } \\
\text { Jump Start } \\
\text { Games }\end{array}$ \\
\hline $\begin{array}{l}\text { Impact of } \\
\text { technology }\end{array}$ & $\begin{array}{c}\text { Independent } \\
\text { learners } \\
\text { Professional } \\
\text { relationship } \\
\text { and professional } \\
\text { status }\end{array}$ & $\begin{array}{l}\text { Preparation } \\
\text { Independent } \\
\text { learners } \\
\text { Inappropriate } \\
\text { use }\end{array}$ & None & $\begin{array}{c}\text { Independent } \\
\text { learners } \\
\text { Management }\end{array}$ \\
\hline
\end{tabular}




\section{Within-Case Analysis}

An examination within two pairs of cases with similar beliefs revealed the following discussion. The instructional technology practices of the teachers in substantial ways were related to (1) their beliefs about teaching and technology and (2) the contextual conditions in their teaching environments. All four teachers used technology to support their existing teaching practices given the conditions in their teaching context. These conditions were (a) chronological age of the students, (b) academic ability of the students, and (c) number of students in the class. These contextual conditions allowed teachers either to expand or limit their instructional technology practices, specifically for student software use, that were primarily guided by their beliefs about teaching and technology.

Anne and Tina

Anne and Tina, teachers with student-centered beliefs, had the following similar conditions for integrating instructional technologies. Both teachers praised the administrative and human support at their schools. Both had a technical support person at their schools, and their schools had adequate infrastructure and equipment available to them. Although the hardware in their rooms was scarce, neither of them saw this as a barrier. They said their schools made computers and other equipment available to them if they wished to use them. Similarly, both Anne and Tina lacked funds to buy the hardware and software to use with their students in their classrooms. They each had unique ways of approaching this problem. Anne raised funds to buy a digital camera and computer parts to build the two computers in her classroom. Tina bought the software herself without even applying to the technology fund available at school. Instead, Anne 
and Tina acknowledged that lack of time during the school day to learn new software and applications was a barrier.

Anne and Tina had similar educational beliefs that were reflected in their views about the curriculum and the roles they assumed when teaching. Anne believed that the purpose of education was to prepare students to be lifelong learners. She saw her role as a facilitator and as an organizer who wished to teach students the critical thinking skills, the process, and learning how to learn so that students would be able to realize how they could apply the process in many different ways. She was concerned with giving students choices within the projects-based units she taught the content through the process. Similarly, Tina believed that the purpose of education was to prepare students for the challenges in life. Students should be prepared for life given a safe and nurturing environment to help them grow, learn, and learn to cooperate. Tina wished to teach her young students how to think critically, how to work together, and how to make compromises. She was concerned with raising her students' self-esteem and bringing them to the level where they would be able to meet the challenges of life.

Anne and Tina had high confidence and comfort, highly positive attitudes about technology integration, and similar beliefs about technology's role in education. They both rated their attitudes, confidence and comfort fairly high and stated that they were capable of learning new technologies to use with their students. Both Anne and Tina viewed technology as a learning tool. For Anne technology was incorporated in her project-based web supported units. Anne used technology as a learning tool when it was appropriate to use it. Tina viewed technology also as a learning tool. However, her use of this learning tool for instruction was limited by the ability of her students. She used 
technology to help her students with their disabilities as opposed to challenge them with their difficulties. Consequently, Tina's use of technology was limited to the extent to which what her students were capable of doing given that they were young students with lower academic skills.

In summary, Anne and Tina varied somewhat in their instructional technology practices although they both held similar beliefs. The differences in their approaches were due to the contextual conditions. Anne was teaching the gifted at a middle school. Anne’s students were older, highly motivated, high academic achievers, and technology savvy. Anne was not concerned if her students would be able to read and write when she gave them an assignment to complete. Tina, however, was teaching students with special needs for Kindergarten through Grade 4. Tina's students had difficulty with reading and writing. They had lower self-esteem as they were aware of the difficulties they had. Anne was able to incorporate technology to the project-based units she designed. As Anne said she was able to do that with an average of five high achieving students. Whereas Tina, she had an average of eight young students who had difficulties with reading and writing. Tina did not wish to make her students more "frustrated" by challenging their difficulties. Instead, she used technology to help them with their difficulties, to help them be independent learners, and help them raise their self-esteem. Tina chose to use developmental software to help students achieve and feel safe.

\section{Kate and Sandy}

Kate and Sandy, teachers with teacher-centered beliefs, had the following similar conditions for integrating instructional technologies. Both teachers praised the administrative and human support at their schools. Although the hardware looked limited 
in their rooms, availability of computers was not an issue at these schools. Both schools had computer labs with dozens of computers. Particularly, Sandy's school had a wireless computer lab, which enabled teachers to bring the laptop computers to their classrooms to use them with their students. Both Kate and Sandy had available funds and other equipment for their use. Kate talked about funds managed by the school's technology committee, and Sandy talked about the money allocated to each classroom teacher at that school to be spent whatever needs teachers wished to supply. Although both Kate and Sandy acknowledged the availability of technology and funds at their schools, they expressed the idea of technology was also kind of a barrier. As a technical person, Kate had to deal with old equipment at her school, and Sandy sometimes had difficulties with the availability of her favorite software, Plato, due to limited licenses and booking the wireless laptops. Different from Kate, Sandy pointed out that time was more of a barrier to learning to use new technologies during the school hours.

Kate and Sandy had similar educational beliefs in that they both proposed teaching students "the essential skills" that they believed was necessary for student success. Kate believed that mastery of essential skills dictated by the curriculum was a gateway for student success. Kate saw her role in the classroom as a leader who introduced, taught, and re-taught the essential skills for student mastery and success. Sandy believed that the purpose of education was to prepare students life after school by educating them for only those life skills they would need in life after school. Sandy wished to teach students survival life skills such as balancing a check-book, writing and speaking Standard English instead of teaching advanced skills that were challenging her students' disabilities with reading and writing. She viewed her role as a model for 
appropriate behavior. Sandy was also concerned about mastery of academic skills dictated by the curriculum into some extent because her students had to take the standardized tests and perform well to be able to graduate.

Kate and Sandy had high confidence and comfort for using instructional technologies. Kate rated her ability to use technology with $100 \%$ confidence, and Sandy rated hers with $78 \%$ confidence. Regardless, they both expressed confidence as not being an issue as they were both delegated for being the technical people at their schools. Kate was the technology support person, and Sandy was the delegated technical person on her floor by her colleagues.

Kate and Sandy, however, varied in their attitudes toward using computers for instruction. Kate had high (80\%) positive attitudes score toward instruction with computers. Sandy's attitudes score (66\%) was below the population mean. The types of technologies and reasons for using them reflected the differences in Sandy's and Kate’s use of technology for instruction. Sandy believed that the fact that technology was available for student use was a "privilege.” So, she used it as a reward because students liked them. Sandy also used technology "as an aide to reinforce" what was already taught. For this purpose, she used Plato. In line with philosophy, educating students for life skills, Sandy used Microsoft Word wizard to show her students how to prepare resumes for job applications. Kate, however, believed technology was a "as a second teacher", "extra pair of hands" and used it more as an independent learning tool than as a reward. Similar to Sandy, Kate had a favorite technology, Compass, which was used for reinforcement and drill and practice. 
In summary, Kate and Sandy reported to have teacher-centered beliefs and integrated technology for mainly drill and practice, reinforcement, and sometimes as a reward. Kate and Sandy had the availability of technology and high confidence and comfort to be able to use technologies for instruction. Their instructional technology practices and reasons for using them were somewhat varied due to the differences in their attitudes. Similar to Anne and Tina, Kate and Sandy were also subject to the contextual conditions for using technologies to the extent they might have integrated otherwise. Kate was teaching 24 Grade 1 students how to read and write. Because her students were just beginning to read and write given their chronological age, their use of technology was limited to the extent of their reading and writing ability. Although Sandy had older high schools students, they were also were limited with their ability to read and write due to their disabilities in reading and writing. In sum, both Kate's and Sandy's instructional technology practices were not only related to their beliefs about teaching and technology but also to the contextual conditions of their teaching.

\section{Cross-Case Analysis}

Cases of Kate, Anne, Sandy, and Tina

An examination across the four cases was conducted to describe the similarities and differences of teachers with diverse beliefs. The following similarities were noted across Kate, Anne, Sandy, and Tina. All four worked at schools with adequate technical infrastructure, hardware, software, and human support. Across the cases, all had at least one computer in the classroom in addition to the computers that were available to them at the lab or at the library. All acknowledged the human support and affirmed the availability of a technical support person at their schools. Due to their previous training 
and personal use, all four teachers expressed confidence and comfort for learning and using technologies for instruction. Finally, all four teachers were frequent technology users for teacher software items. In other words, they were using a variety of computer applications for preparation, management, and communication purposes. They searched and retrieved information from the Internet for their lessons. They used word processing for preparation and management. All four used other computer applications to record and post grades. All four cases used their school email either to communicate with their colleagues or with parents if parents had an access to computers.

An examination across the four cases revealed differences in teachers' practices in relation to their beliefs about education, their beliefs (attitudes) about technology, and the contextual conditions. Teachers' educational beliefs were mainly related to many of their instructional technology decisions for student use. If, for example, they valued mastery of essential skills, Kate and Sandy used technology to maintain that with Compass and Plato. Viewing self-esteem and cooperation as important, Tina used developmental software to support that. Anne believed in process as opposed to mastery and valued higher order thinking skills and teaching students how to learn, she constructed webbased units with EdLine that gave her the flexibility and platform to construct that. However, their educational beliefs by themselves did not guide teachers' instructional technology practices entirely. Their beliefs about technology, which was reflected in their attitudes, influenced what they used and how they used. Anne, Tina, and Kate had positive attitudes about technology, and they were able to acknowledge the impact of technology on their teaching and student learning. All three declared technology created independent learners and acknowledged the place of technology in their preparation and 
management. Sandy, on the other hand, stated that technology had no impact on her instruction due to her use of technology mainly as a reward.

As for the instructional technologies, all four teachers employed a variety of instructional approaches for a variety of reasons. Only one teacher, Anne, declared one type of strategy was not applicable at all. This strategy was using computers as a reward. Using computers as a reward was not applicable for Anne since she incorporated technology into the project-based units in a way that students used learning technologies as a tool to accomplish their assignments. Including Anne, all four used a variety of instructional strategies when integrating technology for reinforcement, as an independent learning tool, individual instruction, small group instructions and others.

Given their beliefs, attitudes, confidence and comfort, technical and human support, these teachers' instructional technology practices were also influenced by (a) the chronological age of their students, (b) academic ability of their students, and (c) number of students in the class. Anne was able to perform such exemplary teaching practices through which she transformed her teaching into web-based. Anne was able to do this given the favorable conditions in her teaching context. She had an average of five high achieving, academically motivated, and technology savvy middle school students. Tina and Sandy had an average of eight to ten students who were challenged with their disabilities. These students were limited with their academic abilities. Kate had 24 young students in her class who were beginning to learn how to read and write. Although they were not challenged with their disabilities, Kate had too many young students for one teacher in a class to be able to expand her teaching practices. 


\section{Conclusion of Case Study Analysis}

The case studies were conducted to portray how teachers with similar and different beliefs are likely to integrate instructional technologies, and how factors other than beliefs relate to teachers' instructional technology practices. Four teachers were sampled using a maximum variation strategy. These case studies put a magnifying glass on teachers' everyday instructional technology practices and examined teachers' beliefs in relation to their instructional technology practices through multiple sources of data. These data were used to describe how teachers use technology, how they make their decisions, and what factors might possibly drive many of their instructional technology decisions given the context of their teaching.

The two pairs of cases were selected as representatives of teacher-centered and student-centered beliefs among those teachers who were likely to be using technology as a result of having participated in at least one of the statewide federal IT professional development projects and worked at schools with suitable conditions for integrating instructional technologies into teaching. The overall findings of the case study analysis indicate that teachers’ instructional technology practices, specifically for student use, were substantially related to (1) their beliefs about teaching and technology and (2) the contextual conditions in their teaching environments. These conditions were (a) chronological age of the students, (b) academic ability of the students, and (c) number of students in the class. These contextual conditions allowed teachers either to expand or limit their instructional technology practices, specifically for student software use, that were primarily guided by their beliefs about teaching and technology. 
Across these four cases, all teachers used instructional technologies frequently for preparation and management purposes. These teachers had students use instructional technologies frequently only for those technologies that supported their existing teaching practices given the limitations or favorable conditions in their teaching context.

In conclusion, neither teachers’ beliefs nor technology availability transform teaching practices. Rather, teachers who integrate instructional technologies with a variety of strategies to support active student learning, have positive attitudes toward technology, and have favorable teaching conditions are able to transform teaching. 


\section{CHAPTER 5}

\section{Summary, Discussion, and Implications}

This chapter includes four brief sections. These sections are intended to provide the following: (1) a summary of research design, (2) research questions, (3) discussion of the results, and (4) implications of the study.

\section{Summary of Research Design}

The main purpose of this study was to investigate teachers' beliefs in relation to their instructional technology practices within the context of their teaching. This study sampled only those technology-using P-12 teachers who worked at one of the 28 Benedum Professional Development Schools where the infrastructure and equipment necessary for technology integration were in place. Only technology-using teachers who worked at technology-rich schools were purposefully sampled to be able to describe how such teachers make their instructional technology decisions given the context of their teaching. In order to better describe how teachers make their instructional technology decisions in relation to their beliefs and other factors, the study employed mixed methods.

For Method 1, the results came from the two surveys: Inventory of Philosophies of Education and Perceptions of Computer and Technology. A total of 113 technology using teachers self-reported their educational beliefs and instructional technology practices with these two surveys. The research design included the following 10 continuous variables based on the surveys. These variables were: (1) teacher-centered beliefs, (2) student-centered beliefs, (3) attitudes toward computers, (4) confidence and comfort, (5) technical support, (6) general school support, (7) ratio of computers-to- 
students, (8) teacher software use, (9) student software use, and (10) instructional strategies used when integrating technologies. Variables 1 through 7 were determined as Independent Variables and 8 through 10 as Dependent Variables in the study. These 10 variables formed the basis of the two different statistical tests, multiple regressions and correlations, employed in the research design to answer the two main research questions with six subheadings.

Following Method 1 analysis, four case studies were conducted to bring more indepth descriptions of how teachers with similar and different beliefs are likely to integrate instructional technologies. Pairs of two teachers were sampled based on their scores from the Inventory of Philosophies of Education survey using the maximum variation strategy. This case study design called for multiple sources of data, which included (1) results from the two surveys, (2) an interview, (3) teacher reflections, (4) a lesson plan, and (5) classroom observations. Case study data was analyzed using constant comparison technique as described by Maykut and Morehouse (1994) and Merriam (1998).

\section{Research Question 1}

Research Question 1 sought to answer how teachers’ beliefs related to teachers’ instructional technology practices. The research design called for identifying teachers' beliefs as predictors and instructional technology practices as criterion variables. Three belief predictors were (1) student-centered beliefs, (2) teacher-centered beliefs, and (3) attitudes toward technology integration. The criterion variables referred to teachers' instructional technology practices and included (a) teacher software use, (b) students software use, and (c) instructional strategies. 


\section{Research Question 1a}

This question sought to answer the following: How do teachers' beliefs relate to the types of technologies teachers use for instruction? Statistical analytic methods employed to answer this question involved determining which of the three belief predictor(s) contributed to teachers' instructional technology decisions for Teacher Software Use items.

Simultaneous multiple regression and itemized correlational analysis yielded that attitudes was the most significant predictor for teachers' choices of a variety of software for teacher use. Teachers' positive attitudes, as opposed to their student-centered and teacher-centered beliefs, was found to be the most important predictor of teachers’ selection of a variety of software for instructional purposes.

Case study analysis confirmed that teachers' positive attitudes toward technology relate to many of their instructional technology decisions for teacher use. Teachers' with positive attitudes toward technology integrate several technologies and acknowledge technology's place in their teaching practices specifically for the purposes of preparation and management. As indicated by all four cases, teachers who have positive attitudes toward technology are frequent users in some capacity. They all used technology to record, check, and post student grades; teachers used their school email either to communicate with one other or with parents and students. All cases were frequent technology users for teacher software items and used a variety of Internet and other computer applications for the purposes of preparation and management. 


\section{Research Question $1 b$}

This question sought to answer the following: How do teachers' beliefs relate to the types of technologies teachers have their students use for instruction? Statistical analytic methods employed to answer this question involved determining which of the three belief predictor(s) contributed to teachers' instructional technology decisions for Student Software Use items.

Simultaneous multiple regression and itemized correlational analysis yielded that attitudes variable was the most significant predictor for teachers' choices of variety of software for student use. Teachers' positive attitudes, as opposed to their studentcentered and teacher-centered beliefs, was found the most important predictor of teachers' having their students use variety of educational software.

Case study analysis confirmed that teachers' having positive attitudes toward technology brings about many of their instructional technology decisions for student use. Teachers' with positive attitudes toward technology integrate technology and acknowledge its place in education for student learning. In addition to teachers' attitudes, case study analysis verified that teachers' beliefs relates to "what types of technologies" teachers use for "what purposes." This means given that teachers have positive attitudes toward computer instruction, they will have their students use a variety of instructional technologies, but the types technologies these teachers use will support their existing teaching practices depending on their beliefs about teaching and technology.

Research Question 1c

This question sought to answer the following: How do teachers' beliefs relate to the types of instructional strategies teachers use for instruction when integrating 
technology? Statistical analytic methods employed to answer this question involved determining which of the three belief predictor(s) contributed to teachers' selection of instructional technologies when integrating technology.

Simultaneous multiple regression and itemized correlational analysis yielded that attitudes was the most significant predictor for teachers' choices of employment of a variety of instructional strategies when integrating technology. The teachers' attitudes variable, as opposed to student-centered and teacher-centered beliefs, was the most important predictor of teacher selection and use of instructional strategies. Correlational analysis yielded that teachers with positive attitudes used seven of the 12 instructional strategy items in the survey. Only three instructional strategies were not correlated with teachers' attitudes. These were using computers: (1) as a reward, (2) to tutor, and (3) independent learning tool.

Case study analysis confirmed that teachers' positive attitudes toward technology related to many of their instructional strategy decisions. Teachers’ with positive attitudes integrated technology with a variety of approaches regardless of their student-centered and teacher-centered beliefs. Different from the survey results, however, the case study results yielded that across the cases teachers used computers as a reward when appropriate. Only one teacher did not use computers as a reward because she was able to incorporate technology into the project-based units whereby the assignments were designed such that students used technology to complete their work. These results indicate that teachers regardless of their educational beliefs may use computers as a reward when appropriate if computers are not entirely integrated into the curriculum through active student use. 


\section{Research Question 2}

Research Question 2 sought to answer how factors other than teachers’ beliefs related to teachers’ instructional technology practices. The research design identified four predictors referring them as "factors other than beliefs." These four factors other than beliefs were (1) confidence and comfort, (2) technical support, (3) general school support, and (4) ratio of computers-to-students. The same three criterion variables (a) teacher software use, (b) students software use, and (c) instructional strategies were used in answering how the four predictors contributed to teachers' instructional technology practices.

\section{Research Question 2a}

This question sought to answer the following: How do factors other than teachers' beliefs relate to the types of technologies teachers use for instruction? Statistical analytic methods employed to answer this question involved determining which of the four predictor(s) contributed to teachers' instructional technology decisions for Teacher Software Use.

Simultaneous multiple regression and itemized correlational analysis yielded that teacher confidence and comfort was the most significant predictor for teachers' choices of technologies for teacher use. Following teacher confidence and comfort, correlational analysis revealed that technical support was significant if teachers wished to design web pages. General school support was significant if teachers wished to use an integrated learning system, such as Compass and Plato. And finally, ratio of computers-to-students became significant in relation to web publishing, using data bases, and spreadsheets. 
Case study analysis confirmed the significance of teachers' confidence and comfort in their selection and employment of a variety of technologies. All four cases were frequent technology users and confirmed that they felt comfortable for learning and using technologies with their students. This means given that teachers have available computer hardware and software at schools and feel confident and comfortable with technology, teachers will use technology for instruction specifically for the purposes of preparation and management.

\section{Research Question $2 b$}

This question sought to answer the following question: How do factors other than beliefs relate to the types of technologies teachers have their students use for instruction? Statistical analytic methods employed to answer this question involved determining which of the four predictor(s) contributed to teachers' instructional technology decisions for Student Software Use.

Simultaneous multiple regression and itemized correlational analysis yielded that teachers' confidence and comfort was the only significant predictor for teachers' selection of variety of software for student use. In the itemized correlational analysis, confidence and comfort was significantly correlated with the five items in the student software use. However, one-on-one correlational analysis revealed that the ratio of computers-to-students was correlated with more student software items compared to confidence and comfort. Following the ratio of computers-to-students, correlational analysis yielded that technical support was a significant predictor if teachers used desktop publishing programs and integrated learning systems. Finally, general school support was significant in relation to integrated learning systems for student use. 
Case study analysis confirmed the confidence and comfort of the teachers who were selected. All four cases acknowledged that they felt comfortable with learning and using technologies with their students, and all four confirmed the availability of technical and human support at their schools. Although across cases teachers stated that they wished to have more hardware in their classrooms, limited number of computers in the classroom was not a hurdle for using computers more frequently with their students. This means given that teachers have available computer hardware and software at schools and feel confident and comfortable with technology, teachers will have their students use technology for instruction.

\section{Research Question 2c}

This question sought to answer the following: How do factors other than beliefs relate to the types of instructional strategies teachers use for instruction when integrating instructional technologies? Statistical analytic methods employed to answer this question involved determining which of the four predictor(s) contributed to teachers’ selection of instructional strategies when integrating technology.

Simultaneous multiple regression and itemized correlational analysis yielded that general school support and ratio of computers-to-students were the most important predictors for teachers' choices of variety of instructional strategies when integrating technology. The ratio of computers-to-students had a significant relation to seven of the 12 instructional strategy items, which included "to promote student-centered learning” and “individual instruction.” Teacher confidence and comfort had a significant relation to four strategy items, and general school support had a significant relation to three instructional strategy items. Technical support was a significant predictor if teachers 
used technology as a communication tool. Thus, several instructional strategies were significant in relation to different predictors. The most common strategies that were found significant across the four predictors were using computers for (1) student-centered learning, (2) independent learning, (3) individual instruction, (4) as a classroom presentation tool, (5) as a productivity tool, and (5) as a communication tool.

Case study analysis confirmed that teachers used a variety of instructional strategies when integrating technology. Although one instructional strategy item, to promote student-centered learning, was significant across the three predictors in the survey, it became clear with cases that using computers to promote student-centered learning meant different things for a majority of teachers. Instead, across the four cases, using computers for reinforcement was most cited. These results indicate that given the conditions that teachers are confident, have adequate technical and human support, and have available technology at their schools, they mainly use computers for reinforcement in addition to several other strategies when appropriate.

\section{Discussion}

This section will discuss the overall significance of the research results and its place in literature in relation to other studies which examined technology-using teachers' beliefs and instructional technology practices. The discussion of the findings can be summarized with the following points: (1) teachers' beliefs are complex and contextually bound, (2) positive attitudes and confidence and comfort are prerequisites for using technology given the availability of technology at schools, and (3) teachers have not shifted their traditional practices into more student-centered practices due to using technologies more frequently. Rather, teachers use technologies with students to support 
their existing practices, and use technologies themselves for preparation and management.

The survey results indicated non-significant findings in terms of the relationship of teachers' student-centered and teacher-centered beliefs in relation to their instructional technology practices. This can be explained with the following reasons. The literature review pointed out that teachers’ beliefs is a messy construct (Pajares, 1992), illstructured (Nespor, 1987), implicitly defined (Clark, 1988), and experience-based (Orton, 1996; Tobin \& LaMaster, 1995) making it also difficult to explicitly define or categorize. This trend was observed in the results of the Inventory of Philosophies of Education. Among the 113 who responded to the survey, $71 \%(n=80)$ of teachers' scores were clustered around the scores of 35 and 42. Since the mean score for teacher-centered beliefs was 38 , this meant $71 \%$ of the teachers who responded to the beliefs survey had mainly teacher-centered beliefs. It is interesting to note that the scores were even more broadly distributed for the same teachers with regards to their student-centered beliefs. These findings confirm the literature above in that teachers' beliefs are ill-structured, implicitly defined, and context-bound. Given the distribution of scores for the teachercentered and student-centered beliefs in this study, the following complementary assumptions can be made: (1) a majority of teachers continue to hold teacher-centered beliefs, and (2) even those with mainly teacher-centered beliefs have a combination of both teacher-centered and student-centered beliefs.

This study results, however, further extends the importance of examining teachers' beliefs within the context of their practices as discussed in the case study findings. The case study findings pointed to the evidence that teachers' beliefs by 
themselves cannot entirely explain teachers’ instructional technology decisions.

Teachers’ practical decisions to some extent are bound to (1) the chronological age of their students, (2) number of students in the class, and (3) academic ability of their students. The possible influences of context on teachers' beliefs were also "informally" confirmed in many of the conversations that were held during the data collection process. Many teachers indicated that some of the statements in the beliefs survey were difficult to choose as the statements did not differentiate the context. These teachers indicated that their answers would vary depending on placing the students in the context of elementary and high school grades. For example, many believed mastery of essential skills that qualify students to pass from one grade level the next held the truth for early elementary grades, but not for later grades with older students.

Due to difficulties with explicitly defining teachers' beliefs, the survey results yielded non-significant findings in describing teachers' beliefs in relation to their instructional technology practices. Instead, the results were significant from the surveys throughout the two statistical tests for teachers' attitudes, which was determined as the third belief variable in this study. This indicates that assessing teachers' attitudes toward technology (as opposed to teachers' educational beliefs) through surveys is more precise, and thus easier to measure and describe.

Findings of this study confirmed the significance of teacher confidence and comfort for selecting and using technologies in addition to having positive attitudes toward using technology for instruction. Teacher confidence toward using and learning to use new technologies was a significant factor as observed in the survey results and case studies in that all four teachers, either young and old, declared no technophobia and 
resistance to use instructional technologies. This confirms Cuban’s (2002) study conducted among the teachers in the technology-rich Silicon Valley Schools, California, in that Cuban noted teachers across all ages were neither afraid nor resistant to learning and using technologies.

Results of this study confirmed that given the context where teachers (a) have technology availability, (b) have positive attitudes, (c) have adequate technical and general school support, and (d) are comfortable with technology, these teachers are likely to be frequent computer users. However, their frequency of use will not transform or shift their practices. They will be frequent users of technologies (1) to prepare and manage their lessons and (2) to support their existing teaching practices. Both of these findings are parallel to the recent literature. Cuban (2002) stated that contrary to expectations, even the serious technology using teachers (a small percentage compared to the entire teacher population) "largely maintain existing classroom practices rather than alter customary practices” (p. 171). Results of this study indicated that teachers mainly used technologies for preparation, management, and communication. Similarly, Cuban maintained that teachers at all levels mainly use technologies to communicate with parents and administrators, prepare syllabi, record grades, and assign research papers.

This study confirms the findings of Windschitl and Sahl (2002) and Cuban (2002) in that technology-using teachers' instructional technology decisions are mainly related to their belief systems. Neither abundance of ubiquitous technology nor teachers’ frequent use of instructional technologies change or transform teaching into more "constructivist" or student-centered practices, a claim made by Becker and Ravitz (1999) and Ravitz, Becker, and Wong (2000). 
In conclusion, this study results point to the following: the instructional technology practices of teachers in substantial ways relate to (1) their beliefs about teaching and technology and (2) the contextual conditions in their teaching environments. These contextual conditions are (a) chronological age of the students, (b) academic ability of the students, and (c) number of students in the class. Teachers' beliefs are the primary agents of brining many of their instructional technology decisions specifically for their selection of technologies for student use. Types of technologies teachers have their students use are directly related to the ways teachers approach teaching and technology. In addition to teachers' beliefs, contextual conditions relate to teachers’ instructional technology practices, as these contextual conditions allow teachers either to expand or limit their instructional technology decisions.

\section{Implications}

The implications of this research are summarized below in relation to the current instructional technology practices among the technology-using teachers. These suggestions are:

1. Technology availability and support as well teacher training are the primary conditions of increasing technology use at schools.

2. Teachers who work at technology-rich schools and who are trained to use technologies have relatively high confidence and comfort and positive attitudes, and, consequently integrate technologies frequently.

3. Increasing technology availability and training alone have not transformed teaching toward student-centered practices. 
4. Future instructional technology training efforts need to tap into teachers' beliefs in that teachers' beliefs will play a major role in the technologies teachers chose to have their students use for teaching and learning. 


\section{References}

Apple Classrooms of Tomorrow (ACOT) (1996). Integrating technology into classroom instruction: An assessment of the impact of the ACOT teacher development center project (Report \#22). Apple Classrooms of Tomorrow: ACOT Library. Retrieved November 24, 03, from http://www.apple.com/education/k12/leadership/acot/library.html

APA Work Group of the Board of Educational Affairs (1995, December). Learnercentered psychological principles: A framework for school redesign and reform. American Psychological Association. Washington, DC.

Becker, H.J. (2001, April). How are teachers using computers in instruction? Paper presented at the 2001 Meetings of the American Educational Research Association.

Becker, H.J., \& Ravitz, J.L. (2001, March). Computer use by teachers: Are Cuban’s predictions correct? Paper presented at the 2001 Annual Meeting of the American Educational Research Association. Seattle, WA.

Becker, H.J. (2000, July). Findings from the teaching, learning and computing survey: Is Larry Cuban right? Revision of the paper for School Technology Leadership Conference of the Council of Chief State School Officers. Washington, DC.

Becker, H.J., \& Ravitz, J.L. (1999). The influence of computer and Internet use on teachers’ pedagogical practices and perceptions. Journal of Research on Computing in Education, 31(4), 356-384. 
Borko, H., \& Putnam, R.T. (1996). Learning to teach. In D.C. Berliner \& R.C. Calfee (Eds.), Handbook of educational psychology (pp. 673-708). New York: NY. Simon \& Schuster MacMillan.

Borko, H., \& Putnam, R.T. (1995). Expanding a teacher’s knowledge base: A cognitive psychological perspective on professional development. In T.R. Guskey \& M. Huberman (Eds.), Professional development in education: New paradigms \& designs (pp. 35-65). New York, NY: Teachers College Press.

Bransford, J. D., Brown, A.L., \& Cocking, R. R. (1999). How people learn: Brain, mind, experience, and school. Washington, DC: National Academy Press.

Brown, C.A. (1999). From the what and why to the how of course support systems: The value of the teachers' perspective. International Journal of Educational Telecommunications, 5(4), 361-385.

Brownlee, J., Purdie, N., \& Boulton-Lewis, G. (2001). Changing epistemological beliefs in Pre-service teacher education students. Teaching in Higher Education, 6(2), 247-268.

Calderhead, J. (1996). Teachers: Beliefs and knowledge. In D.C. Berliner \& R.C. Calfee (Eds.), Handbook of educational psychology (pp. 709-725). New York: NY. Simon \& Schuster MacMillan.

Chall, J.S. (2000). The academic achievement challenge: What really works in the classroom? New York, NY: The Guilford Press.

Chiou, G. (1995). Beliefs and Computer-Based Learning. Educational Technology, 35(3), 48-52. 
Christensen, R. (2002). Effects of technology integration education on the attitudes of teachers and students. Journal of Research on Technology in Education, 3(4), 411-433.

Clark, C.M. (1988). Asking the right questions about teacher preparation: Contributions of research on teacher thinking. Educational Researcher, 17(2), 5-12.

Coley, R.J., Cradler, J., \& Engel, P.K. (1997). Computers and classrooms: The status of technology in U.S. schools. Policy information report. Princeton, N.J.: Policy Information Center, Educational Testing Service.

Connelly, F.M., \& Clandinin, D.J. (1988). Teachers as curriculum planners: Narratives of experience. New York, NY: Teachers College Press.

Conti, G.J. (1989). Assessing teaching style in continuing education: How and why. New Directions for Continuing Education, 43, 3-16.

Cuban, L. (2002). Oversold and underused computers in the classrooms ( $2^{\text {nd }}$ edition). Cambridge, Massachusetts: Harvard University Press.

Cuban, L. (1993). How teachers taught: Constancy of change in American classrooms 1880-1990 (2 ${ }^{\text {nd }}$ ed.). New York, NY: Teachers College Press.

Darling-Hammond, L. Bullmaster, M.L., \& Cobb, V.L. (1995). Rethinking teacher leadership through professional development schools. The Elementary School Journal, 96(1), 87-106.

Dexter, S.L., Anderson, R.E., \& Becker, H.J. (1999). Teachers’ views of computers as catalysts for changes in their teaching practice. Journal of Research on Computing in Education, 31(3) 221-239. 
Driscoll, M.P. (2000). Psychology of learning for instruction $\left(2^{\text {nd }}\right.$ ed.). MA: Allyn \& Bacon.

Eisenhart, M.A., Cuthbert, A.M., Shrum, J.L., Harding, J.R. (1988). Teacher beliefs about their work activities: Policy implications. Theory into Practice, 27(2), 137144.

Ertmer, P.A., Addison, P., Lane, M., Ross, E., \& Woods, D. (1999). Examining teachers’ beliefs about the role of technology in the elementary classroom. Journal of Research on Computing in Education, 32(1) 54-72.

Fullan, M. (2001). The new meaning of educational change ( $3^{\text {rd }}$ ed.). New York, NY: Teachers College Press.

Glatthorn, A.A. (1998). Writing the winning dissertation: A step-by-step guide. Thousand Oaks, CA: Sage Publications, Inc.

Glesne, C., \& Peshkin, A. (1992). Becoming qualitative researchers: An introduction. White Plains, NY: Longman.

Hannafin, R.D., \& Freeman, D.J. (1995). An exploratory study of teachers’ views of knowledge acquisition. Educational Technology, 35(1), 49-56.

Harris, J. (1998). Curriculum-based telecollaboration: Using activity structures to design student projects. Learning \& Leading with Technology, 26(1), 7-14.

Hogarty, K.Y., Lang, T.R., \& Kromrey, J.D. (2003). Another look at technology use in classrooms: The development and validation of an instrument to measure teachers’ perceptions. Educational and Psychological Measurement, 63(1), 139162. 
Honey, M., \& Moeller, B. (1990). Teachers' beliefs and technology integration: Different values, different understandings (Technical Report \# 6). New York: Education Development Center, Inc. Center for Children and Technology.

Merriam, S. B. (1998). Qualitative research and case study applications in education: A revised and expanded from case study research in education. San Francisco, CA: Jossey-Bass Inc.

Maykut, P., \& Morehouse, R.M. (1994). Beginning qualitative research: A philosophical and practical guide. Bristol, PA: The Falmer Press.

McCombs, B.L. (2001). The learner-centered framework on teaching and learning as a foundation for electronically networked communities and cultures. Paper prepared for the PT3 Vision Quest: E-learning essays, Teaching \& Learning. Denver, CO: University of Denver Research Institute.

McCombs, B. L. (2000). Assessing the role of educational technology in the teaching and learning process: A learner-centered perspective. Paper presented at the Secretary's Conference on Educational Technology. Washington, DC.

Morrison, G.R., \& Lowther, D.L. (2002). Integrating computer technology into the classroom (2 ${ }^{\text {nd }}$ Edition). Upper Saddle River, NJ: Pearson Education.

Murphy, E. (2000). Strangers in a strange land: Teachers' beliefs about teaching and learning French as a second or foreign language in online environments. Unpublished PhD dissertation, Univerisite Laval, Montreal, QC.

Niederhauser, D.S., \& Stoddart, T. (2001). Teachers’ instructional perspectives and use of educational software. Teaching and Teacher Education, 17(1), 15-31. 
Niederhauser, D.S., Salem, D.J., \& Fields, M. (1999). Exploring teaching, learning, and instructional reform in an introductory technology course. Journal of Technology and Teacher Education, 7(2), 153-172.

Niederhauser, D.S., \& Stoddart, T. (1994, February). Teachers’ perspectives on computer-assisted instruction: Transmission versus construction of knowledge. Paper presented at the annual meeting of the American Educational Research Association, New Orleans, LA.

Nespor, J. (1987). The role of beliefs in the practice of teaching. Journal of Curriculum Studies, 19(4), 317-32

Norton, S., McRobbie, C.J., \& Cooper, T.J. (2000). Exploring secondary mathematics teachers' reasons for not using computers in their teaching: Five case studies. Journal of Research on Computing in Education, 33(1) 87-109.

Norum, K, Grabinger, R.S., \& Duffield, J.A. (1999). Healing the universe is an inside job: Teachers’ views on integrating technology. Journal of Technology and Teacher Education, 7(3), 187-203.

Office of Technology Assessment, U.S. Congress (1995). Teachers and technology: Making the connection (OTA-EHR-616). Washington, DC: U.S. Government Printing Office.

Orton, R.E. (1996). How can teacher beliefs about student learning be justified? Curriculum Inquiry, 26(2), 133-146.

Pajares, M.F. (1992). Teachers’ beliefs and educational research: Cleaning up a messy construct. Review of Educational Research, 62(3), 307-332. 
Patton, M.Q. (2002). Qualitative research \& evaluation methods ( $3^{\text {rd }}$ edition). Thousand Oaks, CA: Sage Publications, Inc.

Putnam, R.T., \& Borko, H. (2000). What do new views of knowledge and thinking have to say about research on teacher learning? Educational Researcher, 29(1) 5-15.

Ravitz, J.L., Becker, H.J., \& Wong, Y.T. (2000, July). Constructivist-compatible beliefs and practices among U.S. teachers (Report \# 4). Teaching, Learning, and Computing: 1998 National Survey.

Riel, M. (2000, September). New designs for connected teaching and learning. U.S. Department of Education: Secretary’s Conference on Educational Technology.

Riel, M., \& Becker, H.J. (2000, May). The beliefs, practices, and computer use of teacher leaders. Paper presented at the American Educational Research Association. New Orleans.

Ringstaff, C., \& Kelley, L. (2002). The learning return on our educational technology investment: A review of findings from research. San Francisco, CA: WestEd RTEC.

Sadker, M.P., \& Sadker, D.M. (2003). Teachers, schools, and society (6 ${ }^{\text {th }}$ ed.). New York, NY: McGraw-Hill.

Sandholtz, J.H., Ringstaff, C., \& Dwyer, D.C. (1997). Teaching with technology: Creating student-centered classrooms. New York, NY: Teachers College Press. Saye, J.W. (1998). Technology in the classroom: The role of dispositions in teacher gatekeeping. Journal of Curriculum and Supervision, 13(3), 210-234. 
Sivin-Kachala, J., \& Bialo, E.R. (2000). 2000 research report on the effectiveness of technology in schools ( $7^{\text {th }}$ ed.). Washington, DC: Software Information Industry Association.

Tabachnick, B.G., \& Fidell, L.S. (2001). Using multiple statistics (4 ${ }^{\text {th }}$ edition). Needham Heights, MA: Allyn Bacon.

Tobin, K., \& LaMaster, S.U. (1995). Relationships between metaphors, beliefs, and actions in a context of science curriculum change. Journal of Research in Science Teaching, 32(3), 225-242.

Tobin, K., Tippins, D.J., \& Gallard, A.J. (1994). Research on instructional strategies for teaching science. In D.L. Gabel (Ed.) Handbook of research on science teaching and learning (pp. 45-93). New York, NY: MacMullan Publishing Co.

Vallesey, B.G. (2002). Individual philosophy and instructional strategies. In K.R. Helgeson \& A.E. Schwaller (Eds.) Selecting instructional strategies for technology education (pp. 28-42). New York, NY: McGraw-Hill.

Wang, Y. (2002). When technology meets beliefs: Preservice teachers’ perception of the teacher's role in the classroom with computers. Journal of Research on Technology in Education, 35(1), 150-161.

Windschitl, M., \& Sahl, K. (2002). Tracing teachers' use of technology in a laptop computer school: The interplay of teacher beliefs, social dynamics, and instructional culture. American Educational Research Journal, 39(1), 165-205.

Yin, R. (2003). Case study research: Design and methods ( $3^{\text {rd }}$ edition). Thousand Oaks, CA: Sage Publications, Inc. 
Appendix A

Inventory Philosophies of Education

(Reproduced with the permission from one of the authors) 


\section{Inventory of Philosophies of Education}

\section{Participant Code:}

As you read through each of the following statements about schools and teaching, decide how strongly you agree or disagree. Write your responses to the left of each statement, using the following scale:

$1 \quad 2 \quad 3 \quad 4 \quad 5$

Disagree Disagree Neither Agree Agree Agree Strongly

1. A school curriculum should include a common body of information that all students should know.

2. The school curriculum should focus on the great ideas that have survived through time.

3. The gap between the real world and schools should be bridged through field trips, internships, and adult mentors.

4. Schools should prepare students for analyzing and solving the social problems they will face beyond the classroom.

5. Each student should determine his or her individual curriculum, and teachers should guide and help them.

6. Students should not be promoted from one grade to the next until they have read and mastered certain key material.

7. Schools, above all, should develop students' abilities to think deeply, analytically, and creatively, rather than focus on transient concerns like social skills and current trends.

8. Whether inside or outside the classroom, teachers must stress the relevance of what students are learning to real and current events.

9. Education should enable students to recognize injustices in society, and schools should promote projects to redress social inequities. 
10. Students who do not want to study much should not be required to do so.

11. Teachers and schools should emphasize academic rigor, discipline, hard work, and respect for authority.

12. Education is not primarily about workers and the world economic competition; learning should be appreciated for its own sake, and students should enjoy reading, learning, and discussing intriguing ideas.

13. The school curriculum should be designed by teachers to respond to the experiences and needs of the students.

14. Schools should promote positive group relationships by teaching about different ethnic and racial groups.

15. The purpose of school is to help students understand themselves, appreciate their distinctive talents and insights, and find their own unique place in the world.

16. For the United States to be competitive economically in the world marketplace, schools must bolster their academic requirements in order to train more competent workers.

17. Teachers ought to teach from the classics, because important insights related to many of today's challenges and concerns are found in these Great Books.

18. Since students learn effectively through social interaction, schools should plan for substantial social interaction in their curricula.

19. Students should be taught how to be politically literate, and learn how to improve the quality of life for all people.

20. The central role of the school is to provide students with options and choices. The students must decide what and how they learn.

21. Schools must provide students with a firm grasp of basic facts regarding the books, people, and events that have shaped the nation's heritage.

22. The teacher's main goal is to help students unlock the insights learned over time, so they can gain wisdom from the great thinkers of the past.

23. Students should be active participants in the learning process, involved in democratic class decision making and reflective thinking. 
24. Teaching should mean more than simple transmitting the Great Books, which are replete with biases and prejudices. Rather, schools need to identify a new list of Great Books more appropriate for today's world, and prepare students to create a better society than their ancestors did.

25. Effective teachers help students to discover and develop their personal values, even when those values conflict with traditional ones.

26. Teachers should help students constantly reexamine their beliefs. In history, for example, students should learn about those who have been historically omitted: the poor, the non-European, women, and people of color.

27. Frequent objective testing is the best way to determine what students know. Rewarding students when they learn, even when they learn small things, is the key to successful teaching.

28. Education should be a responsibility of the family and community, rather than delegated to formal and impersonal institutions, such as schools. 
Appendix B

Perceptions of Computers and Technology 


\section{PERCEPTIONS of COMPUTERS \& TECHNOLOGY}

\section{Participant Code:}

Purpose: This survey is designed to gain a better understanding of how educators use technology in the classroom and their level of experience with computers. The survey includes sections addressing level of confidence, skill, support, and uses of computers and technology in teaching. Responses will be kept strictly confidential and individual responses will not be identified or reported. Your participation is voluntary.

Thank you for your time and interest.

\section{Please tell us about yourself:}

Name of your school:

Gender: Male Female

Race/Ethnicity:

Native American /American Indian

African American

White/ non-Hispanic

Asian/Pacific islander Hispanic

Other, please specify

Highest degree earned:

Bachelors

Masters

Specialist (Ed.S)

__ Doctorate

Other, please specify

What subject area(s) do you teach? (Check all that apply)

\section{English}

Math

Physical Education

Science

Social Studies

Other, please specify
Art / Music

Media / Technology specialist

Special Education

Vocational Education

Reading

Total teaching experience in years:

What grade level(s) do you currently teach?

Average number of students per class:

Number of computers in your classroom used for instruction:

How many years have you been using computers in your classroom for instruction?

Do you have access to a computer lab? Yes No

If yes, how many hours each week do your students use the lab? 


\section{TEACHER PREPARATION FOR COMPUTER USE}

Directions: For the following items please circle the one response that best reflects the extent to which you've acquired computer skills from the following sources.
$1=$ not at all

$2=$ to a small extent

$3=$ to a moderate extent

$4=$ to a great extent

$5=$ entirely

As part of your undergraduate coursework

$\begin{array}{lllll}1 & 2 & 3 & 4 & 5\end{array}$

Inservice courses / workshops

Independent learning (e.g., online tutorials or books)

Interaction with other faculty / staff

Distance Learning courses

$\begin{array}{lllll}1 & 2 & 3 & 4 & 5 \\ 1 & 2 & 3 & 4 & 5 \\ 1 & 2 & 3 & 4 & 5 \\ 1 & 2 & 3 & 4 & 5\end{array}$

To what extent do you think the following types of computer education would be beneficial to you?

Introductory computer skills

Specific applications (e.g., spreadsheet, desktop publishing)

Specialized training on integrating the computer into the classroom

\begin{tabular}{|c|c|c|c|}
\hline & 2 & 3 & 4 \\
\hline 1 & 2 & 3 & 4 \\
\hline 1 & 2 & 3 & 4 \\
\hline
\end{tabular}

\section{CONFIDENCE AND COMFORT USING COMPUTERS}

Directions: Please read the following statements and circle the one response that best reflects your level of agreement.

$1=$ strongly disagree

$2=$ disagree

$3=$ neutral

4= agree

$5=$ strongly agree

I have had adequate training in using computers.

$\begin{array}{lllll}1 & 2 & 3 & 4 & 5\end{array}$

I use computers effectively in my classroom.

I am comfortable giving computer assignments to my students.

The computer enhances my teaching.

I am comfortable using computers during classroom instruction.

My use of computer technology enhances student performance.

$\begin{array}{lllll}1 & 2 & 3 & 4 & 5\end{array}$

$\begin{array}{lllll}1 & 2 & 3 & 4 & 5\end{array}$

Incorporating multi-media into lessons enhances teaching.

I am comfortable with computer terminology.

I am developing expertise in the uses of technology in the classroom.

\section{GENERAL SCHOOL SUPPORT}

Directions: Please read the following items and circle the one response that best represents your level of agreement.

$$
\begin{aligned}
& 1=\text { strongly disagree } \\
& 2=\text { disagree } \\
& 3=\text { neutral } \\
& 4=\text { agree } \\
& 5=\text { strongly agree }
\end{aligned}
$$

I have adequate time to learn computer skills. I have sufficient access to computers at my school.

I receive a sufficient level of computer related support at my school.

\begin{tabular}{|c|c|c|c|c|}
\hline 1 & 2 & 3 & 4 & 5 \\
\hline 1 & 2 & 3 & 4 & 5 \\
\hline 1 & 2 & 3 & 4 & 5 \\
\hline 1 & 2 & 3 & 4 & 5 \\
\hline 1 & 2 & 3 & 4 & 5 \\
\hline 1 & 2 & 3 & 4 & 5 \\
\hline 1 & 2 & 3 & 4 & 5 \\
\hline
\end{tabular}

Faculty members encourage the use of computers.

The administration supports computer related training.

The administration actively encourages the use of computers in the classroom.

The administration actively encourages the use of computers outside the classroom. 


\section{TYPES OF SOFTWARE USED TO COMPLETE SCHOOL RELATED ACTIVITIES}

$1=$ not at all

$2=$ once $\mathrm{a}$ month or less

$3=$ once a week

$4=$ several times a week

$5=$ every day
Directions: For each type of software please circle your response to indicate how often you use the software (on the left) and how often your students use the software (on the right) to complete school related activities. If you feel an item does not apply then circle (NA).
$1=$ not at all

$2=$ once a month or less

$3=$ once a week

4= several times a week

$5=$ every day

\section{My Use}

$\begin{array}{llllll}1 & 2 & 3 & 4 & 5 & \text { NA } \\ 1 & 2 & 3 & 4 & 5 & \text { NA } \\ 1 & 2 & 3 & 4 & 5 & \text { NA } \\ 1 & 2 & 3 & 4 & 5 & \text { NA }\end{array}$

Word processors (e.g., AppleWorks, MS Word, ClarisWorks)

Spreadsheets (e.g., Excel, Lotus)

Databases (e.g., FileMaker Pro, Access)

Desktop publishing programs (e.g., Pagemaker, Microsoft Publisher,

Printshop)

$\begin{array}{llllll}1 & 2 & 3 & 4 & 5 & \text { NA } \\ 1 & 2 & 3 & 4 & 5 & \text { NA }\end{array}$

Presentation software (e.g., PowerPoint, Persuasion, Hyperstudio)

My Students' Use

$\begin{array}{lllllll}1 & 2 & 3 & 4 & 5 & N A\end{array}$

$\begin{array}{llllll}1 & 2 & 3 & 4 & 5 & \text { NA }\end{array}$

Web publishing programs (e.g., FrontPage, PageMill, Dream Weaver,

Claris Homepage)

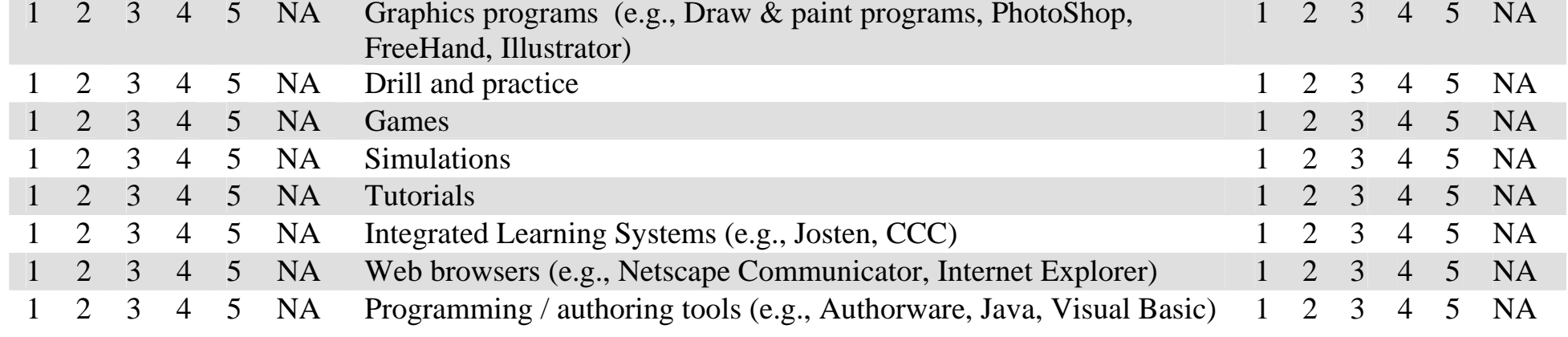

\section{INTEGRATION OF COMPUTERS INTO THE CLASSROOM}

Directions: Listed below are teaching modes in which computers may be used. Indicate how often you use computers in each teaching mode. If you feel an item does not apply then circle (NA).

$1=$ not at all

$2=$ once a month or less

$3=$ once a week

4= several times a week

$5=$ every day

Small group instruction

$\begin{array}{llllll}1 & 2 & 3 & 4 & 5 & \text { NA }\end{array}$

Individual instruction

$\begin{array}{llllll}1 & 2 & 3 & 4 & 5 & \text { NA }\end{array}$

Cooperative groups

$\begin{array}{llllll}1 & 2 & 3 & 4 & 5 & \text { NA }\end{array}$

As a reward

$\begin{array}{llllll}1 & 2 & 3 & 4 & 5 & \text { NA }\end{array}$

Independent learning

$\begin{array}{llllll}1 & 2 & 3 & 4 & 5 & \text { NA }\end{array}$

To tutor

$\begin{array}{llllll}1 & 2 & 3 & 4 & 5 & \text { NA }\end{array}$

To promote student centered learning

$\begin{array}{llllll}1 & 2 & 3 & 4 & 5 & \text { NA }\end{array}$

As a research tool for students

$\begin{array}{llllll}1 & 2 & 3 & 4 & 5 & \text { NA }\end{array}$

As a problem solving/decision making tool

As a productivity tool (to create charts, reports or other products)

$\begin{array}{llllll}1 & 2 & 3 & 4 & 5 & \text { NA }\end{array}$

As a classroom presentation tool

As a communication tool (e.g., email, electronic discussion)

$\begin{array}{llllll}1 & 2 & 3 & 4 & 5 & \text { NA }\end{array}$

$\begin{array}{llllll}1 & 2 & 3 & 4 & 5 & \text { NA }\end{array}$

\begin{tabular}{llllll}
1 & 2 & 3 & 4 & 5 & $\mathrm{NA}$ \\
\hline
\end{tabular}




\section{YOUR PERSONAL USE OF COMPUTERS}

Directions: Please read each statement and circle the one response that best reflects the frequency of your computer use. If you feel an item does not apply then circle (NA).
$1=$ not at all

$2=$ once a month or less

$3=$ once a week

$4=$ several times a week

$5=$ every day

$\begin{array}{llllll}1 & 2 & 3 & 4 & 5 & \text { NA }\end{array}$

For multimedia activities (e.g., CD-ROM, laserdiscs)

For fun/entertainment related activities

As a communication tool (e.g., email, electronic discussion)

As a productivity tool (to create charts, reports or other products)

As a research tool $\begin{array}{llllll}1 & 2 & 3 & 4 & 5 & \mathrm{NA}\end{array}$

$\begin{array}{llllll}1 & 2 & 3 & 4 & 5 & \text { NA }\end{array}$

$\begin{array}{llllll}1 & 2 & 3 & 4 & 5 & \text { NA }\end{array}$

$\begin{array}{llllll}1 & 2 & 3 & 4 & 5 & \mathrm{NA}\end{array}$

\section{TECHNICAL SUPPORT}

Does your school have an on-site computer support specialist or technology coordinator?

Yes No

Don't Know

If no or don't know, then skip this section and move on to the next section.

If yes, how many computer support specialists/coordinators does your school have?

Are your specialists/coordinators Full time

Part time

Don't know

\section{$1=$ strongly disagree \\ $2=$ disagree \\ $3=$ neutral \\ $4=$ agree \\ $5=$ strongly agree}

The on-site specialist/coordinator adequately assists me in problem solving and trouble shooting.

The on-site computer specialist/coordinator is dedicated to helping teachers.

I have adequate access to our on-site computer specialist/ coordinator.

I have to contact our specialist/coordinator several times before I get assistance.

Our computer specialist/coordinator shows me techniques to integrate computer technology into the classroom.

\section{ATTITUDES TOWARDS COMPUTER USE}

Directions: The following statements address general attitudes towards computer use.

Please circle the one answer that best reflects your level of agreement.

I would like every student in my classes to have access to a computer.

Computer skills are essential to my students.

I feel tense when people start talking about computers.

I feel pressure from others to integrate the computer more into my classroom.

I would like my students to be able to use the computer more.

Computers are dehumanizing.

I avoid the computer whenever possible.

Computer instruction is just another fad.

The use of computers should be confined to computer courses.

I like using the computer to solve complex problems.

More training would increase my use of the computer in the classroom.

Computers diminish my role as a teacher.

Computers should be incorporated into the classroom curriculum.

Computers make my job easier.

Computers further the gap between students along socio-economic lines.

Computer skills will help me as a professional.

Learning computers make high demands on my professional time.

Computers change my role as a teacher.

I can help others solve computer problems.

Computers enhance classroom instruction.

\begin{tabular}{|c|c|c|c|}
\hline & $\begin{array}{l}\text { on } \\
\text { sag } \\
\text { utr } \\
\text { ree } \\
\text { ron }\end{array}$ & ag & \\
\hline 1 & 2 & 3 & 4 \\
\hline 1 & 2 & 3 & 4 \\
\hline 1 & 2 & 3 & 4 \\
\hline 1 & 2 & 3 & 4 \\
\hline 1 & 2 & 3 & 4 \\
\hline 1 & 2 & 3 & 4 \\
\hline 1 & 2 & 3 & 4 \\
\hline 1 & 2 & 3 & 4 \\
\hline 1 & 2 & 3 & 4 \\
\hline 1 & 2 & 3 & 4 \\
\hline 1 & 2 & 3 & 4 \\
\hline 1 & 2 & 3 & 4 \\
\hline 1 & 2 & 3 & 4 \\
\hline 1 & 2 & 3 & 4 \\
\hline 1 & 2 & 3 & 4 \\
\hline 1 & 2 & 3 & 4 \\
\hline 1 & 2 & 3 & 4 \\
\hline 1 & 2 & 3 & 4 \\
\hline 1 & 2 & 3 & 4 \\
\hline 1 & 2 & 3 & 4 \\
\hline
\end{tabular}




\section{Appendix C}

Interview Protocol 
Introductory Script

The following will be read to participants prior to the beginning of each interview.

Good morning (afternoon, evening). Thank you for agreeing to participate in this study.

The goal of this study is to investigate how teachers' beliefs relate to their instructional technology practices. The information collected from this study will be used to fulfill dissertation requirements, and may be used for scholarly publications and professional conferences.

I would like to point out several things to you before we start the interview. However, please feel free to interrupt if you have any questions.

1. Your participation is entirely voluntary and you do not have to respond to every item or question.

2. Your responses will remain anonymous and confidentiality will be maintained.

3. No attempt will be made that might reveal demographic or descriptive information concerning your current school and position.

4. I would like to audio tape this interview, but if you prefer not, you may refuse.

5. The information gathered from the interview will not be used to for any other purpose other than what stated above.

6. You may request a copy of the transcript of the interview.

7. The interview should take between 30 minutes to one hour to conduct.

Thank you for agreeing to participate in this study. 


\section{Interview Questions}

1) Can you describe to me the impact of instructional technology integration on your teaching?
a) Arrangement of learning tasks
b) Instructional approaches
c) Assessment methods
d) Collegial relationships

2) Can you describe to me the context in this school for integrating technology?
a) Human support
b) Technical support
c) Barriers
d) Incentives

3) Can you describe to me your own reasons why technology needs to be integrated into the curriculum?

a) The role of technology in curriculum

b) The role of a teacher in curriculum

4) Can you give me an example of

a) What has helped your instructional technology practices?

b) What has hindered your instructional technology practices?

5) How do you make your decisions on using or not using technology for instruction? What factors influence you most when making those decisions?

6) Have you thought of your philosophy statement as an experienced teacher? How does your philosophy statement reflect on your instructional technology use?

7) Would you walk me through this lesson plan you brought and describe to me how you integrated technology?

8) What factors influence you most when making instructional technology decisions?

a) Comfort and confidence?

b) Beliefs about teaching, learning, and technology?

c) Support that you have available at this school?

9) Can you think of anything else that I have not asked and you think might help me to describe the relationship between your beliefs and instructional technology practices? 
Appendix D

Letter to the Case Study Participants

\&

Teacher Reflections 


\section{Letter to the Case Study Participants}

Dear Teacher:

I am conducting my dissertation research to investigate how teachers' beliefs relate to their instructional technology integration practices. I would like to find out (1) what beliefs you have in regards to teaching, learning, and technology (2) what is your approach to technology integration, and (3) what changes (if any) you have made in your instruction due to integrating technology?

I have selected you as one of the four teachers on whom I wish to conduct the case studies toward completion of my dissertation research. If you wish to volunteer to participate in this study, I would ask you to contribute to the study with the followings. I would like you to (1) reflect on the questions enclosed, (2) participate in an interview, and (3) bring a lesson plan to the interview that documents your typical instructional technology practices.

I am aware of the fact that I asking substantial time from you to help me conduct my research. If you wish you to participate in my study, I will be grateful to you for your efforts, and will take all the necessary means to ensure the confidentiality of your identity. The information that I will collect from you will only be used to fulfill my dissertation requirements, and may be used for scholarly publications and presentations.

If you wish to contact me, please do not hesitate to reach me by email dpalak@mix.wvu.edu or phone (304) 292 4172. I appreciate your efforts and taking time to help me conduct this research.

Sincerely,

Deniz Palak 


\section{Reflection Questions}

Dear Teacher:

Please think about the questions below for a few minutes. If you wish to write your responses in a bullet form, full-sentence, or rather wish to draw images, feel free to jot down your ideas in any form with which you are comfortable. Your reflections on these questions may prepare you for our interview conversation and help me better understand your beliefs on teaching, learning, and technology.

If you have chosen to write your reflections on a blank piece of paper, make sure to bring it to our meeting, as I wish to briefly discuss your responses to the reflection questions below during the interview.

I appreciate your assistance and thank you for taking your time.

\section{Questions}

1. Most of us were asked to write our philosophy statement during our pre-service teacher preparation. If you had to rewrite your philosophy statement, what would you say it now?

2. In your opinion,

a. What is the overarching goal of education?

b. What should be in the curriculum?

3. What is the appropriate role of a teacher?

4. What is the role of technology in education? 
Appendix E

\section{Letter to All Participant Teachers}

(Enclosed with the surveys) 
January 8, 2004

Dear Teacher:

I am a doctoral student at WVU and conducting my dissertation research on teachers' beliefs in relation to their instructional technology practices. To complete my dissertation research, however, I need your help. I will appreciate if you could take your time to complete the two surveys enclosed. Please follow the instructions to complete them, and do not write your name anywhere on the paper. If you wish to participate in my study, I will take all the necessary means to ensure that your identity will be anonymous. The information that I collect from this study will only be used to fulfill my dissertation requirements, and may be used for scholarly publications and presentations.

If you have any questions or concerns, please do not hesitate to contact me. My phone number is (304) 292 4172, and you can also reach me by email at dpalak@mix.wvu.edu I appreciate your taking time for volunteering to participate in this study.

Sincerely,

Deniz Palak 